University of Massachusetts Amherst

ScholarWorks@UMass Amherst

Doctoral Dissertations 1896 - February 2014

$1-1-1973$

\title{
A discriminant analysis and evaluation of corporate acquisition criteria.
}

Arthur L. Herrmann

University of Massachusetts Amherst

Follow this and additional works at: https://scholarworks.umass.edu/dissertations_1

\section{Recommended Citation}

Herrmann, Arthur L., "A discriminant analysis and evaluation of corporate acquisition criteria." (1973). Doctoral Dissertations 1896 - February 2014. 5907.

https://scholarworks.umass.edu/dissertations_1/5907

This Open Access Dissertation is brought to you for free and open access by ScholarWorks@UMass Amherst. It has been accepted for inclusion in Doctoral Dissertations 1896 - February 2014 by an authorized administrator of ScholarWorks@UMass Amherst. For more information, please contact scholarworks@library.umass.edu. 


\title{
A DISCRIMINANT ANALYSIS AND EVALUATION OF CURPORATE ACQUISITION CRI'RERIA
}

\author{
A dissertation \\ By \\ Arthur Lyon Herrmann \\ B.S. University of Connecticut, 1950 \\ M.B.A., University of Hartford, 1966
}

Submitted to the Graduate School of the University of Massachusetts in partial

fulfillment of the requirements for the degree of

$$
\text { Doctor of Philosophy }
$$


A DISCRIMINANT ANALYSIS AND EVALUATION OF CORPORATE ACQUISITION CRITERIA

A Dissertation

By

Arthur Lyon Herrmann

Approved as to style and content by:

Qlefander Bavigs

(Chairman of Committee) Alexander Barges

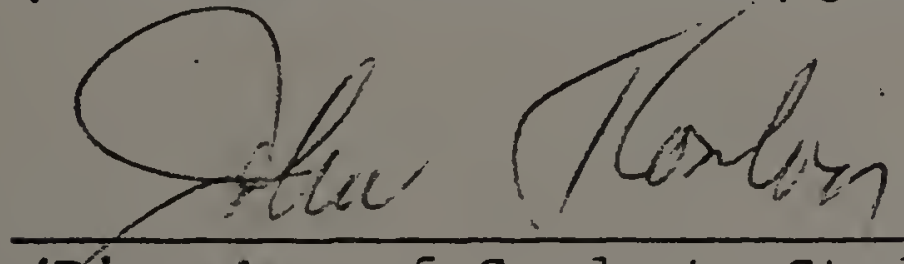

(Director of Graduate Studies) John T. Conlon

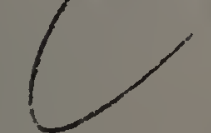

Clu. B. inlusten

(Member) william B. Whiston

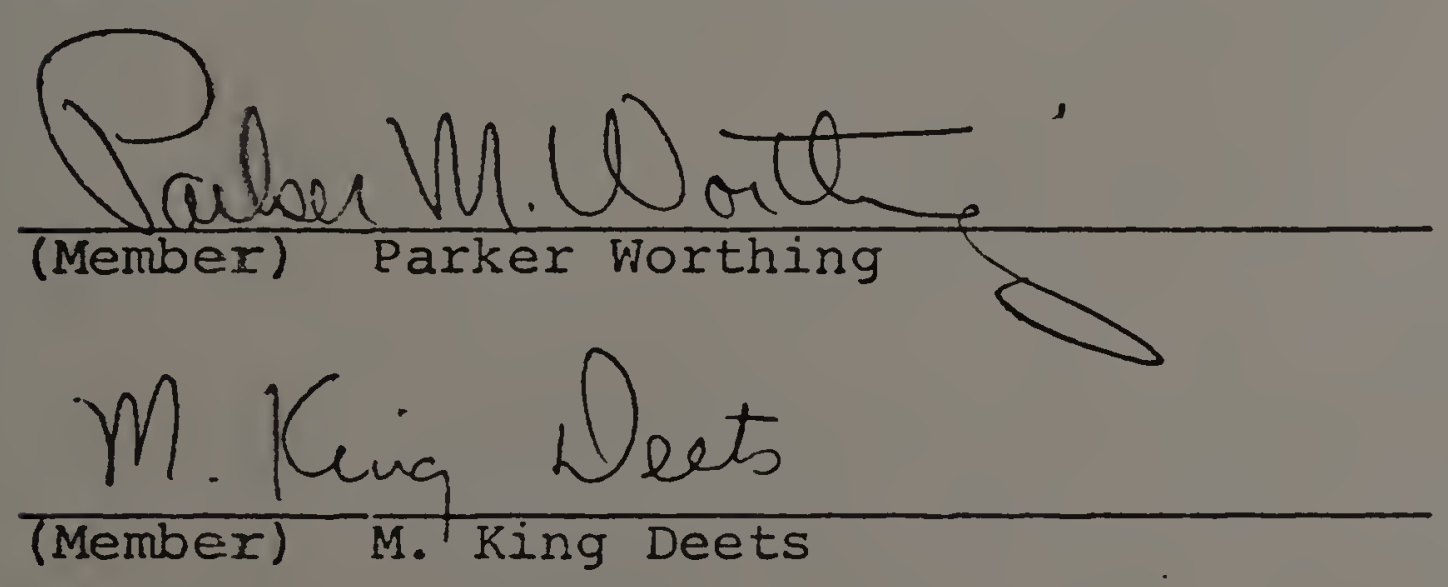

$$
4-9-73
$$




\section{ACKNOWLEDGMENTS}

The writer wishes to express sfecial thanks to Dr. Alexander Barges, Chairman of the Department of General Business and Finance, for his guidance and assistance throughout this research. The writer is further indebted to Dr. Barges for the help, guidance, and encouragement he has generously given for the past three years. A special note of thanks is extended to Dr. William B. Whiston, Director, Center for Business and Economic Research, for his assistance and counsel in the statistical work that was vital to the conduct of the study. Dr. M. King Deets, Dr. Parker Worthing, and Dr. Stephen Michael gave guidance, assistance, and suggestions throughout the research and their contributions are gratefully acknowledged. The writer's appreciation is also extended to the Graduate Faculty of the School of Business of the University of Massachusetts who have earned his sincere admiration and respect.

Finally, a special note of thanks to the writer's wife, Alice, who first encouraged his return to school and who has given the moral support and understanding necessary to complete this research. 


\section{ABSTRACT}

During the 1960's the United States economy underwent a merger movement that was the largest in its history. The profitability and effectiveness of these mergers have been the subject of much research and controversy. Past research analyzed the results of mergers after they occurred; this dissertation concentrates on the acquisition criteria used by actively merging firms prior to the merger process. This study investigates new data and provides a different perspective on the merger phenomenon.

The approach used was a field survey of corporate executive's evaluations of selected acquisition criteria. A questionnaire was mailed to 193 financial officers of actively acquiring corporations requesting their opinions of ten preselected acquisition criteria. A response rate of $68.4 \%$ was obtained from two groups of executives (conglomerate and nonconglomerate). These responses were used as the input to a discriminant analysis model that was the main instrument of the study. The discriminant model that was constructed was used to study the differences in evaluations of criteria by the two groups of executives and to examine the relationships between the criteria preferences within and between the grolps.

Two hypotheses were tested by the discriminant analysis function and by examination and analysis of the data collected. The first hypothesis tested was whether there were significant differences between the evaluations of the acquisition 
criteria by conglomerate and non-conglomerate executives. The discriminant model correctly distinguished a control sample grouf of conglomerate responses from a control sample of non-conglomerate responses with a $67 \%$ level of prediction at a $1 \%$ level of significance. The second hypothesis was suggested by the results of a presurvey conducted by the author; this hypothesis postulated that differing evaluations of continuity of management in the acquired firms would be the most important difference between the two groups of evaluations. Various tests were performed which verified and further emphasized the importance of the management continuation variable as the most powerful discriminator of the discriminant analysis function.

The major findings of the study were that there is a measurable difference between conglomerate and non-conglomerate executive attitudes towards acquisitions and that the prime discriminator of this difference is their differing evaluations of the management continuation variable. These results have certain implications for financial theory in that they give additional information as to the motivations for corporate merger. The results of the survey showed that both the conglomerate and non-conglomerate executives valued profits and growth most highly in their acquisitions; this could explain why previous writers have not found consistent differences in their post-merger performances. Both groups of acquirers had differing opinions on whether the acquired 
management should continue after the merger; this would seem to indicate differing methods of attaining the desired profits and gruwth. Non-conglomerates seem to be merging with the idea of changing the acquired firm's management to take advantage of the carryover of the acquirer's management skills. Conglomerate firms would seem to be investing in acquisitions for reasons of diversity and reduction of risk rather than managerial economies or managerial expertise. The conglomerates seem to be investing in their acquisitions much as a mutual fund or a private investor might. Portfolio theory, therefore, can be seen to be an important additional tool to be used in the study and evaluation of conglomerate acquisition behavior.

This study also discusses the usefulness of the model as a screening device and suggests areas for further research. The dissertation suggests a new direction and emphasis for the study of acquisitions; more theoretical and empirical work is needed to develop these implications. 
$\underline{\text { Page }}$

ACKNOWLEDGMENTS . . . . . . . . . . . . . . . . . .

LIST OF TABLES

LIST OF EXHIBITS . . . • . . . . . . . . . . . . $\quad x$

CHAPTER I - INTRODUCTION . . . . . . . . . . . 1

Limitations of the Study . . . . . . . . . . . 3

Terminology of the Dissertation......... . 4

Purpose of the Research . . . . . . . . . . . . 8

The Structure of the Study . . . . . . . . . . . 10

CHAPTER II - BACKGROUND OF THE STUDY . . . . . . . . 13

Merger Movements in the United States....... 13

The Post-World War II Merger Wave . . . . . . . . 15

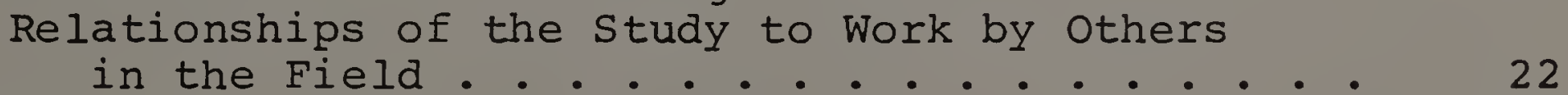

Profitability of Mergers Generally . . . . . . . 22

Profitability of Conglomerate Mergers. . . . . . 28

Studies of Merger Criteria . . . . . . . . . . 37

Empirical Studies of Acquisition Criteria : : : $\frac{37}{48}$

CHAPTER III - DATA COLLECTION . . . . . . . . . 51

Design of the Questionnaire.............

Populations Studies............... . 60

The Data Collection Process.......... 64

CHAPTER IV - METHODOLOGY . . . . . . . . . . . 73

Discriminant Analysis in the Literature : . . . : 73

The Discriminant Analysis Function . . . . . . 76

Application of Discriminant Analysis : . . . . $\quad \frac{76}{79}$

Tests For Normal Distribution.......... 81

The Discriminant Equation . . . . . . . . . . 85

Tabulation of Questionnaire Results . . . . . . 87

Measures of Correlation Between Variables . . : 88

CHAPTER V - RESULTS OF THE SURVEY . . . . . . . . . 91

Classification of the Experimental Group Responses $9_{\perp}$

Classification of the Control Group Responses . • 94

Test of Hypothesis One . . . . . . . . . . . 95

The Discriminant Coefficients. . . . . . . . . . . 997

Test of Hypothesis Two ............. 103

The Variables .................. . 111

Variable $x_{1}$ - Rate of Growth of Earnings . . . . 115 
Variable $x_{2}-$ Return on Investment . . . . . . . . 117 Variable $x_{3}^{2}$ - Rate of Growth of Sales . . . . . . . 119 $\mathrm{x}_{4}$ - Present Management Willing to Continue . . . 120 Variable $x_{5}$ - Complement and Augment Existing

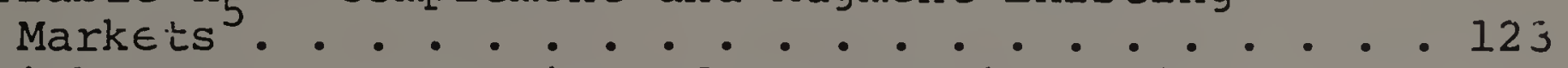

Variable $x_{6}$ - Reputation of the Acquired Firm . . 125

Variable $\mathrm{x}_{7}^{6}$ - Complement and Fit with Existing

$$
\text { Products . . . . . . . . . . . . . } 127
$$

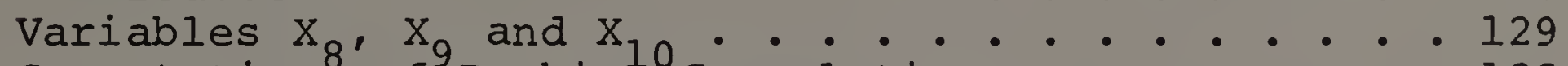

Computations of Ranking Correlations . . . . . . . 132

Responses on Criteria Lists and Manuals - Question

Sumary . . . . . . . . . . . . . . . . . . . . . . 136

CHAPTER VI - SUMMARY AND CONCLUSIONS . . . . . . . . . 137

Implications . . . . . . . . . . . . . . . . . . 143

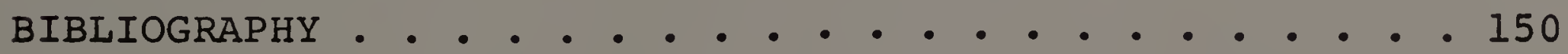

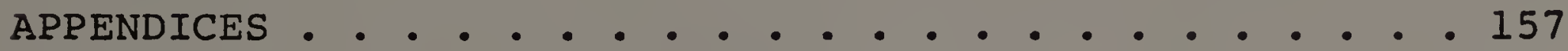


viii

LIST OF TABLES

TABLE

$\underline{\text { Page }}$

I Numer of mergers and acquisitions Recorded by Acquiring Company, 1960-1970 . . . . . . .

II Price-Earnings Ratios of Seven Leading Conclomerates . . . . . . . . . . . • . . 21

III Distribution of Refined Success Index (N=43) • 26

IV Means of Variables for the Pure Internal Growth Group and the Conglomerate Group . . . . . . .

$V$ Significance Tests for Earnings Performance Measures, 1958, 1968 . • • . . • . . . . . 35

VI Classification of the Analysis Group $(\mathrm{N}=24)$. . 93

VII Classification of the Hold-Out Group (N=96) • . 95

VIII Coefficients of Independent Variables Ranked in Descending Order by Contribution to Z Score . . 100

IX Sequence of Variables Added to Discriminant Function and Resulting Group $F$ Tests for Each Group . . . . . . . . . . . . . 104

X Additional Criteria Listed by Respondents . • • 112

XI The Relative Importance of Variables as Ranked by Respondents . . . . . . . . . . . . .

XII The Relative Frequency of Variables Indicated by Respondents •. . . . . . . . . . . . 114

XIII Average Point Score for Each Variable . . . . 115

XIV Rate of Growth of Earnings - Variable $x_{1}$ • • 117

XV Return on Investment - Variable $x_{2}$ • • . . . 118

XVI Size Differential of Discriminant Coefficients $\quad 122$

XVII Management Willing to Continue - Variable $\mathrm{x}_{4}$ - 123

XVIII Complement and Augment Markets - Variable $x_{5} \cdot 125$ 
TABLE

Page

XIX Complement and Fit With Existing Products Variable $\mathrm{X}_{7}$. . . . . . . . . . . . . 128

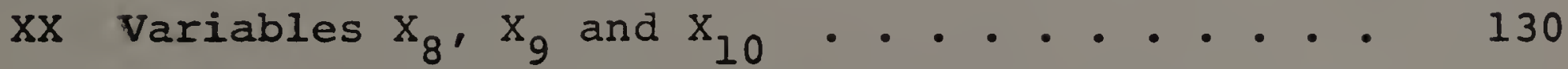

XXI Comparison of Questionnaire Results on Average Point Score and on Discriminant Power for Each Criteria Surveyed . . . . . . . . . . 132

XXII Analysis of Responses to Question one of

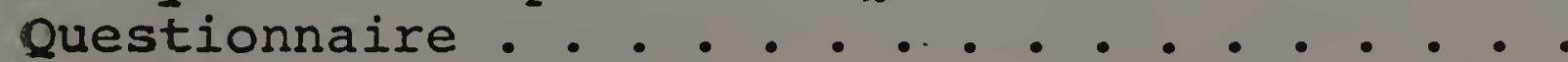




\section{LIST OF EXHIBITS}

A Roger Crane's Model . . . . . . . . . . . .

B Checklist for Evaluating Candidates for Acquisition . . . . . . . . . . . . . . 43

C The Options for Diversification . . . . . . . 45

D An Elementary Fit Chart . . . . . . . . . . 47

E The Questionnaire . . . . . . . . . . . . 57

F Mailing List of 83 Conglomerate Acquirers . . . 65

G Mailing List of 110 Non-Conglomerate Acquirers 67

H Weighting of Responses to Question 2 of Questionnaire for Input to the Discriminant

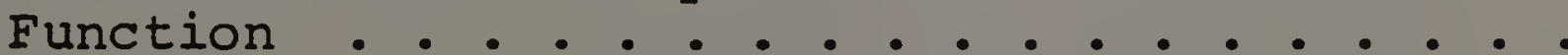

I Plot of the Differences from the Means (Residual Errors) • • • • • • • • • . • • • . . .

$J \quad$ Ranking of 2 Scores for Experimental Group as Determined by the Discriminant Equation . . .

$\mathrm{K}$ Comparison of Stepwise Discriminant Analysis Programs Run with all 10 Variables and Rerun Without Variable $\mathrm{x}_{4}$. . . . . . . . . . . 107

I Analysis of Variance Table Variables $x_{4}$ and $x_{7} \quad 109$ 


\section{C $\begin{array}{lllllll}H & F_{2} & \mathrm{P} & \mathrm{T} & \mathrm{E} & \mathrm{R} & \mathrm{I}\end{array}$}

\section{INTRODUCTION}

While growth of industrial corporations over the last fifty years has resulted primarily from external financing and internally generated funds, ${ }^{1}$ mergers and acquisitions have become an increasingly important source of growth. During the 1960's the American economy underwent a merger movement that was the largest in its history, both in numbers of mergers formed and in dollar size of corporations extinguished. 2 Yet while mergers and acquisitions have increased in numbers and size, little empirical work has been done either by business or academic writers to examine the criteria used by acquiring firms to screen and select their acquisition candidates. Much recent work in finance has been concerned with the effectiveness of mergers and acquisitions as a method of corporate growth. Most of these works analyzed the profitability performance of acquiring firms and compared them to non-acquiring firms or to the total economy. Several of these studies are described in Chapter II where their relationship to this study are established. The results of these previous

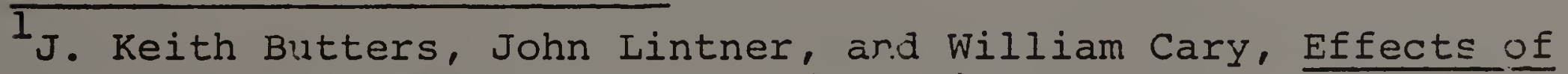
Taxation on Corporate Mergers (Cambridge, Massachusetts: Riverside Press, 1951).

${ }^{2}$ Samuel R. Reid, Mergers, Managers and the Economy (New York: McGraw-Hill, 1968), pp. 73-74. 
studies on merger effectiveness and profitability are varied and show no consistent pattern.

This study was conceived wich the idea that, since the previous analyses were neither consistent nor comprehensive in their findings, a new approach to the study of mergers and acquisitions could add to the understanding of this important area of corporate growth.

Previous studies of mergers and acquisitions analyzed the financial results of mergers. Other studies also attempted to determine subjective evaluations of the success of acquisitions by a similar post-merger analysis. The reason for this emphasis on post-merger study is probably related to the comparative ease of obtaining empirical data from such standard sources as Moodys Standard and Poor's, and the Compustat tapes. In contrast, data concerning acquisition criteria or any such pre-merger data must be collected directly from industry sources and executives and thus becomes a more difficult and extensive data-collecting process. There is also the problem of obtaining an objective response to questions concerning company and executive policy and performance; there is the additional difficulty of collecting data that some companies consider private and classified information. However, there is a need for a new approach to the study of the merger process. By examining the acquisition criteria used by merging firms prior to the actual acquisition process, this study will provide new data and a different perspective on the mer- 
ger phenomenon thereby establishing, or implying what to expect from post-merger data. Limitations of the Study

One limitation of the study is the timing of the research. The present study examines executive attitudes at the time they responded to the questionnaire. Because of the importance of brevity and anonynity in obtaining a high percentage of response, no additional data was collected that might have determined if the attitudes had changed as a result of prior experience or changes in corporate policy. Also, because of the anonymity of the survey, the author was unable to establish a relationship between the use of certain criteria and the success or activity of each corporation's acquisition policy. Additional problems of varying corporate objectives and definitions of success would be encountered if these variables were included in the study. ${ }^{3}$

Another limitation related to the empirical results of the study is the use of ranked data as input to the discriminant model. The data collected by the questionnaire on executive attitudes was ordinal in nature, and many of the standard statistical treatments could not be used since they assume cardinal measurements. These limitations and their treatment are discussed further in Chapter IV of the study.

3H. Igor Ansoff, R.G. Brandenburg, F.E. Portner, and R. Radosevitcy, Acquisition Behavior of U.S. Manufacturing Firms, 1946-1966 (Nashville, Tennessee: Vanderbilt University Press, 1971). 
Another important factor to be considered in evaluating the results of this research study is the financial environment operating at the time of the study. Since any study of corporate merger behavior is affected by the economic and legal environment that the firms encountered at the time of the study, it is important to place this research in its proper historical perspective, as is done in Chapter II. If, for example, the present merger wave regains its momentum or if legal decisions change the ability of conglomerates to acquire, the business environment will change and conclusions drawn from the study will have to be reevaluated. If the time of the survey (summer of 1972) proves to be an atypical period, the results and conclusions of the research can be biased accordingly.

Terminology of the Dissertation

Before proceeding with the study, some basic definitions of terms and variables to be considered should be stated. Many of the terms used in this study have had wide usage and varying meanings in the financial literature and should be defined as used in this study. The terms as defined here will generally be more limited in scope than those used in the general financial literature.

Merger. For the purposes of this study, a merger will be broadly defined as a union of two or more independent businesses united into one organization with a common ownership 
and management. This general term is used to describe several different types and forms of business combinations. There are two major financial forms of mergers--acquisitiors and consolidations; and several industrial or commercial relationships or types of mergers such as horizontal, vertical, or conglomerate--these will all be individually defined as used in the study. Merger will be used as the general allencompassing term for business combinations.

Acquisition. Any merger where one firm (generally the larger) absorbs another firm. The larger acquiring firm retains its identity and little or no effort is made to continue the identity of the acquired company. The acquiring company usually accomplishes the acquisition by expanding its capitalization or using its reserves; acquisitions are usually done one-at-a-time by the acquiring firm.

Consolidation. Another form of merger where two or more firms are combined into a new firm with a different capital structure formed in consequence of the merger. The surviving company is a new corporation with a new charter and new name that absorbs all the former constituents.

Eorizontal Mergers. A merger involving firms engaged primarily in the same industry. A business combination uniting two or more companies engaged in selling the same type of product to similar types of customers. Since horizontal-type mergers often combine direct competitors, antitrust agencies give this type their greatest attention. 
Vertical Mergers. A merger which builds the firm's capabilities in äifferent stages of production either toward its markeis (forward) or toward its sources of supply (backward). This type of combination unites two or more companies operating at different levels of the productive process that were formerly in a supplier-customer relationship. It is generally done to produce economies in production and marketing, or to ensure markets and sources of supply.

Circular and Concentric Mergers. These are variations of the other types of mergers. Circular mergers are concerned with a production or marketing relationship between the products of the merging firms; they are involved with product extension. Concentric mergers involve expansion around the areas of the company's management strengths by adding components that will benefit from the acquiring company's existing management skills.

\section{Conglomerate Mergers. A merger where the acquired} firm's products and markets bear little systematic relation to the acquiring firm's. This type of expansion is often called "economic diversification" in the literature 4 and is characterized by a broad program of diversification achieved primarily through external acquisitions rather than internal.

\footnotetext{
${ }^{4}$ R.M. Allan, Jr., "Expansion by Merger," in W.M. Alberts and Joel Segall (eds.) The Corporate Merger (Chicago: University of Chicago Fress, 1966), Part II, No. 5, p. 101.
} 
expansion. The hallmarks of the conglomerate corporation are that they have grown importantly through acquisition and that they have r.any and diverse operatic in divisions. ${ }^{5}$ Later in this project, groups of conglomerate companies previously studied by other authors will be surveyed. The particular screening rules used by each author to define conglomerate merger will be described as each group is introduced into the present study.

Non-Conglomerate Mergers. A broad classification of mergers including vertical, horizontal, circular, and concentric mergers. For purposes of this study, non-conglomerate mergers will be "all other" mergers not meeting the diversification and external growth criteria of the conglomerates as defined above.

Acquiring Company. The surviving company that remains after an acquisition. The company that retains its identity and capital structure after the acquisition process. Acquired Company. The Company whose identity and title is usually lost in an acquisition. The company whose shares are extinguished in the acquisition process.

5"Disclosure of Supplemental Financial Information by Diversified Companies," The Journal of frcountancy (October, 1967), p. 51. See also Joel Dean, "Causes and Consequences of Growth by Conglomerate Merger: An Introduction," st. John's Law Review, XIIV, Special Edition (Spring 1970), p. 15. In addition, see J. Fred Weston and Surenda K. Mansingka, "Tests of the Efficiency Performance of Conglomerate Firms," Journal of Finance, XXVI (September 1971), p. 921. 
Purpose of the Research

The purposes of the research undertaken in this study were: (I) to examine and classiry acquisition criteria actually used by active corporate acquirers; (2) to investigate and identify any significant relationships and differences between the criteria; ( 3 ) to construct a criteria model from these acquisition criteria that will discriminate between conglomerate and non-conglomerate corporate acquirers; (4) using the model, to classify firms as likely targets for acquisition by either conglomerate or non-conglomerate acquirers; (5) to provide a data bank of criteria information for future research; and (6) to provide a different perspective to the study of mergers and acquisitions.

Specific questions investigated in the sample of actively merging corporations included: (1) Do such companies have a formal written set of acquisition criteria? (2) Among corporations that have written criteria, is there any pattern to these criteria lists? (3) Are there any specific criteria generally considered to be more important to conglomerate or non-conglomerate executives?

In pursuing this examination of merger criteria, the researcher formulated two general hypotheses which will constitute the roundation upon which the acquisition criteria will be studied. These general hypotheses have been formulated in broad terms so that they can be tested with the information collected by a field survey. Should the results of the sta- 
tistical tests of the hypotheses prove to be inconclusive or statistically non-significant, the usefulness of the study would not be destroyed, as the criteria information collected could still be used as the data base for further study of both conglomerate and non-conglomerate acquirers.

HYPOTHESIS ONE: The evaluations by conglomerate executives of commonly used merger criteria will be significantly different in emphasis and importance from the evaluations of non-conglomerate executives of the same merger criteria.

This hypothesis will be tested by constructing a discriminant function of acquisition criteria to analyze the criteria by their computed discriminant scores. If the hypothesis is valid and there is a significant difference between the criteria evaluations of conglomerate and non-conglomerate executives, then the discriminant model will be able to classify criteria lists from an unknown sample as conglomerate or nonconglomerate by means of their computed discriminant score.

The Acquisition Criteria Models

Conglomerate

Model

$$
z_{1}=g_{1}\left(x_{1}, x_{2}, \ldots, x_{n}\right), n=10
$$

Non-Conglomerate

Model

$$
z_{2}=g_{2}\left(x_{1}, x_{2}, \ldots, x_{n}\right) \quad n=10
$$

$z_{1}=\begin{aligned} & \text { cross-section of conglomerate attitudes (discrim. } \\ & \text { inant score) }\end{aligned}$ $z_{2}=\begin{aligned} & \text { cross-section of non-conglomerate attitudes (dis- } \\ & \text { criminant score) }\end{aligned}$

$x_{1}, x_{2}, \ldots, x_{n}=10$ selected acquisition criteria 
HYPOTHESIS TWO: Among the responses examined, the acquisition criterion with the most discriminatory power will be the variable: "Present management willing to continue."

This hypothesis was suggested by the results of a presurvey of nineteen company acquisition manuals. Examination of these manuals showed importance attached to this criterion iy the conglomerate companies. Hypothesis Two was included in the study to test this a priori finding. Hypothesis Two will be tested by ranking each criterion in descending order by the relative size of its computed discriminant coefficient and determining if the relative contribution of the "management continuation" variable proves to be the most important contribution to the conglomerate discriminant scores.

The Structure of the study

The study attempts to investigate and analyze corporate acquisition criteria. The procedure was a field survey of corporate executives' attitudes toward selected acquisition criteria. Two groups of corporate executives (conglomerate and non-conglomerate) were surveyed by mail questionnaire. The two general hypotheses stated above will be evaluated throligh analyses of the resuits of the field survey. Prior to the analysis of acquisition criteria, an examination of the historical development of the present merger movement is made in Chapter II. The major factors which con- 
stitute the environment of the present merger movement are also discussed in this chapter. The relationship of the study to the work of other finascial writers is then traced and established.

In Chapter III the data collection processes of the study are outlined and explained. The questionnaire design and the questions used in the survey are then presented. The characteristics and subdivisions of the populations studied are also presented in Chapter III.

As a necessary bridge between Chapters II and III and a discussion of the results of the survey, a detailed examination of the survey's methodology and testing procedures is presented in Chapter IV. This discussion will explain the use of discriminant analysis in the study as well as the tabulations and correlation analyses to be used in evaluating the results of the survey of acquisition criteria.

In Chapter $\mathrm{V}$ the empirical results of these procedures will be examined and analyzed. The questionnaire results will be used to construct a discriminant function that will be used for analysis of criteria and for testing the hypotheses of the study. The results of the survey will be tabulated for each question and for each variable. Special attention will be given to those criteria that show special qualities as discriminators between conglomerate and non-conglomerate acquirers. 
In the final chapter of the study, the research effort will be summarized and conclusions drawn from the results of the surve $\epsilon_{2}$. These conclusions will be interpreted and thei: relationship to the established literature will be examined. Also, implications for further study will be examined and discussed. 
C $\begin{array}{llllllllll} & \text { A } & \text { P } & \text { T } & E & R & \text { II }\end{array}$

BACKGROUND OF THE STUDY

This chapter will place the present study in its historical perspective by giving a brief summary of the merger movements in American economic life. The development of the conglomerate form of merger will also be traced and discussed, and the relationship of the study to work by others in the financial literature will be established.

Merger Movements in the United States

There have been three clearly discernible merger movements in American economic history. These are (1) the turnof-the-century merger wave, (2) the late 1920's merger wave, and (3) the post-World War II merger wave. ${ }^{I}$ Each of these periods of merger activity will be examined, but only the most recent merger movement will be considered in detail as the first two occurred under different economic and legal environments.

The turn-of-the-century merger movement occurred between 1895 and 1904 with the major period of activity between 1898

${ }^{1}$ Samuel R. Reid, Mergers, Managers and the Economy (New York: McGraw-Hill, 1968), p. 15. See also Eamon Kelly, The Profitability of Growth through Merger . University Park, Pennsyivania: Center for Research of College of Business Administration, Pennsylvania State University, 1967), p. 3. Also see Arthur R. Wyatt and Donald E. Kieso, Business Combinations: Planning and Action (Scranton, Pennsylvania: Inte:national Text Book Company, 1969), p. I. In addition, see Joel Dean, "Causes and Consequences of Growth by Conglomerate Merger: An Introduction," St. John's Law Review, XLIV, Special Edition, (Spring 1970), p. 15. 
and 1902. ${ }^{2}$ the business consolications of this period usually included a large number of firms in an industry with the objectire of controlling competition through the establishment of a douinant firm. Nany of the mergers of this period were of the holding company form and were usually promoted by outside professional promoters. During this period industrial cotbinations such as United States Steel, General Electric, American Iobacco Co., E.I. DuPont, and other giants were formed. The first merger wave ended with the Northern Securities case. ${ }^{3}$ this suprene court decision ruled that the Shertan Anti-Trust sct against monopolies could not be circumented by voluntary mutual agreement to consolidate. This first of the three great merger movements was the most important in relation to the size of the economy at the time of its occurrence.

The second major merger wave took place during the decade of the nineteen twenties. Neasured by numbers of mergers, this wave was greater than the turn-of-the-century one, but the cotbinations were acquisitions rather than consolidations and their average size was consequently smaller. Nevertheless, this 1920 movement was substantial and corporations such

2palph I. Rielson, Merger Movements in American Industry: 1895-1950 (Princeton, New Jersey: Princeton University Press, 1959), p. 60 . See Reid, p. 38. 3 Northern Securities Company v. United States, 193 U.S. 197 $(1904)$. 
as United Aircraft, Bethlehem Steel, General Foods, and Bendix Corp., were formed; Many of the consolidations took the form of vertical combinations which extended the firm backward towaid its source of supply or foreward toward its consumers. The motives in this case were more for technical gains and economies and for independence from other firms for raw materials or distribution. ${ }^{4}$ This period of merger activity coincided with a period of relative prosperity and a "buoyant" stock market. There has been less attention paid to this merger movement than to the others since most financial writers covering the period are more concerned with the great depression of the thirties that ended the movement than with the merger wave itself. Since the studies done on these earlier merger movements were few in number and their results were conflicting and widely criticized in the literature, only those studies of the most recent merger movement will be considered in detail as background for this study.

The Post-World War II Merger Wave

The third merger wave began in the mid 1950's coinciding with the post World War II prosperity and continues to the present. This wave has already been the longest period of merger activity and is the largest in American economic history, both in numbers of mergers and in amount of assets ir.volved. 5 The volume of merger activity fell sharply with the

\footnotetext{
$\overline{4}$ Reid, Op. Cit., Chapter 4 . ${ }^{5}$ Ibid., p. 74 .
} 
bear market of 1970 , but the total overall rate is still substantially higher than levels attained through 1967. Table I gives figures on total numier of mergers from 1960 to 1971 inclusive for manufacturing firms and total firms as reported by the Federal Trade Commission. This table gives only the number and not the dollar amount of mergers recorded but does clearly show the trend of merger activity for the period. There has been much recent criticism of the statistics gathered and used to measure the extent, amount, and type of merger activity. ${ }^{6}$ This is due in part to the difficulties of collecting and compiling such data; however, Table I compiled by a reliable government source gives a clear indication of the recent merger trend's duration and persistence. Whereas the outstanding characteristic of the first merger wave was the absorbtion of competition, and the second emphasized vertical integration, the dominant form of merger in the current wave is of the conglomerate or diversification type. Two reasons are generally given for this shift to the conglomerate form. First, enforcement of the 1950 amendment

\footnotetext{
${ }^{6}$ See for example, Bernard A. Kemp, "Understanding Merger Activity - assessing the Structural Effects of Acquisitions," The Bulletin, N.Y.U. Graduate Schcol of Business, No. 55-56 (April 1969); see also, B.B. Carr and S.J. Browne, "Methoci vs. Myth in Measuring Merger Activity," Mergers \& Acquisitions, VI No. 3 .
} 


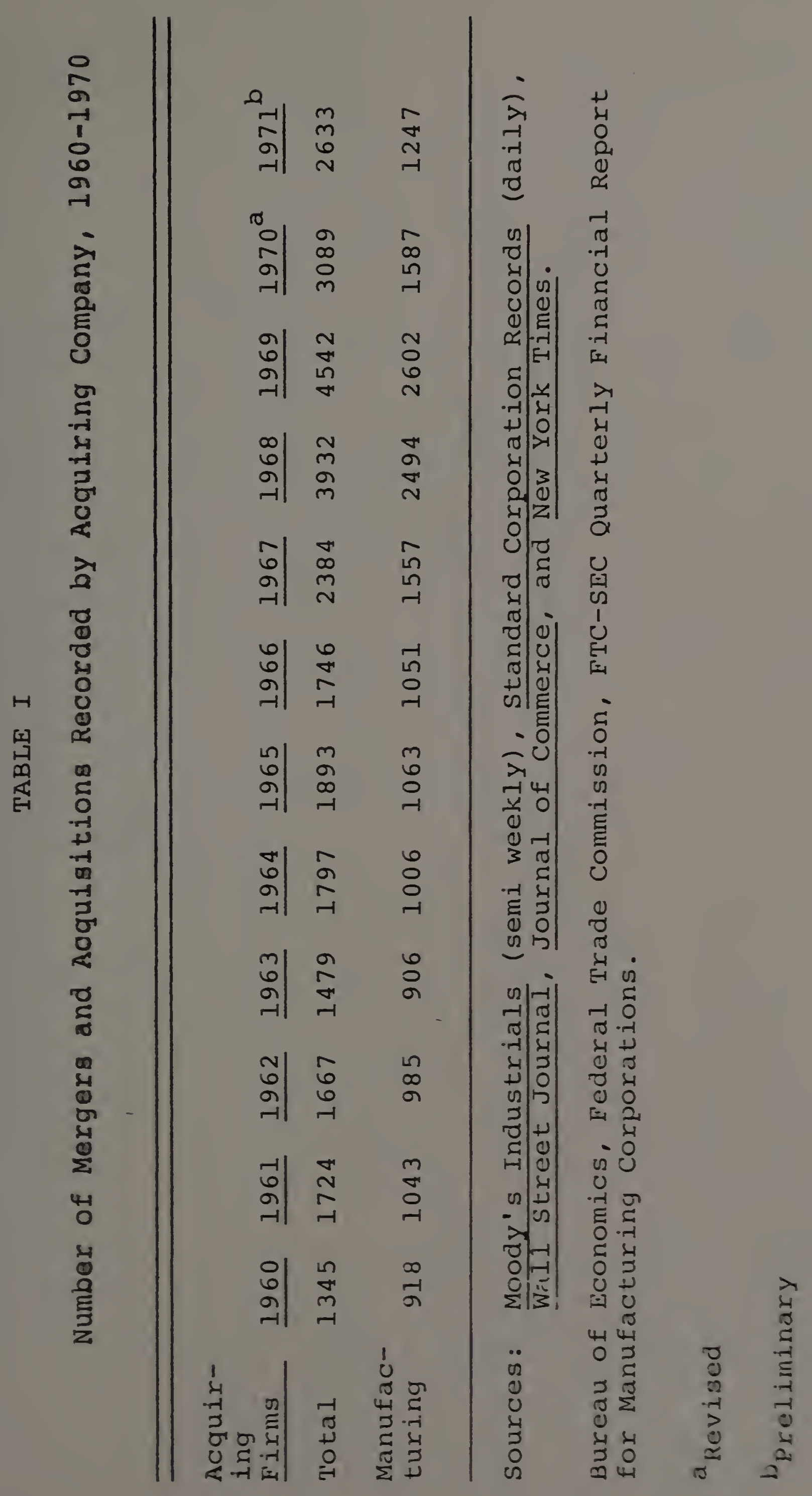


to section 7 of the Clayton $\operatorname{Act}^{7}$ (which gave the government more power to attack horizontal and vertical mergers as interfering with competition) did not directly threaten the conglomerates. Second, good financial gains were possible by conglomerate acquisitions when the acquiring firm's stocks were valued at high price-earnings multiples. Such high price-earnings multiples refiect the belief of investors that conglomerates are "growth" stocks and that any large and steady growth of their reported earnings per share can be projected by a succession of acquisitions. The higher the conglomerate's stock price becomes relative to its earnings per share, the less it actually spends to buy another company when it pays for the acquisition with its highly priced shares. 8

A simple example will illustrate this phenomenon: Conglomerate $A$ is selling at a price-earnings ratio of 30 because the market judges past and expected growth favorably. Company $B$ has shown little growth and is selling at a priceearnings ratio of 10 . Both firms have $1,000,000$ shares outstanding and both are earning $\$ 1,000,000.00$ or $\$ 1.00$ per

\footnotetext{
7 Act of October $14,1914 \mathrm{ch} .323, \mathrm{p} .7,38$ statute 731 , as amended, Act of December 29, 1950, presently codified as 15 U.S.C. P. 18 (1964).

8 Dean, Op. Cit., pp. 15-18. Jerome B. Cohen, "The Economic Aspects of Conglomerates," Saint John's Law Review, XLIV, Special Fdition (Spring 1970), pp. 49-51.
} 
share. The conglomerate's shares are priced at $\$ 30.00$ and company B's shares are priced at $\$ 10.00$ per share. A offers B's stockholders $\$ 15.00$ per shars in Conglomerate A stock for each share of Company B stock; B's stockholders accept the offer of $50 \%$ over market for their stock and accept 500,000 shares of A's stock. The new organization now has $1,500,000$ shares outstanding and earns the same $\$ 2,000,000.00$ that the two companies earned prior to the combination. Thus the earnings per share of Conglomerate A rise to $\$ 1.33$ for a rise of $33-1 / 3 \%$ even though nothing has really changed with each company's internal operation. The new earnings of $\$ 1.33$ are now capitalized at the same $P / E$ ratio of 30 and the price of Conglomerate A's stock rises to $\$ 40.00$ per share. ${ }^{9}$ This process has been termed "the chain letter effect."10 It can continue as long as investors value conglomerate stocks at high price-earnings ratios, as long as there are sufficient suitable acquisition candidates, or until an outside agency checks or controls the process.

Two possible checks to "chain letter" growth have appeared that may affect the conglomerate merger movement in the 1970's.

\footnotetext{
${ }^{9}$ See Marvin M. May, "The Earnings per Share Trap," Financial Analysts Journal (May-June 1968), pp. 113-117, and Cohen, Op. Cit., p. 51 for similar exanples.

10 May, Op. Cit., p. 114, and Gilbert Burck, "The Merger Movement Rides High," Fortune (February 1969), p. 78 .
} 
First, the bear market of 1969-1971 has valued conglomerate price-earnings ratios at a lower rate than the 1960's market. Typical Piz ratios of seven major conglomerates are shown in Table II. It is too early to determine whether the drop in conglomerate $\mathrm{P} / \mathrm{E}$ ratios as shown in Chart II will continue into the 1970's and what, if any, its effect will be on conglomerate merger activity. Future empirical work will be needed to study the relationship between Tables I and II when more current more current data is available.

Second, two other possible future checks to conglomerate merger activity are the 1970 opinions of The Accounting Principles Board--APB \#16, "Business Combinations" and APB \#17, "Intangible Assets." 11

These opinions became effective october 31,1970 and many facets of the opinions remain uninterpreted and untested. At this writing, however, merger consultants ${ }^{12}$ agree that $A P B$ Opinion \#16 will severly limit the use of pooling accounting

11 Accounting Principles Board Opinion \#16, Business Combinations: and Accounting Principles Board opinion \#17, Intangible Assets, (New York, New York: American Institute of Certified Public Accountants, Inc., 1970).

12

G. Deban and S.J. Loscocco, "Pooling vs. Purchase Perturbations," Mergers and Acquisitions, VI, No. 3 (Fall 1971) 16-23. Stanley F. Reed, "Mergers and the AICPA," Mergers and Acquisitions, $V$, No. 5 (September-October 1970), pp. 20-23. 
TABLE II

Price-Earnings Ratios of Seven Leading Conglomerates 1966-1970 (year-ending)

\begin{tabular}{|c|c|c|c|c|c|c|}
\hline & $\begin{array}{c}\mathrm{P} / \mathrm{E} \\
\text { close } \\
1966 \\
\end{array}$ & $\begin{array}{c}\mathrm{P} / \mathrm{E} \\
\text { close } \\
1967 \\
\end{array}$ & $\begin{array}{c}\mathrm{P} / \mathrm{E} \\
\mathrm{C} 1 \mathrm{Ose} \\
1968 \\
\end{array}$ & $\begin{array}{r}\mathrm{P} / \mathrm{E} \\
\mathrm{C} 100 \mathrm{C} \\
1969 \\
\end{array}$ & $\begin{array}{r}\mathrm{P} / \mathrm{E} \\
\mathrm{C} 100 \mathrm{C} \\
1970 \\
\end{array}$ & $\begin{array}{r}P / 2 \\
c 1026 \\
2971 \\
\end{array}$ \\
\hline Brunswick Corp. & 54 & 37 & 25 & 25 & 19 & 21 \\
\hline F M C Corp. & 18 & 19 & 17 & 14 & 13 & 17 \\
\hline Gulf \& Western Ind. & 14 & 16 & 11 & 8 & 8 & 9 \\
\hline Intl. Tel. \& Tel. & 17 & 22 & 20 & 18 & 16 & 16 \\
\hline Litton Ind. & 32 & 39 & 45 & 22 & 14 & 21 \\
\hline Teledyne & 25 & 42 & 34 & 20 & 13 & 15 \\
\hline U.S. Ind. & 8 & 10 & 13 & 12 & 8 & 10 \\
\hline
\end{tabular}

Source: Moodys Handbook of Common Stocks; First quarter 1972 .

which gives tax benefits to both the parties of mergers treated as "poolings". 13 APB Opinion "17 will increase the recording of goodwill. This goodwill, created by the nen accounting, must be amortized without ta\% benefit thus reducing reported net earnings of acguiring companiss. rinils it is too early to assess the effect of these nen f.PE opinions, it seems probable they will have a ciampening effect on future merger activity. Fgain empirical study nili be nesded

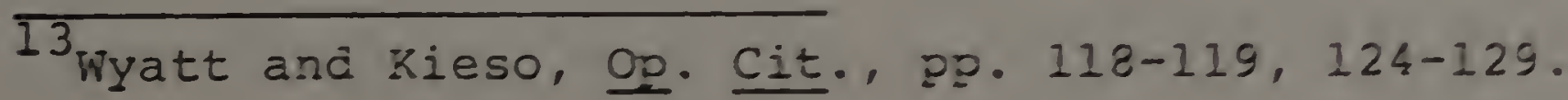


to measure and evaluate any such effect on the current merger wave. The Post-World War II merger wave is still continuing and constitutes the ecosomic and business envircnment of the present study. The conglomerate form of combination is primarily a product of this environment.

Relationships of the Study to Work by Others in the Field

Although researchers in the field of finance have studied earlier merger waves, only studies concerned with the postWorld-War II merger wave will be considered in the present investigation. Previous studies are dated, occurred under different legal and business environments, and the criticisms of them are well documented in the literature. Most recent merger studies have been concerned with profitability of mergers and acquisitions; they are directed at the question of whether or not the merger route is an efficient avenue for corporate growth. These can be divided into two groups: studies of the profitability of mergers generally and studies of the profitability of conglomerate mergers.

Profitability of Mergers Generally

The first extensive general study of the current movement was made by Reid ${ }^{14}$ covering merging and non-merging firms for the period 1950-1959. Alberts and Segal give some "fair-

\footnotetext{
${ }^{14}$ Samuel R. Reid, Corporate Mergers and Acquisitions Involving Firms in Missouri, 1950-1959; Some Economic Results and Administrative Policies and Procedures (Ann Arbor, Michigan: University Microfirm, 1962).
} 
Iy casual data" but note in 1966 "...to our knowledge there has been no published studies of any kind on the results of post-Worid war II mergers."15 since then, four profitability studies have been released; one by Kelly ${ }^{16}$ in 1967 compares the profitability of two groups of firms, one merging and one non-merging.

Kelly compared pairs of corporations which were similar except for the degree of their merger activity and concluded that the form of expansion, external or internal, did not have a significant impact in terms of rate of return. Kelly set a level of significance of $\alpha=.05$ and used nonparametric tests (the sign test and the Wilcoxon matched-pairs signedranks test) to test the significance of his results. He found that the form of expansion (merger or internal expansion) had no significant impact on rate of return on assets, market price, price-earnings ratio, or profit margin. only capital turnover as measured by sales per common share was significantly greater in merging companies. 17

The second study was a dissertation by E.O. Poindexter 18 in 1970 that compared the profit performance of acquiring companies prior to and after merging. He used the percentage

\footnotetext{
15 William W. Alberts and Joel E. Segall (eds.), The Corporate Merger (Chicago: University of Chicago Press, $\frac{1966), \text { p. xi. }}{\text {. }}$ 16 Eamon Kelly, Op. Cit. 17 Ibid. pp. 55 and 70 . 18 Eugene 0 . Poindexter, The Profitability of Industrial Merger (Ann Arbor Michigan: University Microfilms, 1970).
} 
changes in their respective industries as a measure of the profitability of the mergers. The mean average annual profitability of all acquiring companies relative to their industries was - 1.05 percent. This result was based on averages and $48 \%$ of the companies in the sample had higher earnings, $51.2 \%$ had lower earnings, and $0.7 \%$ were the same as their respective industries. Thus though the average result was below the industry average, about half of the merging companies were more profitable than their industries. His results ranged from a high of $+20.69 \%$ to a low of $-43.40 \%$ with a standard deviation of $9.51 \% .19$ While the average profitability of merging firms was negative, a few obtained good returns which probably tempts other firms to engage in merger activity.

Poindexter used the following formula for profitability: $\pi=\left[\frac{\mathrm{CE} 3}{\mathrm{CE} 2} \cdot \frac{1}{5}-\frac{\operatorname{IE} 3}{\operatorname{IE~} 2} \cdot \frac{1}{5}\right]-\left[\frac{\mathrm{CE} 2}{\operatorname{CE} 1} \cdot \frac{1}{5}-\frac{\operatorname{IE} 2}{\operatorname{IE} 1} \cdot \frac{1}{5}\right]$

where

$$
\begin{aligned}
\pi= & \text { relative profitability } \\
\mathrm{CE} 1= & \text { the five year average company earnings per share } \\
& \text { in the base period }(t-10 \text { to } t-5) \\
\mathrm{CE} 2= & \text { the five year average company earnings per share } \\
& \text { in the period five years prior to merger } \\
\mathrm{CE} 3= & \text { the five year average company earnings in the } \\
& \text { five year period after merger ( } t \text { to } t+5)
\end{aligned}
$$

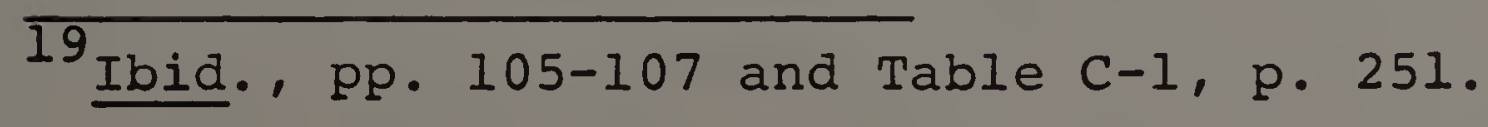


IE $I$ = the five year average industry earnings in the base period prior to merger $(t-10$ to $t-5)$

IE 2 = the five year average industry earnings per share in the five yearis prior to merger

IE 3 = the average five year industry earnings per share in the five years after merger

and $t=$ time of merger

In a third study, Hogarty 20 compared the the investment performance of 43 heavily merging firms with the average investment performance of firms in their respective industries. His measure of success was the "refined" success index $S_{r}$ computed as follows:

$$
\mathrm{S}_{\mathrm{r}}=\frac{1}{\mathrm{n}}\left\{\left[\left(\mathrm{P}_{64}+\sum_{\mathrm{T}=\mathrm{t}-1}^{64} \mathrm{D}_{\mathrm{T}}\right] \mathrm{P}_{t-2}\right]-\left[\left(\text { IPI) }{ }_{64} /(\text { IPI })_{t-2}\right]\right\}\right.
$$

where $\mathrm{S}_{\mathrm{r}}=$ refined success index

$P=$ end of year price of stock of acquiring firm

$D=$ annual cash dividend per share of acquiring firm

IPI = investment performance index, where

$(\text { IPI })_{1}=\left(p_{1}+d_{1}\right) / p_{0}$

$1,0=$ time subscripts for base period

$\mathrm{p} \quad=$ price per share of common for industry

$\mathrm{d}=$ dividend per share for industry

$64, t=$ time subscripts refering to 1964 and year of acquisition

$\mathrm{n}=$ number of years between $t-2$ and $1964 .^{21}$

20 Thomas F. Hogarty, "The Profitability of Corporate Mergers," Journal of Business, XIIII (July 1970), pp. 317-327.

21 Ibid., p. 321 . 
Hogarty found that the investment performance of heaviIy merging firms is "generally worse" than the average investment parformance of firms in tileir respective industries as shown by Table III.

\section{TABLE III}

Distribution of Refined Success Index $(N=43)$

Category

Success

Ambiguous

Failure

Mean

Median

Standard Deviation
$-0.10(-0.05) *$

$-0.09(-0.06) *$

$0.15(0.14) *$
Number

of firms

$3(5)$

$19(24)$

$21(14)$

* Numbers in parentheses are results obtained assuming reinvestment of dividends. The category limits were as follows: (1) $\mathrm{s}_{\mathrm{r}} 0.100$, success; (2) $-0.100 \mathrm{~s}$. 0.100 ,

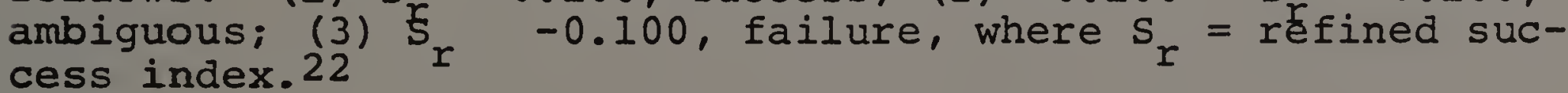

In a more recent paper, Lev and Mandelker ${ }^{23}$ compared returns to stockholders of acquiring and non-acquiring firms over a

\section{Ibid., p. 322}

23 B. Lev and G. Mandelker, "Microeconomic Consequences of Corporate Mergers," Journal of Business, XLV No. I, (January 1972) pp. 85-104. 
five year period. They found that the long run profitability of acquiring firms outperformed comparable nonmerging firms in "annual rate of return" as measlired by the market annuai rate of return with dividends reinvested. The formula for this measure was:

$$
\begin{aligned}
& \text { Annual rate of return }=\left(P_{t}+a_{t}\right) / P_{t-1} \\
& \text { where } P_{t}=\text { stock price at end of year } t \text {. } \\
& d_{t}=\text { cash dividends paid during } t \text {. }
\end{aligned}
$$

The mean difference between acquiring firms and the control group showed a 5.6 percent advantage to the acquiring firms for annual rate of return. However, this measure was not statistically significant at the .05 level. Results with respect to other effects of mergers such as risk, growth rate, or financial structure were not distinguishable between the groups. 24

Two other recent works have been done, the first by S.B. Block $^{25}$ deals with changes in the prices of stocks of both acquirers and acquired companies before and after their mergers. Block's results isolate a significant merger effect on acquired companies, but his results on acquiring companies using the same tests showed that in the post-merger period there was no significant difference (measured at $\alpha=.05$ ) in

\footnotetext{
24 Ibid., Table I, p. 90.

25 Stanley B. Block, "The Effect of Mergers and Acquisitions on the Market Value of Common Stocks," Southern Journal of Business, IV (October 1969), pp. 189-195.
} 
stock prices between acquiring companies and their paired control companies. Another paper by R.A. Shick ${ }^{26}$ deals with the retur: on investment of shartholders of acquiring firms. Unfortunately, Shick's sample was too small for inferences about mergers in general although his merger evaluation models could be useful for future study.

The general studies of mergers occurring during the present merger wave can be seen to deal primarily with the profitability aspects of the problem. The results of these studies as reported above show no consistent pattern of profitability for external or merger growth over internal growth during the periods studied.

\section{Profitability of Conglomerate Mergers}

Since the conglomerate is a relatively new type of corporate form, one might not expect that a large volume of research material would be available. This is not the case however. In the Introduction to the most recent major study of the conglomerate merger, a 1171 page volume published by Saint John's Law Review, 27 Edwin M. Zimmerman writes: "This volume is a selective addition to the awesome amount of com-

\footnotetext{
${ }^{26}$ Richard A. Shick, "The Analysis of Mergers and Acquisitions," The Jo irnal of Finance, XXVII, No. 2 (May 1972), pp. 495501.

27 "Conglomerate Mergers and Acquisitions," St. John's Law Review, XLIV, (Spring 1970).
} 
mentary provoked by the conglomerate merger. No other development in industrial organization in modern times has given rise to a iike quantity of scholariy and professional atterition and dispute." 28 It is interesting to note that of the 78 articles in the edition not one contained empirical data on conglomerate performance. The St. John's study is divided into four sections--antitrust, economics, financial aisclosure, and tax implication of the conglomerate trend. There were no profitability studies of conglomerate mergers. There are a few profitability studies of the conglomerate merger in the literature. J. Fred Weston stated in a 1971 article that "only three statistical studies of conglomerate performance have been published." 29 The first study mentioned in Weston's article was that of Professor Samuel R. Reid, published in 1968.30 Reid was interested in the motivations behind active acquisition programs; he evaluated conglomerate performance on measures reflecting the interests of stockholders and of managers and drew conclusions as to which group benefited more from the acquisition program. Profitability measures were regarded as in the interest of the stockholders and growth measures were regarded as primarily in the interest of the acquiring firm's managers.

\footnotetext{
${ }^{8}$ Ibid. , p. 3.

$29 \mathrm{~J}$. Fred Weston and Surenda K. Mansingka, "Tests of the Efficiency Performance of Conglomerate Firms," Journal of Finance, XXVI (September 1971), p. 919.

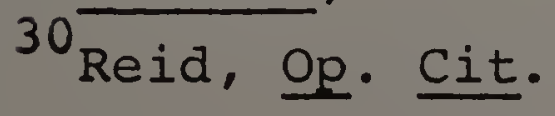


Reid used three profitability measures in his study:

(I) The relative change in market price $\mathrm{Y}_{4}=\frac{\mathrm{MP}_{t}-\mathrm{MP}_{t-1}}{\mathrm{MP}_{t-1}}$

(2) The increase in profits relative to assets

$$
\begin{aligned}
& Y_{5}=\frac{P_{t}^{*}-P_{t-1}^{*}}{A_{t-1}} \\
& Y_{6}=\frac{P_{t}^{*}-P_{t-1}^{*}}{S_{t-1}}
\end{aligned}
$$

where:

$$
\begin{aligned}
& M P=\text { market price of common } \\
& P_{t}^{*}-P_{t-1}^{*}=P_{t} \frac{N_{t-1}}{N t}-P_{t-1} \\
& P=\text { earnings available for common } \\
& N=\text { number of shares outstanding } \\
& A=\text { assets } \\
& S=\text { sales }
\end{aligned}
$$$$
t, t-1=1961 \text { and 1951, respectively. }{ }^{31}
$$

Reid compared the performance of pure "internal growth" firms with conglomerates on the three profitability measures shown above and found that all three variables favored the internal growth firms although the results were not statistically significant at $\alpha=.10$. Table IV shows the results of Reids' comparison of conglomerates with internal growth firms on the profitability measures.

${ }^{3 I_{\text {Ibid. }}, \mathrm{p} .182}$ 
TABLE IV ${ }^{32}$

Means of Variables for the Pure Internal Growth Group and the Conglomerate Group

\begin{tabular}{llcc}
\hline \hline Variable & Internal Growth & Conglomerate & $F$ - Ratio* \\
\hline$Y_{4}$ & 6.0804 & 4.342 & 0.60 \\
$Y_{5}$ & 0.121 & 0.042 & 1.69 \\
$Y_{6}$ & 0.109 & 0.034 & 1.58 \\
\hline
\end{tabular}

Number of firms 48 46

*F values based on one-way analysis-of-variance tests of the significance of differences in group means. $F_{1,46(\alpha=.10)}=2.82$. Lorie and Halpern's 1970 study $^{33}$ was the second mentioned by Weston. They studied 117 mergers which were classed as conglomerates. The investment return to the stockholder of the acquired firms was studied and compared with the market performance of broad market indexes for comparable periods. Since Lorie and Halpern were concerned with the point of view of the stockholders of the acquired companies and not the acquiring companies, their study is not comparable with the other profitability studies.

\section{$\overline{32}$} Ibid. , Table 9.13, p. 194 .

33 James H. Lorie and Paul Halpern, "Conglomerates: The Rhetoric and the Evidence," Journal of Law and Economics, XIII (April 1970). 
The third study cited by weston is that of Smith and Schreiner ${ }^{34}$ who used an ex ante model based on modern portfolio theory which focused on (1) expected portfolio returs E as a measure of profitability, and (2) the standard deviation of portfolio return $S$ as a measure of risk. These measures were defined by the following equations:

$$
\begin{gathered}
E=\sum_{j=1}^{m} x_{j} E_{j} \\
S=\left[\sum_{i=1}^{m} \sum_{j=1}^{m} x_{i} x_{j} s_{i} s_{j} c_{i j}\right]^{1 / 2}
\end{gathered}
$$

where $E_{j}=$ expected return from investment $j$ $\mathbf{s}_{j}=\begin{aligned} & \text { standard deviation of return from } \\ & \text { investment } j, j=1,2, \ldots, m\end{aligned}$

$s_{i}=$ standard deviation of return from investment $i, i=1,2, \ldots, m$ $x_{j}=\begin{aligned} & \text { relative proportion of the portfolio made } \\ & \text { in investment } j\end{aligned}$

$x_{i}=$ relative proportion of the portfolio made in investment $i$

$\begin{aligned} c_{i j}= & \text { correlation coefficient between returns } \\ & \text { from investments } i \text { and } j\end{aligned}$

$\mathrm{m}=$ total number of investments ${ }^{35}$

Their findings indicated superior diversification for investment companies over conglomerates using $D^{\prime}$ as a measure

\footnotetext{
${ }^{34}$ K.V. Smith and J.C. Schreiner, "A Portfolio Analysis of Conglomerate Diversification," Journal of Finance, XXIV (June 1967), pp. 413-428.

35 Ibid. , p. 415 .
} 
of diversification of some portfolio $P^{\prime}$ as follows:

$$
D^{\prime}=\frac{E\left(P^{\prime}\right)-E\left(P^{0}\right)}{S\left(P^{\prime}\right)} \quad \text { where } P^{0}=\begin{aligned}
& \text { the risk-free } \\
& \text { rate of return }
\end{aligned}
$$

Using a simulation based on the industries in which the firms were operating a sample of 27 conglomerates and mutual funds was ranked in decreasing order by diversification measured $D^{\prime}$. The measures range from a high of .749 for MIT Growth Fund to a low of .223 for AJ Industries. of 8 mutual funds studied, 4 ranked in the top four places and all 8 funds ranked in the top 14 places. Of the 19 conglomerates rated on the $D^{\prime}$ measure, 13 ranked lower than the lowest mutual fund. 36

The importance of Smith and Schreiners' work is the use of the portfolio approach as an additional tool for conglomerate managements to assist them in evaluating prospective acquisitions. 37

All three of these studies cited cover the period of the 1950's through the early or mid-1960's and thus do not include the period of greatest merger activity of the current

36 Ibid. , Table III, p. 423.

37 R. Westerfield, "A Note on the Measurement of Conglomerate Diversification," Journal of Finance, XXV, No. 4 (September 1970), pp. 909-914. 
merger wave. 38 Weston's own recent article with S. K. Mansinghka ${ }^{39}$ covers the period of 1958 to 1968 and deals with conglomerate profitability. The findings of their study were contrary to other profitability studies, notably S. R. Reid's, 40 in that the earnings rates of conglomerates were found to be improving during the period studied. Weston and Mansinghka calculated the arithmetic means of earnings performance measures for a sample of conglomerate firms and for two random samples of industrial and manufacturing firms. A comparison of the results for 1958 and 1968 was done by computing the F-statistics for the differences between the means of these earnings measures for each group for each period. Their results and the statistical tests are shown in Table V below:

\section{8}

A more recent unpublished doctoral dissertation by D.F. Rankin, "Security Based Conglomerate Acquisitions: The Effect on Residual Ownership," University of Mississippi, 1970, deals with performance results of conglomerates for their residual owners. Market price was taken into account which gave gains in wealth for the owners, but unfortunately this study ended in 1968 before the severe drop in conglomerate market prices.

39 glomerate market prices.

40 Reid, Mergers, Managers \& the Economy.
. 
TABLE $\mathrm{v}^{41}$

Significance Tests for Earnings

Performance Measures, 1958, 1968

EBIAT/Total Assets

EBIT/Total Assets

Earnings Ratio's

Group Sample Means

F Statistic's
C with $R_{1}$ and $R_{2}$ Jointly
C, $R_{1}, \quad R_{2}$

$\begin{array}{llllll}C & R_{1} & R_{2} & C & R_{1}, & R_{2}\end{array}$

$\begin{array}{lll}5.8 & 9.2 & 6.8\end{array}$

$6.21(.01)$

$\begin{array}{lll}8.7 & 16.7 & 12.6\end{array}$

$9.54(.01)$

Earnings Ratio's

F Statistic's

Group Sample Means

C with $R_{1}$ and $R_{2}$ Jointly

$\begin{array}{llllll}C & R_{1} & R_{2} & \text { C } & R_{1}, & R_{2}\end{array}$

$\begin{array}{lrrrr}\text { EBIAT/Total Assets } & 10.4 & 8.5 & 7.6 & 0.70 \\ \text { EBIT /Total Assets } & 15.1 & 15.6 & 13.3 & 0.44\end{array}$

Notation: C represents conglomerate firms $N=61$ in 1958, $N=63$ in 1968

$\mathbf{R}_{1}$ represents random sample of firms $\mathrm{N}=61$ in 1958 , $N=63$ in 1968

$\mathbf{R}_{2}$ represents random sample of firms $\mathrm{N}=58$ in 1958 , $N=63$ in 1968 .

EBIAT = earnings before interest and preferred dividends but after taxes.

EBIT = earnings before interest, preferred dividends, and taxes.

Number in parentheses indicate the reiationship is significant at the 1 percent level.

$\overline{{ }^{41} \text { Weston and Mansinghka, }}$ Op. cit., p. 926. 
For the year 1958, the means of the two earnings ratio's for the random sample groups (taken jointly) were higher than the means of the conglomerate group by a difference significant at the one percent level. By 1968, there was no significant difference in Weston and Mansinghka's measures of earnings performances between the groups.

This relative increase in conglomerate earnings rates as shown in Table $\mathrm{V}$ was interpreted by Weston and Mansinghka to mean that conglomerates were economically efficient since they could raise the earnings to the average for industry in general. Previous studies, particularly that of Reid, implied that conglomerates were not economically efficient because of poor comparative profitability performance (see Table IV). Weston treats the conglomerate movement as a new industry and states that, as such, it will attract an excess number of firms and thus should have a higher than average failure rate as well as individual conglomerate firms with higher-than-average profitability. The Reid book and weston and Mansinghka's article are thus in disagreement and an exchange of criticism and reply has appeared in the Journal of Finance. ${ }^{42}$ Both these studies demonstrated their points of view empirically with ex-post-factor analysis of profitability

$\overline{42}$ See Weston and Mansinghka above, and S.R. Reid, "A Reply to the Weston/Mansinghka Criticisms Dealing With Conglomerate Mergers," Journal of Finance, XXVI, No. 4 (September 1971), pp. 937-946. 
data on the companies studied. An examination of the results of these and the other studies results in the conclusion that there is still clarification needed as to the profitability of conglomerate mergers as well as that of the non-conglomerate mergers from a different point of view from the traditional analyses. This study will examine the acquisition criteria used by acquiring firms prior to merger to see what profitability implicatons might exist. If significant differences are found between the criteria used by conglomerates and other acquiring firms, an examination of such differences should prove useful as an additional approach to the study of conglomerate behavior and profitability.

Studies of Merger Criteria

Previous studies of conglomerate and non-conglomerate performance attempted to evaluate and compare merger profitability and to deduce the objectives and efficiencies of mergers. There have also been some general works in the literature concerned with acquisition criteria. This study will build from these largely descriptive works on criteria and attempt to give an empirical base to the study of acquisition criteria which has been lacking in most previous studies. The study will investigate and idertify acquisition criteria and will attempt to build them into a discriminant model that will classify the criteria preferred by conglomerate and nonconglomerate executives. 
In September, 1963, the Graduate School of Business Administration of the University of Chicago conducted a seminar to examine the problems of growth by merger. The papers and discussions which followed were later publiched in The Corporate Merger, edited by William W. Alberts and Joel E. Segall. 43 They point out the "discussions of the central, critical problem of the specific criteria to use in deciding with whom to merge, and on what terms, have tended to be brief, sketched on broad strokes and consequently vague." They further point out that "analyses of particular mergers . - have tended either to be largely descriptive or to depend heavily on intuition." 44 The lack of empirical basis for the work in the field of merger criteria is well documented.

The current work on criteria can be divided into normative writings which concentrate on the corporate objectives of mergers, and the descriptive, or "how to do it", writings, which are written by successful businessmen enumerating the criteria they found to be effective. Of the writers concerned with objectives, probably the most widely cited is $\mathrm{H}$. Igor Ansoff, whose works focus on business strategy and diversification. 45

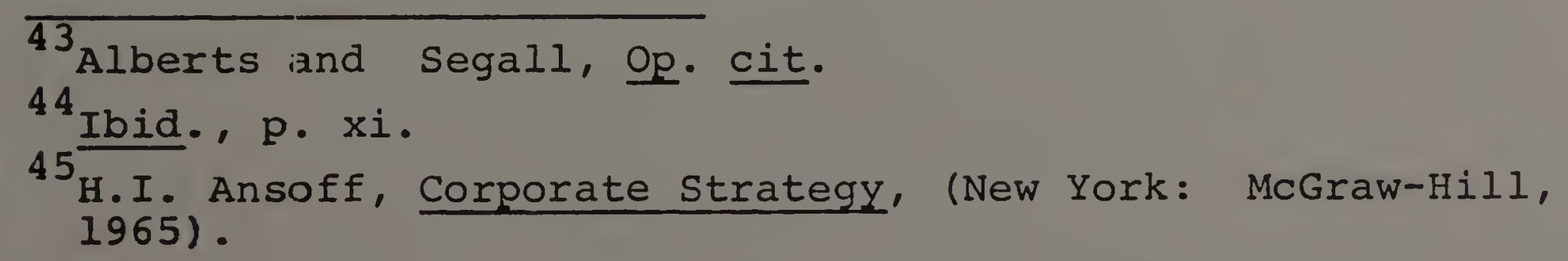


In an article written with $\mathrm{J}$. Fred Weston, 46 Ansoff concludes that the proper approach to merger is: first, an internal appraisal concerned with the firm's objectives and then an investigation of the kinds of mergers related to these objectives. Finally, Ansoff and Weston examine the organizational implications of the differing objectives and types of mergers. This is done by an evaluation of the carryover of management capabilities between industries. The merging company assesses its management capabilities and moves into those industries where its strength can carry over to the acquisition. The management capabilities that Ansoff and Weston evaluate are: financial management, general management, research and development, engineering, manufacturing, and sales. The potential degree of carryover of these management capabilities then is used to determine the level of control or the degree of integration to be attempted in the merger.

Another writer concerned with corporate objectives is Roger R. Crane. 47 Crane suggests defining corporate objectives first and then numerically weighing each objective in order to quantify its relative importance. Each prospective

${ }^{46} \mathrm{H}$. Igor Ansoff and J. Fred Weston, "Merger Objectives and Organization Structure," Quarterly Review of Economics and Business II (August 1962), pp. 49-58.

47 Roger Crane, "The Place of Scientific Techniques in Mergers and Acquisitions," The Controller (July 1961), pp. 326-329, 340-342. 
acquisition is then given a value which represents the extent to which each acquisition satisfied each objective. A scale of -10 to +10 was used. In his example, -10 indicated that the acquisition seriously threatened the objective, 0 indicated the acquisition had no effect on the objective, and +10 indicated that the acquisition "virtually guaranteed" the objective. An example of Crane's model is shown in Exhibit A.

Each prospective acquisition can be further evaluated by considering risk and market conditions in a similar matrix evaluation model.

Wyatt and Kieso 48 also recommend the establishment of broad corporate objectives as the first step in the merger process. Once these broad objectives have been established, their next step is to construct a set of evaluation criteria that more narrowly describes the direction of expansion and the kinds of companies to be considered. Wyatt and kieso use a detailed checklist for this more intensive analysis of prospective acquisition candidates. The checklist they recommend is the one shown in Exhibit B which was developed by Robert M. Allen, Jr 49 , one of the practitioners whose approach to mergers will be discussed next.

$\overline{48 \text { Wyatt and Kieso, Business Combination. }}$ 49 Robert M. Allen, Jr., "Expansion by Merger," in Alberts and Segall, Op. cit., Part II, No. 5, p. 108. 


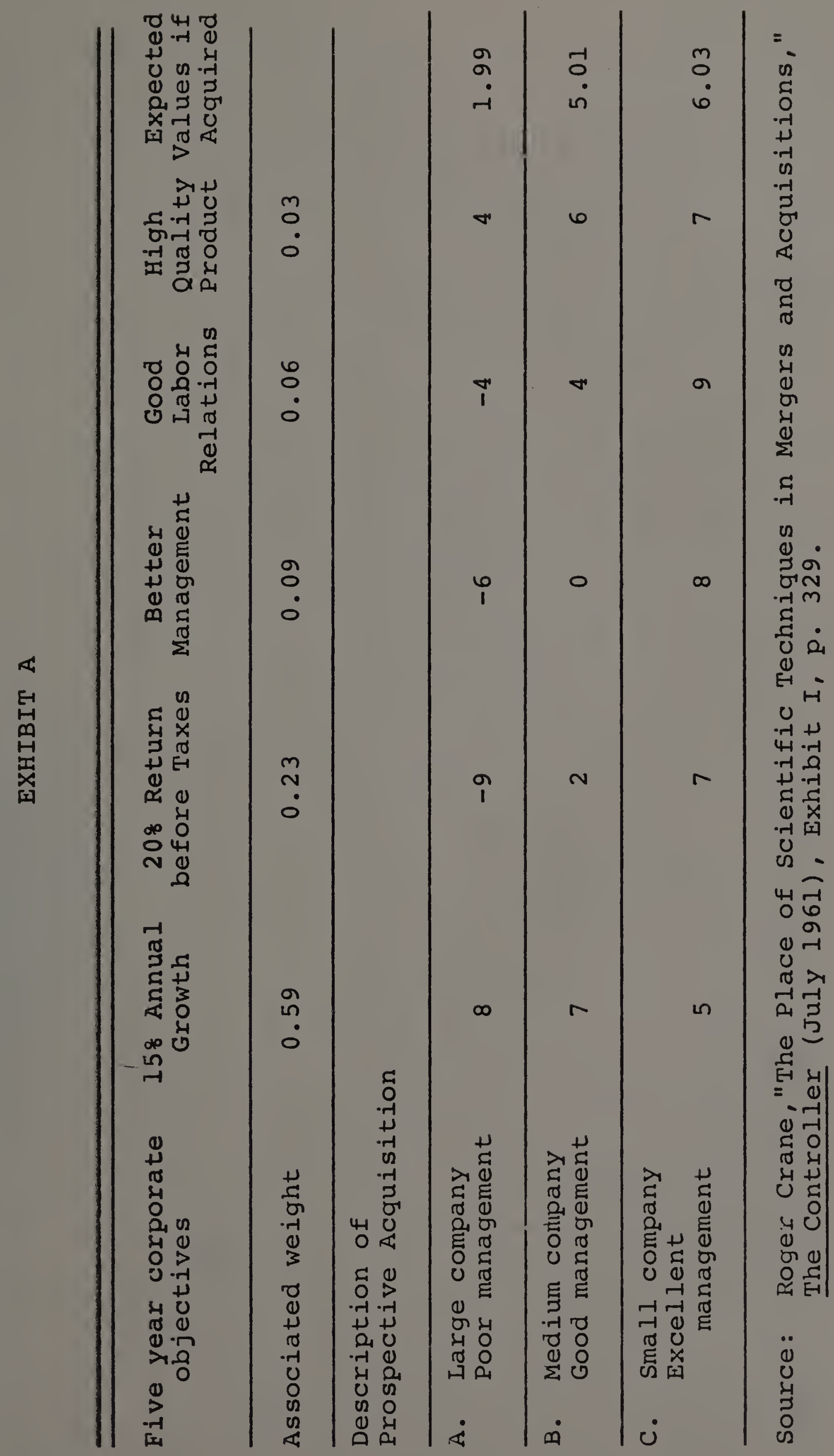


As might be expected, the practitioners concerned with acquisitions have given their formulas for successful mergers basea on their individual corporate experience. The most frequently cited of these sources is "Expansion by Merger" by Robert M. Allan, Jr., whose criteria list "summarizes criteria used by several companies" whose acquisition programs he had reviewed. Allan first specifies some of the alternatives open to the acquiring firm; he then examines goals and objectives; and, finally, he offers issues and criteria to be considered. Allan's criteria checklist has been reproduced in Exhibit $B$ and was offered as a generalization from his own acquisition experience to be "helpful to managers who are planning an acquisition program." 50

Stanley Foster Reed, editor of the Journal Mergers and Acquisitions, constructs a model for presenting, rating, and selecting industry candidates for acquisition. 51 His sixsided model shows the diversification possibilities available to a potential acquirer. His model, which is reproduced in Exhibit $C$, shows three non-conglomerate extension possibilities and three conglomerate possibilities. Once the direction of expansion has been decided on, Reed developes a strategy that will numerically rate potentially profitable companies. He uses a chart which evaluates "complements" that

\footnotetext{
${ }^{50 \text { Ibid., p. } 101 .}$

51 Stanley Foster Reed, "Corporate Diversification," Mergers and Acquisitions, $V$ No. 4 (July-August 1970), pp. 4-16.
} 
EXHIBIT B

Checklist For Evaluating Candidates For Acquisition

Industry Analysis

1. Industry Growth

a. Sales trend

b. Earning trend

c. Secular trend

d. Seasonal pattern

e. Sensitivity to general economic conditions

2. Industry Characteristics

a. Product mix

b. Product change

c. Nature of market and demand

1. Identity of customer

2. Domestic vs. inter- 5 . national

3. Factors that affect demand

3. Competition

a. Number of companies

b. Geographic pattern

c. Share-of-market trends

d. Barriers to entry

\section{Company Analysis}

1. Company Characteristics

a. Product comparability

b. Rate of introduction of new products

c. Nature of market and demand

d. Profitability ratios

e. Activity ratios

f. Liquidity measures

2. Distribution

a. Channels

b. Advertising policy

c. Field sales

3. Economics

a. Fixed-variable costs

b. Industry cost comparisons

c. Materials and labor costs

d. Adequacy of cost inform- e. Production capacity

f. Foreign competition

g. Nonprice competition

4. Technology

a. Degree of sophistication

b. Patents, etc.

c. Rate of technological change

d. Similarity of production processes

e. Amount of R\&D

f. Obsolescence risk

Economics

a. Labor-capital ratio

b. Demand elasticity

c. Price trends

d. Operating margins

e. Imports

f. Degree of government regulation c. Need for reguilding

d. Executive compensation structure

e. Degree of dependence on few men

5. Return on Investment

a. Terms of purchase

b. Method of exchange

c. Debt position

d. Working capital needs

e. Additional investments required

f. Earnings projections

g. Excess available funds

6. "Takeoff" Platform

a. Accessibility of other industry segments

b. Capitalizing on accessibility 
EXHIBIT B (Cont.)

4. Management

a. Compatibility

b. Age of key men c. Key factors for success

d. Action needed to enter these segments 


\section{CONGLOMERATE EXTENSIONS}

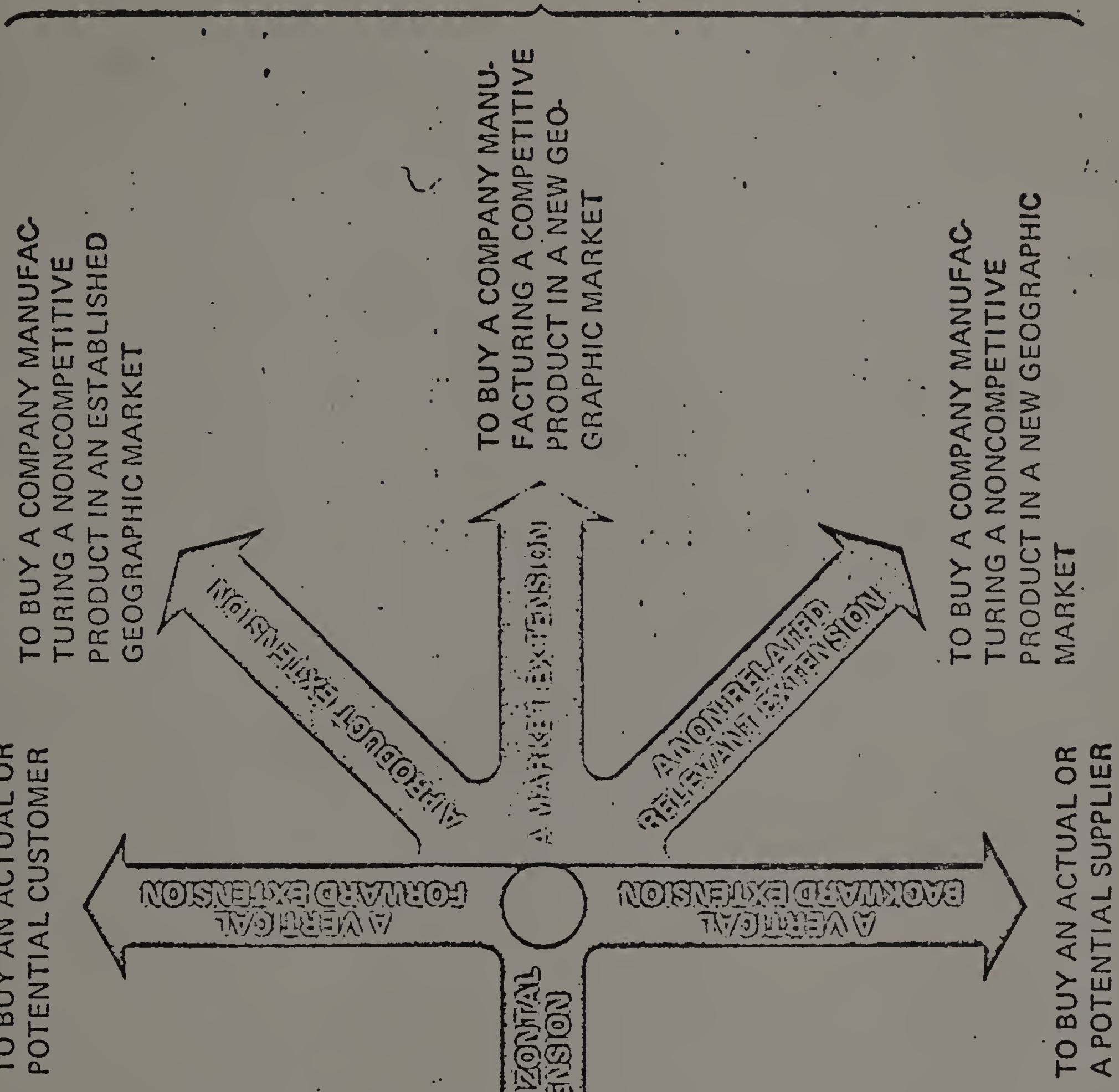

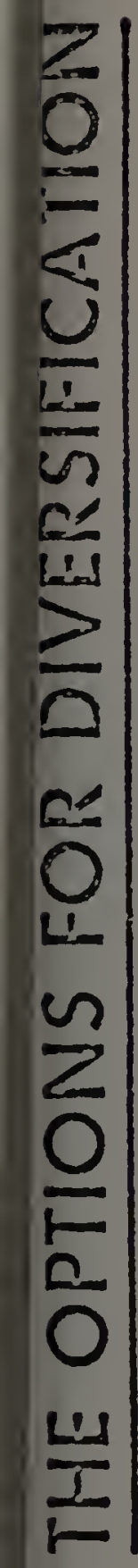

(1)

o 
complete or add to an area of the business, and "fits" that involve maximum exploitation of the company's resources. His "Fit Chart", which is similar to Roger Crane's, is shovin in Exhibit D. 52

Robert W. Hollman, an executive of General Foods Corporation writing in the same journal ${ }^{53}$ suggests that acquirers translate their criteria into a profile for screening candidates. A recent book by G. Scott Hutchinson 54 contains a special section on "Investigation and Appraisal" of mergers and acquisitions. The six articles 55 in this section are all general treatments of the subject based on the individual business experiences of six corporate officers. No survey work or data collection beyond their individual companies is mentioned by any of these authors. The practitioners writing from their company's field experience list the criteria they

\section{2}

Ibid., p. 8.

53 Robert W. Hollman, "Evaluation of the Corporate Complex," Mergers and Acquisitions, I, 3, No. 1 (January-February 1968).

${ }^{54}$ G. Scott Hutchinson (ed.), The Business of Acquisitions and Mergers, (New York: Presidents Publishing House, 1968).

55 Ibia., Part II: James E. Halbkat, Continental Can Co. "Identifying Attractive Opportunities;" Harold J. Downes, North American Rockwell Corp. "The Marketback Approach to Diversification;" Edward R. Moran, The Bendix Corporation, "Screering Potential Acquisiticn Candidates;" Sidney Fread, Lehigh Valley Industries, Inc. "Appraising Prospective Acquisitions;" Allan Lynn, Associated Products, Inc. "How to Make Contact;" Mattin S. Ackerman, Cooper Ostrin DeVarco, and Ackerman, "Tailoring the Pattern of Approach." 


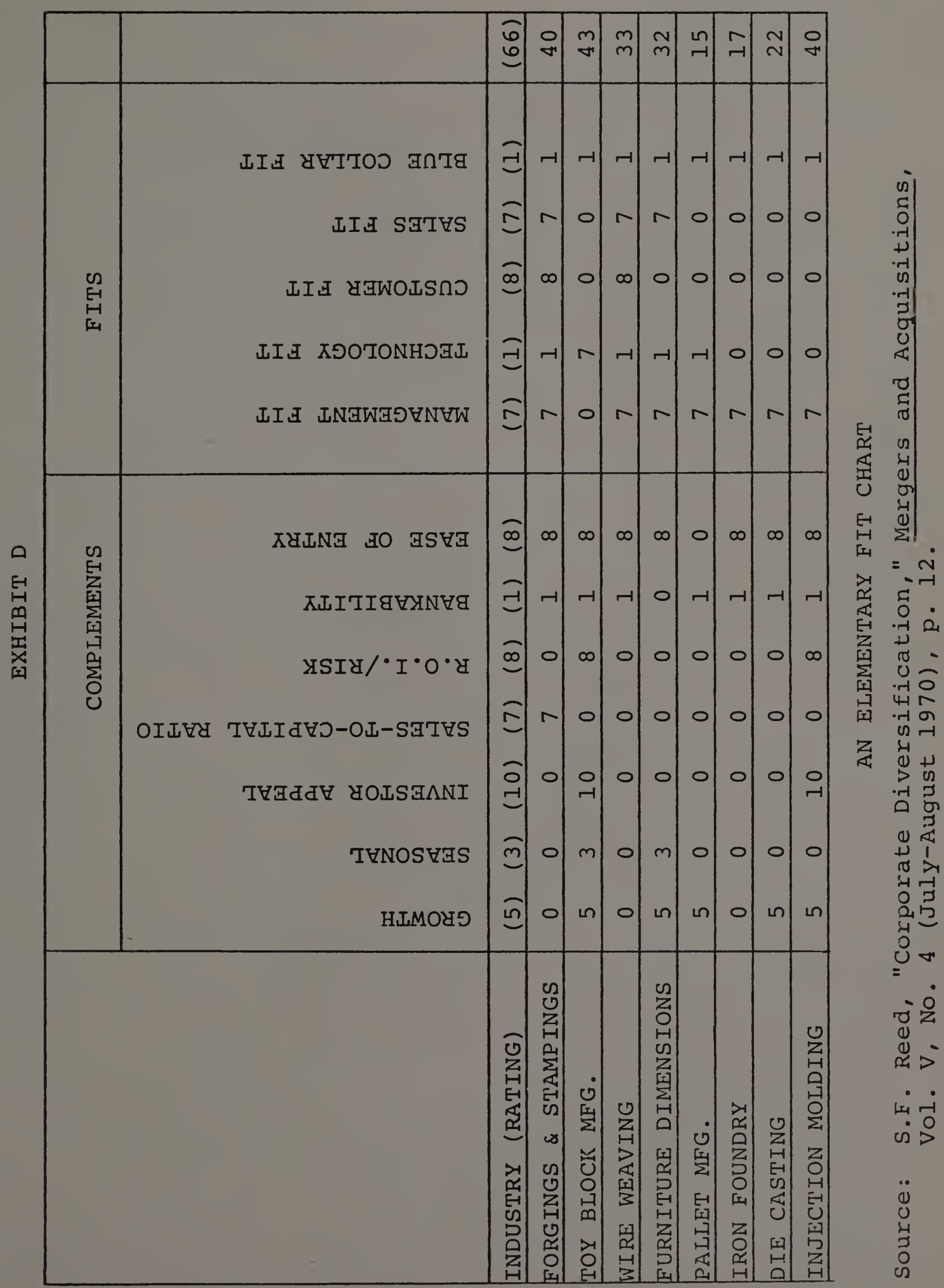


actually used, which gives too small a base for any general conclusions.

Empirical Studies of Acquisition Criteria

There have been two acquisition studies indirectly concerned with acquisition criteria that have done some data collecting. While neither of these studies is primarily interested in acquisition criteria, both did include some findings in this area. The earliest of these two studies was conducted by John Kitching in 1966.56 In his widely quoted article, Kitching lists six main reasons why acquisitions succeed. One of the six is "having acquisition criteria that are consistent and that are rigorously applied." 57 Even this article does not construct a consensus or a recommended list of criteria. The article is based on a study of 22 large companies that participated in 69 mergers from 1960 to 1965. The research was done by field interviews with company executives and no attempt was made to quantify successful or unsuccessful executive judgements on criteria. Rather, a "pattern" of executive experience and beliefs was "detected" and summarized.

The second study based on empirical data which had findings in the acquisition area that was done by H. Igor Ansoff.

56 John Kitching, "Why Mergers Miscarry?" Harvard Business Review (November-December 1967), p. 84-101.

57 Ibid., p. 99. 
and three associates and was published in $1971 .^{58}$ The portion of this study that concerned acquisition criteria was based on a quesiionnaire survey return of 93 useable responses from 412 manufacturing firms which had at least one acquisition between 1946 and 1965. The companies were further divided into two groups, one in which respondents had a single acquisition during the period and the other in which respondents had "many" acquisitions. The study was primarily concerned with the success of mergers and acquisitions and whether careful and deliberate planning of mergers produced more successful results than unplanned acquisitions. In the process of collecting data on pre-merger planning, the study examined "reasons for engaging in acquisition activities," and found that the greatest emphasis was on the "relationship between the products, markets, and technologies of the merging firms." 59 No formal criteria were specified. Nor were conglomerate results isolated or compared with non-conglomerate results. Because of their definition of acquisition programs, conglomerate firms were less likely to have been included in their sample than in a general sample of acquiring firms. 60

58 H. Igor Ansoff, R.G. Brandenburg, F.E. Portner, and R. Radosevich, Acquisition Behavic of U.S. Manufacturing Firms, 1946-1965 (Nashville, Tennessee: Vanderbilt University Press, 1971).

59 Ibid., p. 29 and 112 .

60 Ibid., p. 30 . 
Thus, while the literature does contain two studies which did examine some aspects of pre-merger activity, there has been little research primarily directed at acquisition criteria. The reasons for this lack of empirical work on acquisition criteria are probably related to the difficulties of collecting such data. Profitability data are readily available in Moody's standard and Poor's, and industry sources; while criteria lists and evaluations must be collected from the individual companies and executives themselves.

It is apparent that there is a need for empirical verification of existing writings on acquisition criteria and a corresponding need to provide a statistical base for any future work on acquisition criteria or screening models. 
C $\mathrm{H}$ A $\mathrm{P}$ T $\mathrm{E}$ R III

DATA COLLECTION

In the previous chapter, the relationship of the study to the work by others in the financial literature was established. This chapter examines the data collection process of the study, the questionnaire design, and the characteristics of the populations studied.

Three different approaches to collecting data were considered: (1) a search of the pertinent literature, a personal interview approach, and (3) a questionnaire survey of active acquiring corporations. The first approach, a search of the merger and acquisition literature, was conducted to examine the background for this study and to establish the need and relevance of the study. As noted in Chapter II, the literature search revealed little information on merger criteria and two empirical studies which were only indirectly concerned with merger criteria. 1 These readings established the need for an empirical study of criteria, and also eliminated the method of a literature search due to the lack of pertinent and current material. Secondary data sources were therefore rejected as a feasible inethod for the project, but were used as the

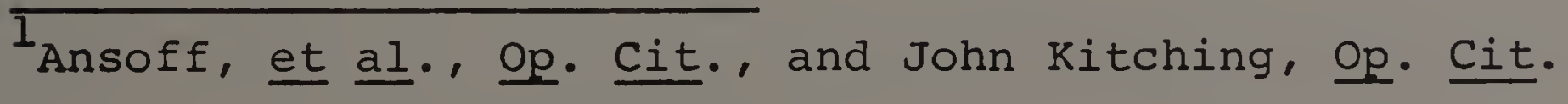


starting point for the study.

The personal interview approach ${ }^{2}$ was the second method of study considered; this method has several important advantages. First, the information obtained by interviews of corporate officials would be complete and comprehensive for the particular company studied. Second, many of the disadvantages of the questionnaire method could be avoided. For example: the interviewer would be sure that the respondent was quaified to answer the questions and that he thoroughly understooc them; also explanations of responses would give greater insight into specific corporate situations. ${ }^{3}$ The personal interview method was rejected, however, since it would result in too small a sample to achieve the objectives of the study. Personal interviews were used, however, for pretesting the questionnaire.

The research technique that seemed most likely to achieve the desired results of the study was a statistical survey of the acquisition criteria of active acquiring firms. This approach requires a large amount of statistically usable data; the data-gathering method that was selected as most efficient for this type of survey was the mail questionnaire.

\footnotetext{
2 see for example, John Kitching, Ibid. ${ }^{3}$ Selltiz, Johoda, Deutsch, Cook, Research Methods in Social Sciences (New York: Holt, Rinehart, and Winston, 1967).
} 
The choice of the mail questionnaire method of data collection has several obvious advantages. For a single survey as proposed, it is the technique which is the fastest and least expensive. Since the data sought is considered confidential by some companies, an anonymous mail questionnaire would help to overcome any hesitancy to provide such proprietary information. The mail questionnaire would overcome the problem of geographic bias that would have been present in any interview technique due to the difficulty and cost of interviews of distant companies. Another advantage of the mail questionnaire is that the responses, while not as comprehensive as those obtained by interviews, could be limited by the question structure to numeric answers that would serve as input to data processing equipment and which would be more universally adaptable for the data bank of corporate criteria information which can be used for further research.

Design of the Questionnaire

The questionnaire (which will be presented shortly as Exhibit E) was designed for ease of reading, handling, and responding. Due to the limited population of corporations surveyed, a high response rate was of special importance. A number of factors were found to affect expected rate of 
return: ${ }^{4}$

1. Length of questionnaire

2. Questionnaire simplicity

3. Innerent interest of subject to respondents

4. Attractiveness or appeal of format

5. Accuracy of mailing list

6. Nature of responding group

7. Incentives to increase desire ${ }_{5}$ to respond

8. Personalized covering letter.

A short one-page questionnaire was designed based on these factors. The primary information to be gathered by the questionnaire was an evaluation of the importance of selected merger criteria by the individual respondents. Since this information was to be obtained by a ten-part ranking question with detailed instructions, it was placed second to a simpler opening question. 6 The opening question of the questionnaire asked whether or not the corporation had a written list of acquisition criteria. This question fulfilled the requirements of a beginning question in that it was brief and directed the respondents' attention to the deeper questions that followed. ${ }^{7}$

A.E. Kimball, "Increasing the Rate of Return in Mail Surveys," Journal of Marketing, XXV, No. 6 (October 1961), p. 63 .

${ }^{5}$ S.C. Plog, "Explanations for a High Return Rate on a Mail Questionnaire," Public Opinion Quarterly, XXVII (Summer 1963), pp. 297-298.

${ }^{6}$ Selltiz et al., Op. Cit., p. 311. H.W. Boyd and R. Westfall, Marketing Research Text and Cases (Homewood, Ill.: Richard Irwin, Inc., 1972), p. 244 .

7 Luck, Wales, and Taylor, Marketing Research (Englewood Cliffs, New Jersey: Prentice-Hall, Inc., I961), pp. 148150 . 
Fs stated above, the second question was the most important of the survey. Ten frequently used acquisition criteria selected from a pilot study were listed with an answer-blank beside each, and the respondent was asked to rank the five most important criteria in order of their importance to the respondent corporation's acquisition program. By confining the respondents to ten given important criteria rather than having each of them record his complete list, the question was kept within a manageable range of ten criteria to be analyzed as the ten variables in the study. In a later question, respondents were asked to add any omitted criterion they felt important.

The ten acquisition criteria selected for the second question were the result of a previous survey by the author which collected nineteen acquisition criteria lists and manuals representative of nineteen corporations active in mergers (five of which were among the 193 companies later sent the questionnaire). The nineteen lists were obtained from merger consultants and brokers, from corporate finance departments of large stock brokerage firms, and a few directly from the corporations. All the criteria from the nineteen l.ists were arrayed in a tabular array of data matrix with a column for each criterion and a row for each of the nineteen companies. The ten criteria most frequentIy mentioned were chosen as the ten criteria to be used in the survey as question two. In constructing questionnaires, 
the sequence of the questions may bring bias ${ }^{8}$ and the same applies to lists within a question. ${ }^{9}$ In order to minimize this bias it was decided to list the ten selected criteria in descending order of their total occurrences on the nineteen lists.

As mentioned above, item three on the questionnaire asked the respondents to write in any criterion they felt was important that had been omitted from question two. While there were many more questions that could have been asked, additional questions were eliminated in the interest of brevity in the hope that busy executives would more likely answer a one-page questionnaire than a longer and more complex one. The final questionnaire used is reproduced in Exhibit E.

In order to increase the probability of response and of obtaining valị data, a personalized cover letter and a stamped return envelope were included in the mailing. 10 Due to the proprietary nature of the data sought and the sensitivity of merger executives to possible antitrust

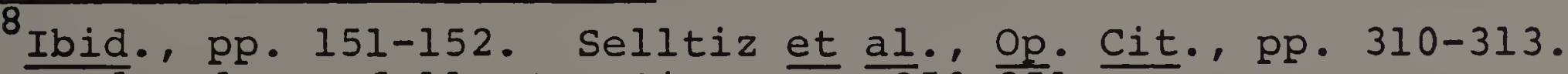
$\overline{B o y d}$ and Westfall, op. Cit., pp. $\frac{1}{250-25 i . ~}$

${ }^{9}$ G.E. Lindzey and L. Guest, "To Repeat-Check Lists Can Be Dangerous, " public Opinion Quarterly, XV (1951), pp. 351358 .

${ }^{10}$ Luck et al., Op. Cit., pp. 169-171. Jeanne E. and John T. Gullahorn, "An Investigation of the Effects of Three Factors on Response to Mail Questionnaires," Public Opinion Quarterly, XXVII (1963). G. Allan Roeher, "Effective Techniques in Increasing Response to Mailed Questionnaires," Public Opinion Quarterly, XXVII (1963), pp. 299302 . 


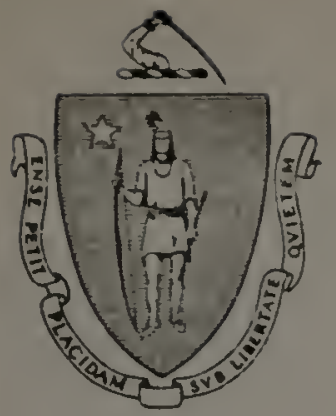

jehool of Business Administration

\section{A STUDY OF EXECUTIVE ATTITUDES TOWARDS SEIECTED ACQUISITION CRITERIA}

As a corporate executive knowledgeable about your campany's acquisition program, your help in providing the information requested in this questionnaire will be greatly appreciated and will be of much help to a doctoral candidate in the completion of a Ph.D. dissertation.

Plcase remember that your answers are anonymous and you do NOT sign your name or identify your company UNLESS you would like the results of the survey sent to you when it is completed. Thank you.

1. Does your company have a written list of acquisition criteria or a manual for mergers and acquisitions?

Yes

No

If yes, we would appreciate a copy for inclusion in a Statistical analysis of criteria (individual returns will be kept confidential).

2. Following is a list of ten frequently used acquisition criteria. The writer realizes that these are neither mutually exclusive nor independent; however, please rank the five most important in your acquisition program, putting a 1 before the criterion you rank most important of those listed, a 2 before the second most important, etc. Please put NA (for not applicable) after any criteria that your company either does not consider at all or considers to be unimportant.

Rate of growth of earnings

Return on investment

Rate of growth of sales

Present management willing to continue

complement and augment existing markets

Reputation of acquired firm

complement and fit with existing products

size of company to be acquired (Maximm or minimum limits)

price/earnings multiple of candidate

Compatibility of management objectives

3. Any other important criterion not listed? (write in below)

Thank you for your cooperation in this doctoral research project. 
action, complete anonymity was promised unless the executives chose to identify themselves or their companies. The cover letier is shown in Appendix A. Both the cover letter and the questionnaires were typed by automatic typewriter; the letters had personalized salutations typed-in with the same typewriter and were hand-signed in ink. Both were typed on University of Massachusetts $8-1 / 2 \times 11$ letterheads which lent the reputation and prestige of the University to the project.

Both the questionnaire and the accompanying cover letter were pretested by a series of six personal interviews with executives active in the merger and acquisition field-three executives were with conglomerate acquirers and three were with non-conglomerates. Each executive was asked to read the letter and then fill in the questionnaire. After completion, the author then discussed the mailing with the executives and asked for their suggestions for improving or clarifying it. Several changes were suggested and were included in the final draft. The original second question had asked the respondent to rank the criteria from 1 to 10 . Since the criteria were not mutually exclusive, several respondents complained of difficulty in ranking further criteria beyond the five most important, so the question was reworded to ask for ranking of 1 through 5 in order of 
importance. 11 The other major changes recomended nere: use of personalized salutations and addresses (by name $\equiv \equiv$ well as tiıle), use of University letterheacis, ance a short one-page questionnaire; all the recommendations were incorporated in the final draft and a $70 \%$ response was obtained.

The pretest interviews were given to too small a group for meaningful statistical tests; however, they were used as general tests of the reliability and validity of the questions. Trio of the executives interviewed were executives of a major conglomerate and were members oi its regional acquisition committee; their answers were compared as a check on the reliability of the questionnaire. In ranking the ten criteria listed, both executives selected four of their five first choices the same and in the same order; they differed only in their choice of their fourti most important criterion. See Appendix B for these responses. As a validity check all six men interviewed were asked, after completing the questionnaire, if they felt the questions had accurately measured their attitudes toward the listed merger criteria. The feedback at this point indicated that the respondents felt the guestions were valid. Feedback from the interviews also resulted in reducing the rankings of the ten criteria from $1-10$ to $1-5$

TIwenty-nine of the 131 respondents to the revised questionnaire ranked the criteria $1-10$ even though oniy asked for $1-5$. 
as well as the other recommendations already mentioned above. Populations studied

The population of firms to be examined for acquisition criteria consisted of firms active as acquirers in the merger field. Two samples of such firms were constructed; one consisting of conglomerate acquirers and the other classified as non-conglomerate acquirers. Rather than construct two new populations of firms, it was decided to send the questionnaires to officers of corporations previously studied in the finance literature.

The two groups of acquirers to be studied are labeled "conglomerate" and "non-conglomerate," terms which have been ambiguous and confusing in the finance literature. ${ }^{12}$ In order to minimize any such confusion and to relate the present project to other merger studies of corporations, lists of companies previously examined were examined and combined to form the two populations to be examined by this study. The corporations selected for the "conglomerate" group were all engaged heavily in merger activity during the decade of the sixties, all had made their growth primarily by external means, and all showed diversification into at least several

12J.F. Weston, "The Nature and Significance of Conglomerate Firms," St. Johns Law Review, XLIV (Spring 1970), pp. 6680. Wyatt \& Kieso, p. 23. J.M. Kuhlman and R.M. Duke, "A Concept of the Conglomerate Firm," St. Johns Law Review, XLIV (Spring 1970), pp. 61-65. 
industrial categories.

The basic list used for the population of conglomerate firms was a set of sixty-three corporations used by J. Fred Weston and Surenda K. Mansinghka in their 1971 study of conglomerate profitability. 13

Weston and Mansinghka used two screening rules in selecting the companies included in their conglomerate list. Their screening rule \#1 required that $20 \%$ or more of the asset increase of the firm be achieved by external acquisitions; rule \#2 was that the firms be involved in ten or more 3-digit SIC industry categories or in five or more 2-digit SIC categories. 14

Because there were ten variables to be examined and the necessity of subdividing responses into two subgroups, a larger sample was considered necessary. The probability of a modest percentage return of the questionnaire made it necessary to increase the size of the population surveyed. Since the list of conglomerates studied by Keith Smith and John Schreiner ${ }^{15}$ showed few new names and the list of companies studied by S. R. Reid ${ }^{16}$ was not published, these sources were not used. Another source of conglomerate cor-

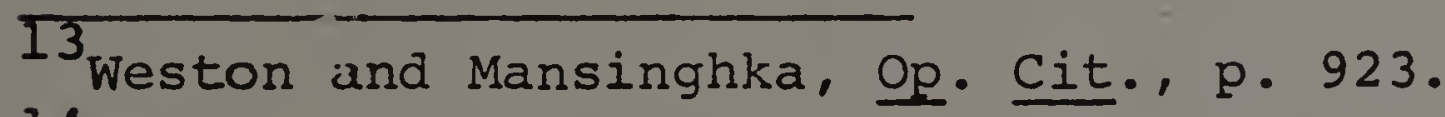
14 Ibid. , p. 922 . 15 Smith and Schreiner, Op. Cit., p. 923 ${ }^{16}$ Reid, ㅇp. Cit.
} 
porations was examined and found to be suitable. Mergers and Acquisitions, a journal devoted to mergers and acquisitions, 17 maintains an index of corglomerate stock performance made up of 57 conglomerate issues. Twenty additional companies were added to the list from this source making a total of eighty-three conglomerates in the population to be surveyed.

The requirements of the Merger and Acquisitions conglomerate list were not as well defined as Weston's. Their list was formed in January of 1969 and consisted of the 57 most "active" conglomerates at that time. The Merger and Acquisition definition of a conglomerate was a company the major portion of its growth through outside acquisitions and that the acquisitions should be companies with new products active in new markets (a diversification criterion more vague than Professor Weston's.)

The non-conglomerate list was made up of companies previously studied by Hogarty, Poindexter, and Kelly. The lists used by these authors were checked for duplications; conglomerate companies were eliminated, and some companies had been absorbed by still larger firms and were also eliminated. Hogarty's ${ }^{18}$ list of forty-three firms were all active in the merger field in the sixties, assets of their

\footnotetext{
$\overline{17 \text { Mergers and Acquisitions }}$ is published by Mergers and Acquisitions, Inc., $1725 \mathrm{~K}$ Street, N. W. , Washington, D.C. 18 Hogarty, op. Cit.. pp. 318-319.
} 
acquired firms must have been at least $20 \%$ of the asset size of the listed acquirer, and the major acquisitions were publicly held corporations. E. O. Poindexter's 19

list of one hundred and six companies was constructed from Moody's Industrial Manuals from 1956 to 1968. Moody's listed 664 mergers from 1956 to 1963. Poindexter started with this basic list and by eliminating mergers for cash, mergers for which insufficient data was given, and mergers in which the parent already exercised control, he pared the list down to 134 mergers, consumated by the $106 \mathrm{com}-$ panies. This list was further reduced by eliminating conglomerates and companies already listed by Hogarty. Kelly's ${ }^{20}$ criteria was that the acquirer should have over 208 increase in sales due to merger activity, but he selected only twenty-one companies in nineteen industries so his total contribution to the "non-conglomerate" list was only eight additional companies. Six other companies on Kelly's original list occur on the Poindexter list and the balance have been absorbed by other companies. Since Kelly had studied his selections for the period of 19461960, a further check was made. In 1971 Mergers and Acquisitions journal published a list of all mergers and acquisitions of U.S. companies with a dollar value of over

\footnotetext{
$\overline{19}$ Poindexter, Op. Cit., pp. 42-49.

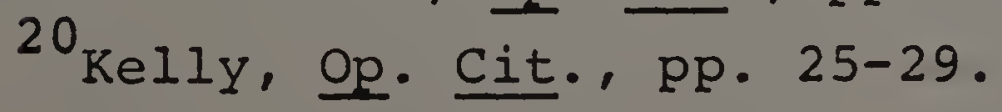


$\$ 700,000.00^{21}$ during the period 1966-1970. Each company added from Kelly's list was checked in this source and only those still actively acquiring during the period of 1966-1970 were included in the final non-conglomerate list. The total number of companies in the non-conglomerate list from all three sources was 110 .

Combiring the "conglomerate". sample of 83 corporations with the "non-conglomerate" sample of 110 corporations gave a total of only 193 companies to be surveyed. Exhibits F and $G$ show the mailing lists for the samples of conglomerate and non-conglomerate companies surveyed.

From each of these two larger samples, two subsets of acquiring firms were randomly divided into an analysis sample to construct the merger criteria model and another subset to test the ability of the discriminant model to predict and classify.

The Data Collection Process

Since each group had to be further divided into an analysis sample and a test sample, a high rate of response to the questionnaire was important.

Recognizing this, each questionnaire and covering letter wrs typed by automatic tynewriter and a personalizer. salutation and address was typed on each with the same type-

${ }^{21}$ Mergers and Acquisitions, Inc., Roster Cross-Index 19661970, 1971, Special Issue. 


\section{EXHIBIT F}

Mailing List of 83 Conglomerate Acquirers

59 Firms Responding* (Response Rate 71.1\%)

53 Responses Statistically Useable (Response Rate 63.9\%)

$\begin{array}{ll}\text { American Standard } & \text { Emhart Corp. } \\ \text { American Brands } & \text { Fuqua Industries, Inc. } \\ \text { AVco Corp. } & \text { GAF Corporation } \\ \text { Avnet Corp. } & \text { General Telephone \& Elec- } \\ \text { Bangor Punta Corp. } & \text { Gronics Corp. } \\ \text { Cities Service Corp. } & \text { Georgia Pacific Corp. } \\ \text { Continental Oil } & \text { Glen Alden Corp. } \\ \text { Eaton Corp. } & \text { W. R. Grace \& Co. } \\ \text { Olin Corp. } & \text { Hondaille Industries, Inc. } \\ \text { National Distillers and } & \text { Indian Head Inc. } \\ \text { American Metal Climax Inc. } & \text { International Tel \& Tel Corp. } \\ \text { City Investing Co. (Inc.) } & \text { Walter Kidde \& Co. Inc. } \\ \text { Boise Cascade Corp. } & \text { Kinney Service Inc. } \\ \text { Colt Industries Inc. } & \text { Lear Seigler Inc. } \\ \text { Consolidated Foods Corp. } & \text { Ling-Temco-Vought Inc. } \\ \quad \text { Inc. } & \text { Litton Industries Inc. } \\ \text { Dart Industries Inc. } & \text { Martin Marietta Corp. } \\ \text { Diamond Shamrock Corp. } & \text { Midland-Ross Corp. } \\ \text { Dresser Industries Inc. } & \text { Monogram Industries Inc. } \\ \text { Emerson Electric Co. } & \text { Lehigh Valley Industried Inc. } \\ \text { National General Corp. } & \text { A. J. Industries Inc. } \\ \text { Northwest Industries Inc. } & \text { A-T-O Inc. } \\ \text { Occidental. Petroleum Corp. } & \text { FMC Corp. } \\ \text { Ogden Corp. } & \text { North American Rockwell } \\ \text { Rapid-American Corp. } & \end{array}$

*The 59 responding firms are not specifically identified because the responses were anonymous. 


\title{
EXHIBIT F (Continued)
}

\author{
Reliance Electric Co. \\ $\mathrm{T} R \mathrm{~W}$, Inc. \\ Republic Coiporation \\ Arvin Industries Inc. \\ SCM Corporation \\ Bath Industries Inc. \\ The Signal Companies Inc. \\ The Bendix Corporation \\ The Singer Company \\ Borg-Warner Corporation \\ Studebaker-Worthington Inc. Brunswick Corp. \\ Teledyne Inc. \\ Chris-Craft Industries Inc. \\ Tenneco Inc. \\ Conwood Corporation \\ Textron Inc. \\ MSI Industries Inc. \\ Transamerica Corporation \\ Penn Central Co. \\ U.S. Plywood-Champion \\ Papers Inc. \\ Squibb Beech-Nut Inc. \\ White Consolidated Industries E. R. Squibb \& Sons Inc. \\ Inc. \\ Whittaker Corporation \\ Steward-Warner Corp. \\ Eltra Corporation \\ UMC Industries Inc. \\ United Brands Company \\ United Industrial Corp. \\ Bell Intercontinental Corp. \\ Foremost-McKesson Inc. \\ Eagle-Pitcher Industries Inc. \\ U. S. Industries \\ Gulf and Western Ind.
}




\section{EXHIBIT G}

Mailing List of 110 Non-Conglomerate Acquirers

73 Firms Responding* (Response Rate 66.4\%)

67 Responses Statistically Useable (Response Rate 60.9\%)

Amerace Esna

American Can

American Motors

Armco Steel Corp.

Continental Can Corp.

Coca Cola Corp.

Merck \& Co., Inc.

Owens Illinois Corp.

Warner-Lambert

Allis-Chalmers Mfg. Co.

American Broadcasting

Companies Inc.

Berkshire Hathaway Inc.

Blaw-Knox Company

Carpenter Technology Corp.

American Pacesetter

Carrier corporation

Chemway Corporation

Copperweld Sttel Company

General Portland Cement co.

Federal-Mongul Corp.

Ideal Basic Industries Inc.

National Tea Co.

Stokeley-Van Camp Inc.

Sutherland Paper Co.
Kern County Land Company

American Petrofina

Fibreboard Corp.

Texas Instruments

Bowmar Instrument

Leonard Refineries Inc.

Lynch Corporation

Marquette Cement Mfg. Co.

National Can Corp.

The National Sugar Refining Co.

Michigan Seamless Tube Co.

Philip Morris Inc.

McCrory Corp.

Revion Inc.

Beech-Nut Inc.

Hooker Chemical Corp.

National Gypsum Co.

John Morrell \& Co.

Sunshine Biscuits Inc.

Detroit Steel Corp.

Diamond International Corp.

The Dow Chemical Co.

U. S. Gypsum

Dun \& Bradstreet Inc.

*The 73 responding firms are not specifically identified because the responses were anonymous 
EXHIBIT G (Continued)

Acme Markets

Air Produrts \& Chemicals Inc.

Air Reduction Company Inc.

American Cement Corp.

American Cyanamid Company

American Standard Inc.

Amsted Industries Inc.

The Anaconda Company

Allied Chemical Corp.

Aluminum Co. of America

Associated Dry Goods Corp.

Bell \& Howell Co.

Beatrice Foods Co.

The Boeing Company

Brown Shoe Company Inc.

Bunker-Ramo Corp.

Burlington Northern Inc.

Consolidation Coal Company

Colgate-Palmolive Co.

Cessna Aircraft Co.

Cunningham Drug Stores Inc.

National Biscuit Company

Ohio Brass Company

Packaging Corp. of America

Pepsi-Cola General Bottlers Inc.

Pet Incorporated

Pfizer Inc.

Procter \& Gamble Company

Purex Corporation Ltd.

The Quaker Oats Company

Ralston Purina Company
Federated Department Stores Inc. The Flintkote Company Ford Motor Company General Dynamics Corp. Gimble Brothers Inc. Harris-Intertype Corp. Hercules Incorporated International Harvester Co. Ingersoll-Rand Co. Jones \& Laughlin Steel Corp. Joy Manufacturing Co. Kaiser Aluminum \& Chemical Corp. Kerr-McGee Corporation King-Seeley Thermos Co. Lone Star Cement Corp. Martin-Marietta Corp. The May Department Stores Co. McCrory Corp. MCGraw-Edison Company The Mead Corporation Minnesota Mining \& Manufacturing Reynolds Metals Company Robertshaw Controls Company Sharon Steel Corporation Saxon Industries Inc.

St. Regis Paper Company

Standard Oil Company (Indiana)

Texaco Inc.

Union Carbide Corporation

Weyerhaeuser Company

Richardson-Merrell Inc. 
writer. The covering letter (Appendix B) included an appeal for feedback of information from industry to the academic world as well as a personal appeal for assistance. The form and substance of the covering letter as well as the individual salutations and typing were the result of suggestions given during the pretest interviews. The construction and pretest of the questionnaire is discussed earlier in this chapter.

The questionnaire and covering letter (and a self-addressed, stamped, return envelope) were sent to the 193 companies. The source used to obtain the names, titles, and addresses of an executive in each of the surveyed companies was the Reference Book of Corporate Managements 1971-72, published by Dun and Bradstreet, Inc., New York, New York, 1971. For each of the companies, the survey was personally addressed to an executive in the firm who was judged most likely to have a direct knowledge of the company's acquisition program. The package was addressed to the vice-president of corporate planning, the vice-president of corporate development, the financial vice-president, or the corporation treasurer in that order of preference (many survey firms had only one of the listed titles--few had more than two).

Ten companies were selected at random from both the conglomerate and non-conglomerate lists for a sample mailing of the questionnaire. The sample mailing returns were 
important to see if the instructions would be followed and if a follow-up mailing was necessary. The response rate of this first mailing was an encouraging 17 responses or 85\%. This high rate of response preciuded a follow-up letter and none was sent; also none was scheduled for the main mailing which followed. Three of the responses to question number two did not follow directions which dropped the useable response percentage to $70 \%$. This was still a high enough return to yield a sufficient data bank and it was decided not to change the instructions on the questionnaire for the main mailing which was to follow.

The main purpose of the study was to examine any differences between conglomerate and non-conglomerate evaluations of the criteria. It was important, therefore, to keep the responses from these two groups separate for individual analysis while still keeping the responses anonymous as promised in the questionnaire. The individual questionnaires were typed by automatic typewriters on University letterheads. Different styles of letterheads were used for each group: the non-conglomerate group had a subheading of "School of Business Administration," the conglomerate letterheads has no sub-heading. Thus as the responses were returned in the self-addressed envelopes (some that included letters or company acquisition manuals were returned under separate covers), it was possible to sort them into their proper group by an examination of the ques- 
tionnaire letterhead.

The second mailing of 173 questionnaires was sent to complete the survey of 193 total firms. A total of 132 companies responded to both mailings for a total response rate of $68.4 \%$. Of the conglomerate firms, 59 of 83 responded for a response of $71.1 \%$; and 73 of 110 non-conglomerates responded for a response rate of $66.4 \%$. Two survey packages were returned "unclaimed" and one was returned with the comment that company policy forbade the completion of the survey questionnaire. The total response rate of $68.4 \%$ must be considered very favorable considering the nature of the data sought, the type of high-ranking corporate executives contacted and the fact that no follow-up letters were sent. Of the 59 "conglomerate" answers, fifty-three were useable for statistical analysis; of the 73 "non-conglomerate" answers, sixty-seven were useable for the experiment. A record was kept of the return envelope cancellation postmarks and a good geographic spread was attained (for example, 21 returns were postmarked from Texas and California of 27 sent to those areas). No regular statistical computations were done, however, on the geographic spread of the returns because of the possibility of inter-office transfers, and the large number of illegible and uncancelled return envelopes. The total of 120 useable returns--53 conglomerate and 67 non-conglomerate 
provided the sample upon which the criteria discriminant analysis and the criteria tabulations were conducted. 
C $\begin{array}{lllllllllll} & \text { A } & \text { P } & \text { T } & \text { E } & R & \text { IV }\end{array}$

METHODOLOGY

The results of the questionnaire survey are used in this project in two ways. First, the usable returns are used to construct a discriminate model based on acquisition criteria preferences between conglomerate and non-conglomerate executives. Second, the data collected are tabulated and examined for any significant relationships or correlations between variables and between groups. The methodologies used will be discussed in this chapter and the results of the experiments will be discussed in Chapter V.

\section{Discriminant Analysis in the Literature}

The use of the statistical technique of discriminant analysis which will be used in this study has some precedence in financial research. An early use of discriminant analysis (DA) in the financial literature was made by Durand in $1941^{1}$ in an evaluation of the credit ratings of automobile loan applicants. The technique was used again in 1959 by Walter ${ }^{2}$ to

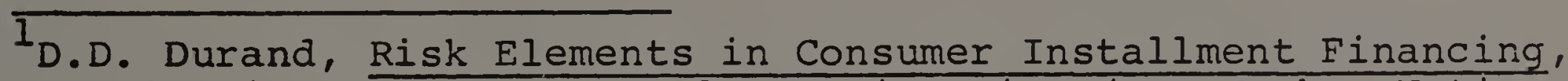
Studies in Consumer Installment Financing (New York: National Bureau of Economic Research, 1941), pp. 105-142.

2 J.E. Walter, "A Discriminant Function for Earnings Price Ratios of Large Industrial Corporations," Review of Economics and Statistics, XLI (February 1959), pp. $4 \overline{4-52}$. 
construct a discriminant model to classify large firms by their high or low price-earnings ratios. Another study using the discriminant technique for the evaluation of credit risks was done by Myers and Forgy ${ }^{3}$ for the screening of installment loans in 1963. More recent uses of the technique have been in the area of marketing research ${ }^{4}$ and in the area of investments ${ }^{5}$ both in 1965 .

Probably the most widely quoted article using the discriminant analysis technique in finance was Edward Altman's 1968 article $^{6}$ on the prediction of bankruptcy through a discriminant model of financial ratios. Altman applied DA to a set of financial ratios and derived a predictive model of bankruptcies that correctly classified a test sample of 25 bankrupt firms with a predictive accuracy of $96 \%$ and correctIy classified a test sample of 66 non-bankrupt firms with a

3. Myers and E.W. Forgy, "Development of Numerical Credit Evaluation Systems," Journal of the American Statistical Association, L (September 1963).

4 R.E. Frank, "Bias in Multiple Discriminant Analysis," Journal of Marketing Research, II (August 1965), pp. 250-258.

$5 \mathrm{~K} . \mathrm{V}$. Smith, Classification of Investment Securities Using MDA, Institute paper \#101 (Lafayette, Indiana: Purdue University, Institute for Research in the Behavioral, Economic, and Management Sciences, 1965).

6E.I. Altman, "Financial Ratios, Discriminant Analysis and the Prediction of Corporate Bankruptcy," Journal of Finance, XXIII, (September 1968), pp. 589-610. 
predictive accuracy of 798 (significant at the .001 level.) ${ }^{7}$

Two more recent articles concerned with mergers have used the technique to construct preủictive financial models. Professors Richard Norgaard and David Crary used discriminant analysis in a 1970 paper to identify merger targets in the property and liability insurance industry. 8 A similar use of the discriminant analysis technique was developed in a 1971 article by Simkowitz and Monroe to identify merger targets of conglomerate acquirers. ${ }^{9}$ They used a discriminant model to identify target firms by their financial characteristics. Their model correctly classified $63.2 \%$ of a sample of 87 firms (significant at the .01 level.) 10

This study will use the discriminant analysis technique to construct a model of merger criteria that will classify

7 Ibid., pp. 601-602. For comments on these results, see Craig G. Johnson, "Ratio Analysis and the Prediction of Firm Failure," and E.I. Altman, "A Reply," both in Journal of Finance, XXV (December 1970), pp. 1166-1172. Also, Mark Hanna, "Corporate Bankruptcy Potential, Stockholders' Returns, and Share Valuation: Comment," and E.I. Altman, "Reply," both in the Journal of Finance, XXVII (June 1972), pp. 711-721.

${ }^{8}$ R.L. Norgaard and D.T. Crary, "Identifying Merger Targets in the Property and Liability Insurance Industry," Financial Analysts Journal (June-February 1970).

9 M.J. Simkowitz, and R.J. Monroe, "A Discriminant Analysis Function for Conglomerate Targets. "Southern Journal of Business (1971), pp. 1-16. $1{ }^{\text {Ibid.. p. } 12 . ~}$ 
sets of merger criteria as characteristic of conglomerate or non-conglomerate acquirers.

The Discriminant Analysis Function

Discriminant analysis is used in the present study to analyze and classify merger criteria and to construct the acquisition criteria model. Discriminant analysis enables a researcher to study the relationship between a set of independent variables (e.g., acquisition criteria) and a dependent classification variable (e.g., conglomerate or non-conglomerate preferences). The entire profile of independent variables is analyzed simultaneously rather than sequentially which takes into account the interrelationships and correlations between the independent variables.

The basic concept of the method is to produce one linear combination of the independent variables which will best correlate with the dependent variable. This linear combination is given a number value called the " $z$ " value or discriminant score. The model is written in the following form which transforms the individual variable values $x_{i}$ into a single discriminant score " $\mathrm{Z}$ " used to classify responses as conglomerate or non-conglomerate:

$$
z_{j}=v_{1} x_{1} j+v_{2} x_{2} j+\ldots+r_{i} x_{i} j+\ldots+v_{n} x_{n} j+E_{j}
$$
where: $\begin{aligned} z_{j}= & \text { the discriminant score of the } j^{\text {th }} \text { subject, } \\ & j=1, \ldots, m\end{aligned}$

$v_{i}=\begin{aligned} & \text { the discriminant coefficient for the } i^{\text {th }} \text { inde- } \\ & \text { pendent variable, } i=1, \ldots, \mathrm{n}\end{aligned}$ 


$$
\begin{aligned}
x_{i j}= & \text { the value of the } i^{\text {th }} \text { variable of the } j^{\text {th }} \text { sub- } \\
& \text { ject responding } \\
\varepsilon_{j}= & \text { the residual error of the } j^{\text {th }} \text { subject. }
\end{aligned}
$$

The same set of coefficients is applied to the variable value $x_{i}$ for each subject. This results in a new $z$ score for each subject. This score is then used to determine into which of the dependent groups a particular data response falls. In the linear discriminant function, the coefficients are obtainec so as to maximize the following ratio: ${ }^{12}$

$$
\text { variance between means on } z
$$

Thus it is seen that the rule of optimization for the linear aiscriminant function is to obtain coefficients so as to mazimize the E ratio of between-means variances to within groups variances. ${ }^{13}$ This rule was first proposed by R.A. Fisher ${ }^{14}$ in 1946 anc has been the basis for most work in discriminatory analysis since then. With only two groups (and any number of variables) the coefficients are determined by assigning one group a score of 1 and the other a score of 0

\footnotetext{
11 H. H. Wie, D.H. Bent, and C.H. Hull, Statistical Package for the Social Sciences (New York: UcGrâ-Hill, 1970), p. 175 . 12 J.C. Nunnally, Psychometric Theory (New York: McGrawHili, 1967), p. 391. 13 Ibid., p. 392 .

14 R.A. Fisher, Statistical Uethods for Research Workers (Edinburgn: Oliver and Boyd, 1946), PD. 285-289.
} 
(any two numbers would do as well). Next, the variables are used in multiple regression to obtain the regression coefficients that will maximize the correlation of each variable with the group scores. This method of discriminant analysis assumes and utilizes a common variance-covariance matrix for the $\mathrm{x}$ variables in the two populations. The regression coefficients obtained in this way become the discriminant coefficients used for obtaining the discriminant score $\mathrm{Z}$ for each case. 15

Inputs will be the results of the survey of $\mathrm{m}$ subjects (corporate executive's responses) on variable $x_{i j}(i=1, \ldots, n)$ where $n=10$ (the ten preselected acquisition criteria). Thus, inputs to the model will be the values $x_{i j}$ for each of a known group of both conglomerate and non-conglomerate responses which will determine a set of coefficients $v_{i j}$ for the discriminant function $\mathrm{z}$ which will separate each of the responses such that each will best be classified into one of the two groups. A small randomly selected sample of known conglomerate and non-conglomerate responses will be used as analysis groups to construct the discriminant function. After a set of coefficients is determined for the responses within this known group, the model can be tested by putting responses from other corporations into the model to check if

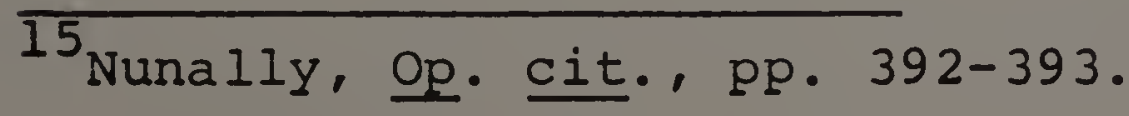


the previously determined " $Z$ " score can correctly classify them into the proper group. If there are statistically significant iffierences between the conglomerate and non-conglomerate and non-conglomerate groups, the model should be able to correctly sort them.

Discriminant analysis, which is usually performed by a computer using a standard library program, is employed here to study a set of executive evaluations of ten merger criteria ( $x_{i j}$ values) measured on conglomerate and non-conglomerate firms where the object is to classify the valuations as well as to construct a criteria profile of such firms. The models of corporate acquisition criteria can then be studied and analyzed for individual characteristics, correlations, and relationships.

Application of Discriminant Analysis

Discriminant analysis was chosen as the statistical tool in this study because it allows the researcher to study the linear relationship between the set of ten acquisition criteria (independent variables) and the two groups of firms (dependent variable) while taking into account the interrelationships among the independent variables. The results of the mail questionnaire on executive rankings of merger criteria were used as the input to the discriminant model. The respondents ranked their preferences of the ten criteria with a value of one for most important, two for second most 
important, etc. for five choices. One hundred and twenty questionnaires were returned completed correctly in this manner. The answers were then weighted in reverse order giving a first choice the value of five, second choice the value of four, etc. through the first five choices. All criteria ranked six through ten, or ranked "0", blank, or "NA" (for not applicable) were given a zero value. In cases where rankings were tied, the tied rankings were given the average of the ranks they would have received if there were no ties. ${ }^{16}$ The total value of each response was fifteen. See Exhibit H. These numerical equivalents of each respondent's rankings were used as input to the MDA model. Thus, for each useable response, there was an input for each of the ten criteria variables ranking from zero to five (with allowance for ties). A card was then punched for each of the one hundred and twenty useable responses.

One further test was needed before determining the discriminant function. The discriminant program selected for use in this study was the Biomedical Computer Program "BMDO4M - Discriminant Analysis - Two Groups - Version of May 26, 1964. Health Sciences Computing Facility, UCLA." 17 This program assumes that the grouped data input are cardinal

${ }^{16}$ Sidney Siegel, Nonparametric Statistics for the Behavioral Sciences (New York: McGraw-Hill, 1956), p. 217.

17 W.J. Dixon (ed.), Biomedical Computer Programs (Berkeley: University of California Press, 1968). 


\section{EXHIBIT H}

Weighting of Responses to Question 2 of Questionnaire for Input to Discriminant Function

\begin{tabular}{cccc}
\hline $\begin{array}{c}\text { Respondent } \\
\text { Ranking } \\
\text { (Order of Preference) }\end{array}$ & $\begin{array}{c}\text { Input } \\
\text { Value }\end{array}$ & $\begin{array}{c}\text { Respondent } \\
\text { Ranking } \\
\text { of Preference) }\end{array}$ & $\begin{array}{c}\text { Input } \\
\text { Value }\end{array}$ \\
\hline 1 & 5 & 7 & 0 \\
2 & 4 & 8 & 0 \\
3 & 3 & 9 & 0 \\
4 & 2 & 10 & 0 \\
5 & 1 & 0 & 0 \\
6 & 0 & Blank & 0 \\
\hline
\end{tabular}

data. Even though "these assumptions are so often violated (often with justifiable reasons) during the process of data analysis as to make the distinction of questionable utility,"18 It was felt that because the ranking data used in this study was clearly ordinal that certain tests of the input data should be made.

Tests For Normal Distribution

Two tests of the normality of the residual error term, $E_{j}$, were performed. If the residual errors from the mean

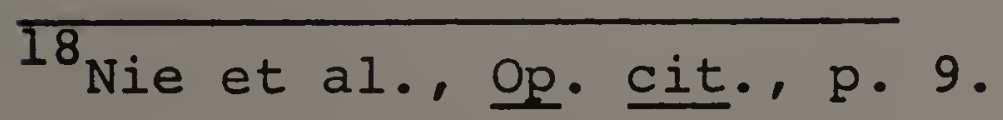


of the input data can be shown to appear approximately normally distributed with mean zero, the discriminant equation is a good predictor of the dependent variable. ${ }^{19}$ First, the residual errors had to be computed for the fitted data input. All one hundred and twenty data cards were run through the MDA program and one discriminant equation with ten coefficients (one for each variable) was computed for the entire set of data. A mean " $z$ " score was computed for each of the two subsets of data (conglomerate and non-conglomerate) along with the standard deviation of each subset. All the "z" scores for each subset were ranked from the highest to the lowest values. The mean for each group was then subtracted from each subgroup score leaving a ranked column of residuals for each subset of input data. The two groups of residual errors were then plotted to visually compare their distribution with a normal distribution. Arithmetic probability graph paper was used for the plot with the $y$ axis arithmetically scaled to span the total spread of the residual values from the mean and the $\mathrm{X}$ axis scaled to the relative cumulative frequency of a normal curve (expressed in percentage). on this type of paper, 20 "the degree to which all plotted points lie on a straight line determines the closeness of fit

\section{9}

Ibid., pp. 175 and 179.

20 Arithmetic probability paper, No. 3227 , plain scale (Norwood, Massachusetts: Codex Book Company). 
of the given distribution to a normal distribution." 21 The fifty-three "conglomerate" responses and the sixty-seven "non-conglomerate" responses were scaled as percentages of the total return for their group and plotted on the same graph. The results are shown in Figure $I$; it is seen that both sets of data closely fit a straight line, indicating that both are very nearly normally distributed.

A second test for normality was performed on the ranked residual data. For both subsets of data, the ranked residual errors from the means were divided by the standard deviation from the mean; this gave the number of standard deviations from the mean for each observation. A chi-square test of "goodness of fit" was then computed between the observed number of data points and the expected number of data points in a normal distribution differing from the mean by one, two, and three standard deviations. The results of the chi-square test of goodness of fit showed that the error in both data subsets could not be proven different from a normal distribution. A $x^{2}$ value significant at the .05 level of significance was used with one degree of freedom. ${ }^{22}$ From both tests of the errors, we assume that errors in the data are normally distributed, and the discriminant analysis programs are useable tools. The discriminant equation was then computed.

\footnotetext{
21 Murray Spiegel, Theory and Problems of Statistics (New York: MCGraw-Hill, 1961), p. 136. ${ }^{22}$ Siegel, op. cit., pp. 42-47.
} 


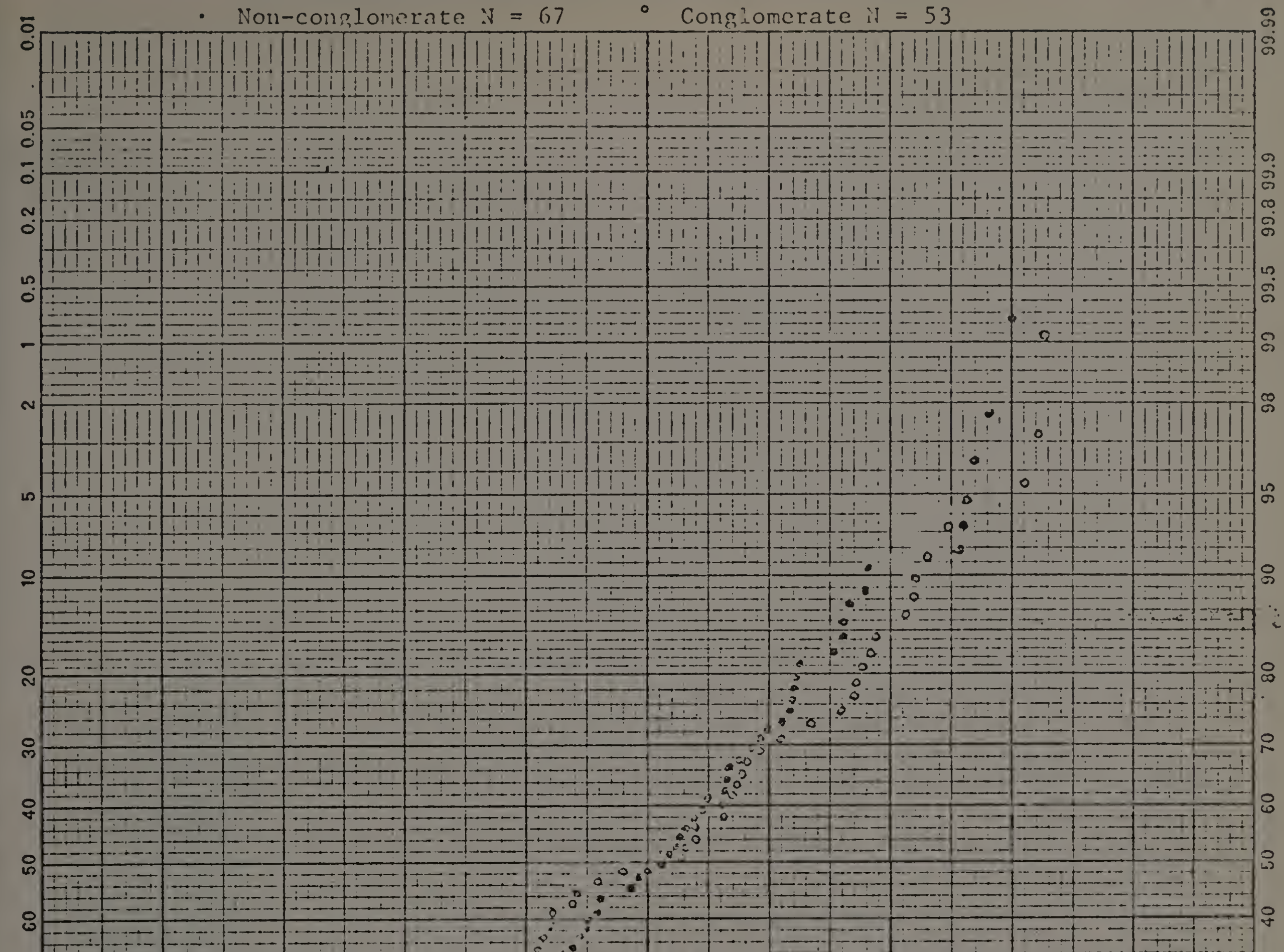

.

ऽ

응

\%

$\sigma$
$\sigma$
$\sigma$
$\sigma$
$\infty$
$\vdots$
$\sigma$
$\sigma$
$\sigma$
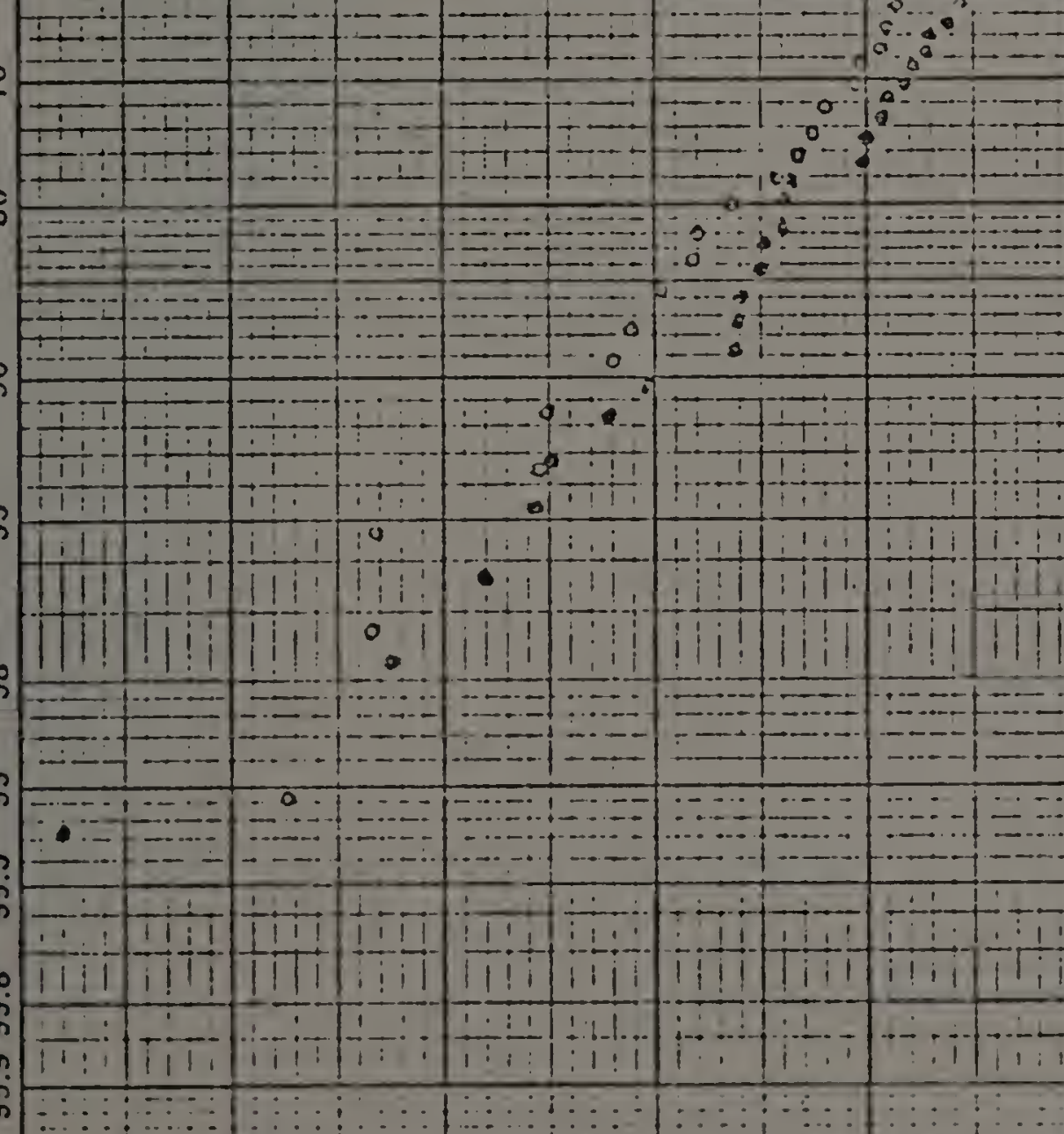
The Discriminant Equation

From the populations of fifty-three useable conglomerate repliıs and sixty-seven useatie non-conglomerate replie:, twelve from each subgroup of responses were randomly selected to make an analysis group of twenty-four executive responses to be used to construct the discriminant function. The remaining replies (forty-one conglomerate and fifty-five nonconglomerate) were held-out to be used as a target group for later testing of the discriminant function determined by the analysis group. The twenty-four replies selected for the experimental group are a small sample representing only $20 \%$ of the total replies, but this sample was large enough to give significant statistical tests to the classification of the analysis group and still leave a large enough control group to test the ability of the resulting discriminant function to predict and classify unknown responses.

The analysis group of twenty-four responses was run through the BMDO4M program and the following discriminant equation was developed:

$$
\begin{aligned}
z= & -0.01367 x_{1}+0.02734 x_{2}+0.03027 x_{3}+0.06934 x_{4}+0.04785 x_{5} \\
& -0.04688 x_{6}-0.02637 x_{7}-0.02441 x_{8}-0.01367 x_{9}+0.00488 x_{10}
\end{aligned}
$$

The equation was tested for accuracy of its classification of the 12 known conglomerate replies and the 12 known non-conglomerate replies by means of a chi-square test. The 96 responses of the holdout (control) sample were then classi- 
fied by the discriminant equation using the discriminant coefficients to determine a $\mathrm{z}$ score for each response. The results of these classifications wiil be examined in detail in Chapter V. Also in Chapter V, the results of these classification tests will be used as tests of the ability of the discriminant model to separate conglomerate from non-conglomerate responses and thus can be used to test Hypotheses one of the study.

Since the input to the discriminant function was standardized data, the relative size of each discriminant equation coefficient determines the contribution each corresponding variable discriminatory power of the function. In order to measure the relative contribution of each variable, F tests were computed for each variable to test the differences of the group means between the two known groups. Also a stepwise discriminant procedure was used to calculate F values for testing the difference between group means as each successive variable was added to the discriminant function. At each step, that additional variable was added which had the highest partial $F$ value; the group $F$ value testing the difference between the two groups evaluated by the newly enlarged discriminant function was then computed as each additional variable was added to the discriminant model. ${ }^{23}$ one variable showed the highest discriminatory power, and the $\overline{{ }^{33} \text { Nie et al., Op. cit., p. } 180 .}$ 
addition of the other variables did not increase the power of the model to discriminate between the groups. An explanation is offered for this finding. ince some variables wili be shown to be regarded highly by both groups, there would be little difference between the means of the two groups ( $F$ value) on their ratings of such a variable. The results of the individual $F$ tests and the stepwise regression procedure will be shown and discussed in Chapter $V$ where they will also be used to test Hypotheses Two of the study.

\section{Tabulation of Questionnaire Results}

The multiple discriminant analysis method of constructing a model based on a set of independent variables places importance on the differences and correlations of the independent variables in their relationships to the dependent variables. Therefore, when examining the contribution of each variable to the discriminant function, the differences between variable rankings by members of the two groups, as measured by $F$ values, becomes more important than the relative ranking itself. That is, criteria ranked uniformly high (or low) by both groups will contribute less to the discriminant function than if they had been ranked differently by each group. However, such high (or low) total rankings by both groups would be important information for anyone studying both groups' evaluation of the variables. It is important, therefore, to collect and tabulate further information 
on each variable considered in the survey. Tabulating each variable by total point rankings as well as by frequency of choice will give additional information for understanding the criteria models and for a better evaluation of the acquisition programs of each group. These tabulations, which will be shown and evaluated in Chapter $V$, will be done by group (conglomerate and non-conglomerate) as well as by variable and activity.

Additionally, tabulations of the answers to question number one will be done to check the similarities or differences in the two groups' use of acquisition manuals. Any relationships or correlations between companies with acquisition manuals and those without them will be examined as well as any correlations between criteria choices and the use (or non-use) of criteria lists.

Question three will also be examined to see if any consistent pattern of interest can be detected. Also, the answers to question three can be used as source of criteria for future study. For example, any criterion appearing more frequently as a reply to question three than any criterion in question two probably should have originally been included in question two in the survey.

Measures of Correlation Between Variables

In order to complete the study of the questionnaire results, the project examines the relationship between ranked 
variables within each group of responses. Correlation analysis gives the researcher one summary statistic which describes the degree of association between variables. The static which measures the degree of correlation is the coefficient of correlation; a test of significance is also needed to show the level of probability of the association. ${ }^{24}$ The choice of correlation measure to be used is based on the characteristics of the data being examined. When the data to be analyzed are ranked in ordinal scale in two ordered series, the association or correlation between the two sets of ranks can be measured by either the Spearman Rank Correlation Coefficient or the Kendall Rank Correlation Coefficient. ${ }^{25}$ The Kendall and Spearman coefficients have different underlying scales and are not directly comparable to each other and comparisons or relationships between variables should only be done with coefficients computed by the same test. However, both coefficients have the same power-efficiency and their levels of significance are comparable. ${ }^{26}$ The chief difference between then is that the Kendall coefficient is "somewhat more meaningful" when the data contains many tied ranks and the Spearman when the data is "more or less continuous." 27 There

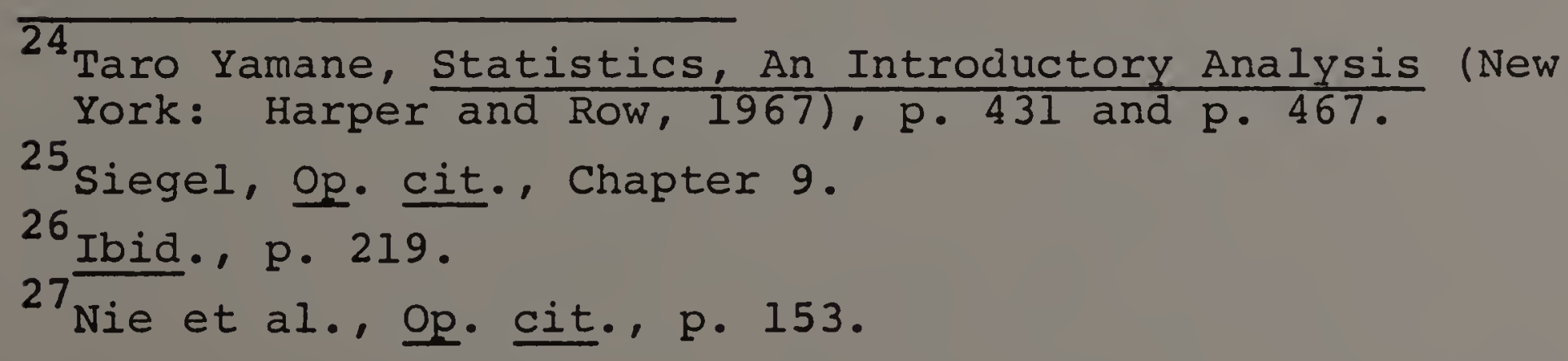


is no fixed rule about selecting either the Kendall or Spearman coefficients so both were computed.

Rank-order coefficients of corielation between the two sets of data were computed for both the "conglomerate" responses and the "non-conglomerate" responses by both the Spearman and Kendall methods. Thus, the correlations of the rankings of between the ten variables were measured for both groups and by two different measures; this made a total of four computer runs. The two coefficients were computed by subprograms of the Statistical Package for the Social Sciences (SPSS); the subprogram NONPAR CORR was used for all four computations. 28

These computer runs gave output tables showing, for each variable pair, the selected correlation coefficient, the number of cases used in the calculation, and the significance level of the coefficient. The results of these runs as well as the results of all procedures discussed in this chapter will be examined and analyzed in Chapter $V$.

${ }^{28 \text { Ibid. , pp. } 153-156 .}$ 


\section{C $\begin{array}{lllllll}H & \text { A } & \text { P } & \text { T } & \text { E } & R & V\end{array}$ \\ RESULTS OF THE SURVEY}

The basic purpose of this study was to examine and analyze corporate merger criteria. Hypotheses were formulated about these merger criteria and a questionnaire was designed and mailed to collect data for the study. The results oi this survey will be examined and findings discussed in this chapter.

\section{Classification of the Experimental Group Responses}

The experimental group of 24 randomly selected responses (12 known conglomerate and 12 known non-conglomerate) was run through the BMDO4M program to form the discriminant equation as shown in Chapter IV. The results of the computer run are shown in Exhibit $J$ where the "first group" are the 12 randomly selected conglomerate responses and the "second group" are the 12 randomly selected non-conglomerate responses. All ten variables were used in the function. The responses are ranked by their $\mathrm{Z}$ scores as computed by the discriminant model with the high positive values associated with the known conglomerate responses and the lower values associated with the known non-conglomerate responses. An examination of the results of the analysis group run in Exhibit $J$ shows that a $\mathrm{z}$ score of +0.11572 best divides the two groups.

Using the value of $\mathrm{z}=+0.11572$ as a cut-off value, the discriminant function classified the analysis group as shown 


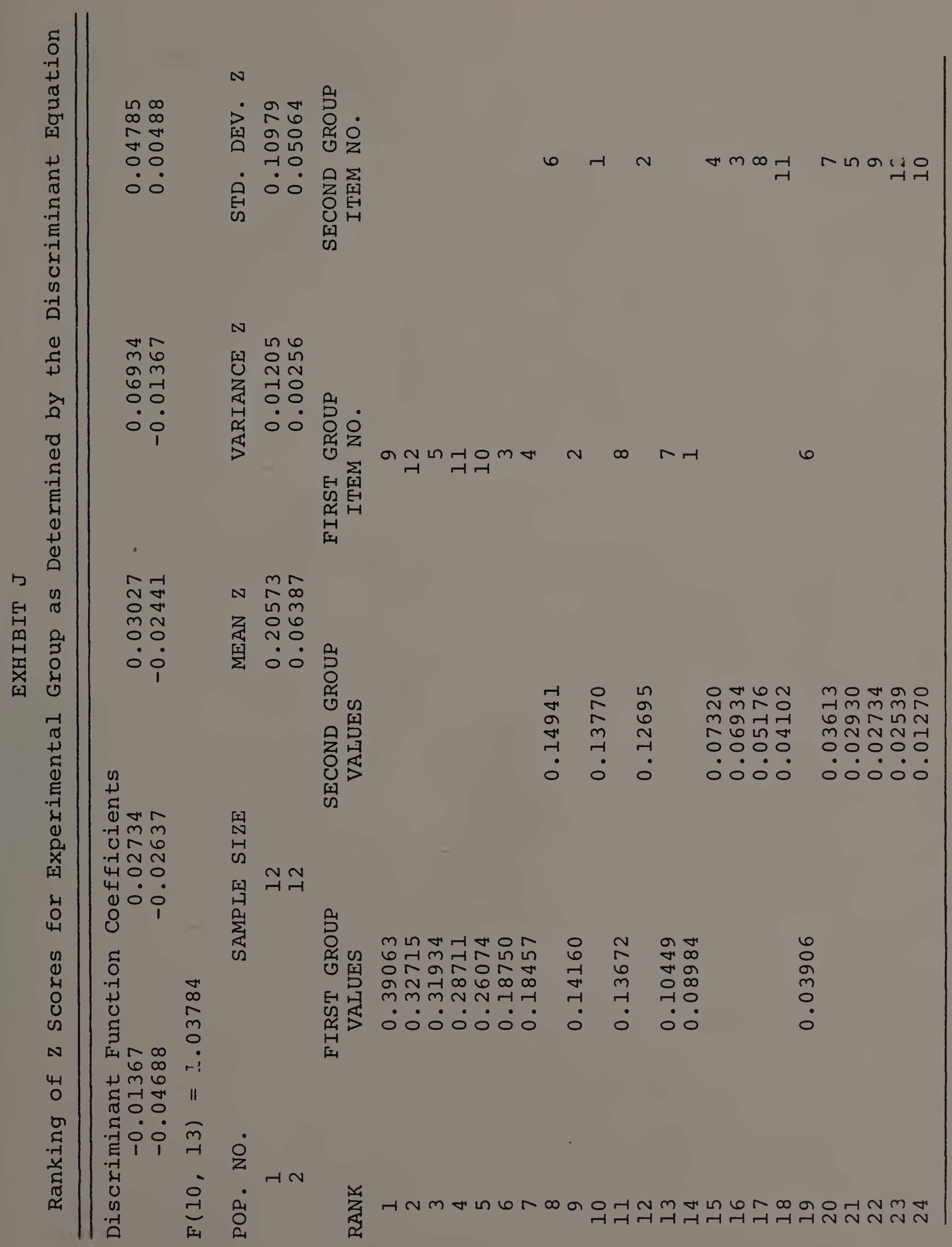


in the classification matrix shown in Table VI. Each of the two subsets of twelve respondents were known to belong to either the conglomerate or non-congiomerate group before the computer run. The classification matrix shows the number of correct and incorrect classifications based on the "z" scores of the analysis run.

\section{TABLE VI}

Classifications of the Analysis Groups ( $N=24)$

\begin{tabular}{|c|c|c|c|c|}
\hline \multirow[b]{2}{*}{ Actual Group } & \multicolumn{3}{|c|}{ Predicted Group } & \multirow[b]{3}{*}{12} \\
\hline & Conglomerate & Non-Cc & glomerate & \\
\hline Conglomerate & $975 \%$ & 3 & $75 \%$ & \\
\hline Non-Conglomerate & $25 \%$ & 9 & $25 \%$ & 12 \\
\hline & 12 & 12 & & 24 \\
\hline
\end{tabular}

Row one contains the number of responses that were known to be conglomerate while column one contains the number of responses classified by the model as conglomerate. Row two contains the number of responses that were known to be nonconglomerate while column two contains the responses the model classified as non-conglomerate. Therefore, row 1 column 1 contains the responses of known conglomerates correctly classified by the model; row 2 column 2 contains the correctly classified non-conglomerate responses. Row 1 column 2 shows the number of incorrectly classified conglomerate responses and Row 2 column 1 shows the number of incorrectly classified non-conglomerate responses. The sort of the analysis firms can be seen to be $75 \%$ correct. A chi-square test 
for $2 \times 2$ contingency tables of two independent samples ${ }^{1}$ was run and the null hypothesis that there was no difference in the two groups was rejected at a significance level of .02 $<\alpha<.05$. This high level of classification of the model is not unexpected since it sorted the twenty-four responses that were used as input. Classification of the Control Group Responses

In order to test the predictive power of the model, the ninety-six responses of the control group were used. The discriminant equation determined by the analysis (or experimental) group was used to classify the hold-out group by multiplying the discriminant equation coefficients for each of the ten variables times the weighted ranking of that variable for each respondent giving a computed " $\mathrm{Z}$ " value for each respondent's data card. The hold-out responses are then sorted by their " $\mathrm{Z}$ " value using the dividing "Z" value of +0.11572 that was determined as the dividing value of the analysis group. The resulting classification of the fortyone conglomerate firms and the fifty-five non-conglomerate firms is shown in Table VII.

$\overline{1}_{\text {Sidney Siegel, Nonparametric Statistics for the Behavioral }}$ Sciences (New York: McGraw-Hill, 1956), pp. 107-109. 
TABLE VII

Classification of the Hold-Out Group (N=96)

\begin{tabular}{|c|c|c|c|c|}
\hline \multirow[b]{2}{*}{ Actual Group } & \multicolumn{3}{|c|}{ Predicted Group } & \multirow[b]{3}{*}{$41100 \%$} \\
\hline & Conglomerate & Non- & lomerate & \\
\hline Conglomerate & $75.6 \%$ & 10 & $24.4 \%$ & \\
\hline Non-conglomerate & $40 \%$ & 33 & $60 \%$ & $55100 \%$ \\
\hline & 53 & 43 & & 96 \\
\hline
\end{tabular}

This sort was correct for $75.6 \%$ of the conglomerate firms and for $60 \%$ of the non-conglomerate firms; the total hold-out group was correctly classified at a $67 \%$ level of prediction. This lower level of prediction than the analysis group was to be expected since the analysis group was sorted by an equation derived from its own group while the hold-out group was composed of completely different responses. A chisquare test for $2 \times 2$ contingency tables was run again and the hypothesis that there is no difference between the holdout groupswas rejected at a significance level of .01. This level of significance is slightly higher than the analysis group although the sort is not as effective; this can be explained by the larger group $(N=96)$ for the hold-out group. Thus the discriminant model computed by the program can be seen to be $67 \%$ effective for identifying conglomerate and non-conglonerate criteria evaluations.

Test of Hypothesis One

The main hypothesis of the study was that the evaluations of merger criteria by conglomerate and non-conglomerate 
executives will be sufficiently different to allow for accurate classification and valid conclusions to be drawn from the classificátion model. This hypothesis was tested by constructing the discriminant function of corporate acquisition evaluations and testing to see if it could select and classify correctly.

As shown in the previous section, a criteria discriminant analysis function was constructed that successfully predicted the classifications of the hold-out group at a $67 \%$ rate. The discriminant model can be used to prove Hypothesis one of the study which was:

The evaluations by conglomerate executives of commonly used merger criteria will be significantly different in emphasis and importance from the evaluations of non-congloemrate executives of the same criteria.

To test this hypothesis, a null hypothesis was formulated that there is no difference between the two groups' evaluations of acquisition criteria. The null hypothesis tested was:

$$
\overline{\mathrm{z}}_{1}=\overline{\mathrm{z}}_{2}
$$

The mean discriminant score of the conglomerate group is equal to the mean discriminant score of the non-conglomerate group. A significance level of $\alpha=.05$ was set for the rejection of the null hypothesis. The discriminant model was used as the statistical test of the hypothesis to test if there is enough difference between the groups for the model to give a meaningful sort of the two groups. The results of 
the chi-square $2 \times 2$ contingency test on the results of the model's sort of the hold-out group of responses was used to determine the rejection region for the null hypothesis. The chi-square test figured on the $2 \times 2$ classification shown in Table VII gives the probability of that sort under the null hypothesis to be less than .01. The null hypothesis that there is no difference between the groups was therefore rejected at the .01 level of significance, and the original Hypothesis one that there are differences in the evaluations was verified by the experiment.

\section{The Discriminant Coefficients}

A further study of the discriminant equation can give considerable additional information for the study of the importance of each variable to the two groups of exeuctives surveyed. The discriminant equation of the model as determined from the twenty-four responses in the analysis group was:

$$
\begin{aligned}
z= & -0.01367 x_{1}+0.02734 x_{2}+0.03027 x_{3}+0.06934 x_{4}+0.04785 x_{5} \\
& -0.04686 x_{6}-0.02637 x_{7}-0.02441 x_{8}-0.01367 x_{9}+0.00488 x_{10}
\end{aligned}
$$

The ten coefficients are used to compute the $z$ score for each response by multiplying the respondent's evaluation of each variable $\left(X_{i}\right)$ by that variable's coefficient. Thus, the ten coefficients can be seen as measures of the importance of the contribution of each independent variable to the dependent variable. This is achieved first by examination of the 
signs of the regression coefficients. ${ }^{2}$ A positive sign in this case means that, other things being equal, the larger the value of the dependent variable or $\mathrm{z}$ score. Negative coefficients would diminish the value of the dependent variable. The other factor in understanding the relationships and contributions expressed by the discriminant equation is the size of the coefficients as well as their signs. ${ }^{3}$ In this study the independent variables were the respondent's standardized rankings of the ten acquisition criteria. In the study, all the rankings of the independent variables were measured on the same scale of one through five preferences, weighted, $5,4,3,2,1$ in reverse order of preference, with the same total of fifteen points per response. Thus, all responses were recorded with the same values, and each coefficient measures the relative contribution of each independent variable to the discriminant power of the function. $^{4}$ The $\mathrm{z}$ score used in the study to sort the conglomerate responses from the non-conglomerate responses was previously shown to be +0.11572 . The larger coefficients would weigh their corresponding variables toward a $\mathrm{z}$ score higher than +0.11572 while the negative and smaller coefficients when multiplied by their corresponding variable rating would

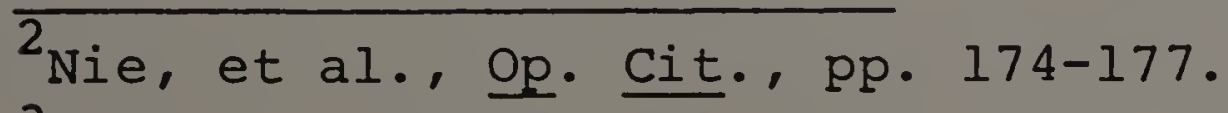
${ }^{3}$ Ibid. , p. 177 .

${ }^{4}$ Simkowitz and Monroe, Op. Cit., p. 8.
} 
tend to diminish the $\mathrm{z}$ score and cause it to be lower than the cut-off value of +0.11572 . $z$ scores higher than +0.11572 are associated with conglomerate responses and $\mathrm{z}$ scores lower than +0.11572 are associated with non-conglomerate responses. In Table VIII each of the ten variables is ranked in descending order according to the size of its coefficient in the discriminant model. The coefficients are thus arrayed in descending order of their relative importance as ranked by the conglomerate (higher $\mathrm{z}$ score) group of corporate executives. The $F$ values of the difference between the means of the two known groups are given for each variable taken individually.

At this point in the analysis of the discriminant function, most discriminant analysis business studies ${ }^{5}$ evaluate the contributions of each variable (as measured by its discriminant coefficient) and select out only those variables whose contribution to the function is judged to be significant. In the present study, however, such a procedure could have eliminated variables like $x_{1}$ (Rate of growth of earnings) whose absolute contribution to the discriminant function was relatively small, but which was highly ranked on almost every response and thus is an important consideration in any study of acquisition criteria. Since both conglomerate

5Altman, Op. Cit., p. 594; Norgaard and Crary, Op. Cit., pp. 91-92; and simkowitz and Monroe, Op. Cit., pp. $8-9$. 
TABLE VIII

Coefficients of Independent Variables Ranked in Descending Order by Relative Contribution to $\mathrm{Z}$ Score

\begin{tabular}{|c|c|c|c|c|}
\hline Rank & Variable & Variable Discription & Coefficient & $\begin{array}{l}\text { Individ- } \\
\text { ual Var- } \\
\text { iable } \\
\text { F Values } \\
\text { d.f.l,22 }\end{array}$ \\
\hline 1 & $x_{4}$ & $\begin{array}{l}\text { Present management will- } \\
\text { ing to continue }\end{array}$ & +0.06934 & $5.9915^{\mathrm{a}}$ \\
\hline 2 & $x_{5}$ & $\begin{array}{l}\text { Complement and augment } \\
\text { existing markets }\end{array}$ & +0.04785 & 0.2075 \\
\hline 3 & $x_{3}$ & Rate of growth of sales & +0.03027 & 0.1484 \\
\hline 4 & $\mathrm{x}_{2}$ & Return on investment & +0.02734 & 0.9225 \\
\hline 5 & $x_{10}$ & $\begin{array}{l}\text { Compatibility of manage- } \\
\text { ment objectives }\end{array}$ & +0.00488 & 0.2895 \\
\hline 6 & $\mathrm{x}_{1}$ & Rate of growth of earnings & -0.01367 & 0.0162 \\
\hline 7 & $\mathrm{X}_{9}$ & $\begin{array}{l}\text { Price/earnings multiple of } \\
\text { candidate }\end{array}$ & -0.01367 & 1.1194 \\
\hline 8 & $x_{8}$ & $\begin{array}{l}\text { Size of company to be } \\
\text { acquired (max. of min.) }\end{array}$ & -0.02441 & 0.8652 \\
\hline 9 & $x_{7}$ & $\begin{array}{l}\text { Complement and fit with } \\
\text { existing products }\end{array}$ & -0.02637 & 1.0338 \\
\hline 10 & $x_{6}$ & $\begin{array}{l}\text { Reputation of acquired } \\
\text { firm }\end{array}$ & -0.04686 & 1.2114 \\
\hline
\end{tabular}

$a_{\text {significant at the } .025 \text { level. }} F_{1,22}(.10)=2.95$ $F_{1,22}(.05)=4.30 \quad F_{1,22}(.025)=5.79 \quad F_{1,22}(.01)=7.94$

and non-conglomerate respondents ranked this variable highIy, its importance as a sorting variable was small, but its importance as an acquisition criterion is obviously high. Each of the ten original independent variables, therefore, remained in the study and will be examined individually. 
The $F$ values of the ten discriminart coefficients, as shown in Table VIII column 5, measure the $F$ ratios of the between-mean variance to the within group variance for each criteria. The individual $\mathrm{F}$ values shown in Table VIII were computed for each variable separately using the following general formula for $F$ tests with $r$ variables:

$$
F=\frac{S_{b} / g-1}{S S_{W} / n-r-g+1}
$$

where $\mathrm{SS}_{\mathrm{b}}=$ Sum of squares of the deviations of group means around the grand mean

$$
\begin{aligned}
\mathrm{SS}_{\mathrm{w}}= & \text { Sum of squared deviations of the values within } \\
& \text { a group around the mean score of the group } \\
\mathrm{g}= & \text { The number of groups } \\
\mathrm{n}= & \text { The number of responses in the analysis group } \\
\mathrm{r}= & \text { The number of variables in the discriminant } \\
& \text { function set (for individual } \mathrm{F} \text { values, } \mathrm{r}=1, \\
& \text { so } \mathrm{n}-\mathrm{r}-\mathrm{g}+\mathrm{I}=\mathrm{n}-\mathrm{g}) .6
\end{aligned}
$$

By using a stepwise regression procedure which adds an additional variable at each step, it is possible to observe the difference between the two groups evaluated by the discriminant function as it is developed by the addition of each variable. In the stepwise regression method used, the discriminant function starts with one variable which has the largest individual $F$ value computed by the formula above

6.J. Dixon (ed.), Biomedical Computer Programs (Berkeley: University of California Press, 1968), p. 214i. 
(where $r=1$ ). At each succeeding step, one variable was entered on the basis of its partial E value. The partial F vaiue for each variable is computed by entering each unincluded variable into the existing discriminant function at each step and computing the $F$ value for each of the entering variables at that step of the equation. This type of $F$ test is called a partial Etest. ${ }^{\top}$ The variable with the largest computed partial F value then entered the discriminant function at each step. When variables are added one by one in steps to the discriminant function, the $F$ test on the function itself at each step can be cailec the overall f test. This is another name for the discriminant function F test including all the variables which have entered the function at that $s t e p$.

The stepwise regression was done by running the experimental grcup of 24 responses through the computer program "BMDOM - Stepwise Discriminant Fnalysis". 8 This program first computes the individual F ratios for each variable as described abore, and then constructs a discriminant function in a stepwise manner starting with the variable with the highest individual E value. At each succeeding step, the variable entered was the variable that gave the greatest improvezent in the total discriminatory power of the function

\footnotetext{
'M.R. Draper and H. Smith, foplied pegression Rnalysis (Hew York: Join wiley is Sons, Inc., 1965), pp. 71-72. BDizon (ed.), op. Cit.
} 
(as measured by the $F$ value of the discriminant function). ${ }^{9}$

The $F$ values for the individual variables are shown in column 5 of Table VIII and again in column 3 of Table IX. The overall $\mathrm{F}$ values of the discriminant function as it is developed are shown in column 6 of Table IX. At each step, the variable entered is given along with both its partial and individual $F$ values. The resulting overall $F$ value for the discriminant function is given at each step along with its related degrees of freedom (column 7) and column 8 shows the table of $\mathrm{F}$ value distribution at the .10 significance level for comparison with the discriminant function's overall $\mathrm{F}$ test at each step.

Test of Hypothesis Two

The values of the F ratios for each variable and for the discriminant function as determined by the stepwise regression which will be used in this section to test Hypothesis Two of the study which was:

Among the responses examined, the acquisition criterion with the most discriminatory power will be the variable: "Present management willing to continue."

To test this hypothesis, a null hypothesis was formulated that there was no difference in discriminatory power between any of the 10 variables. The null hypothesis tested was that the $F$ ratios of all the variables would equal:

Ibid., p. $214 \mathrm{a}$ 


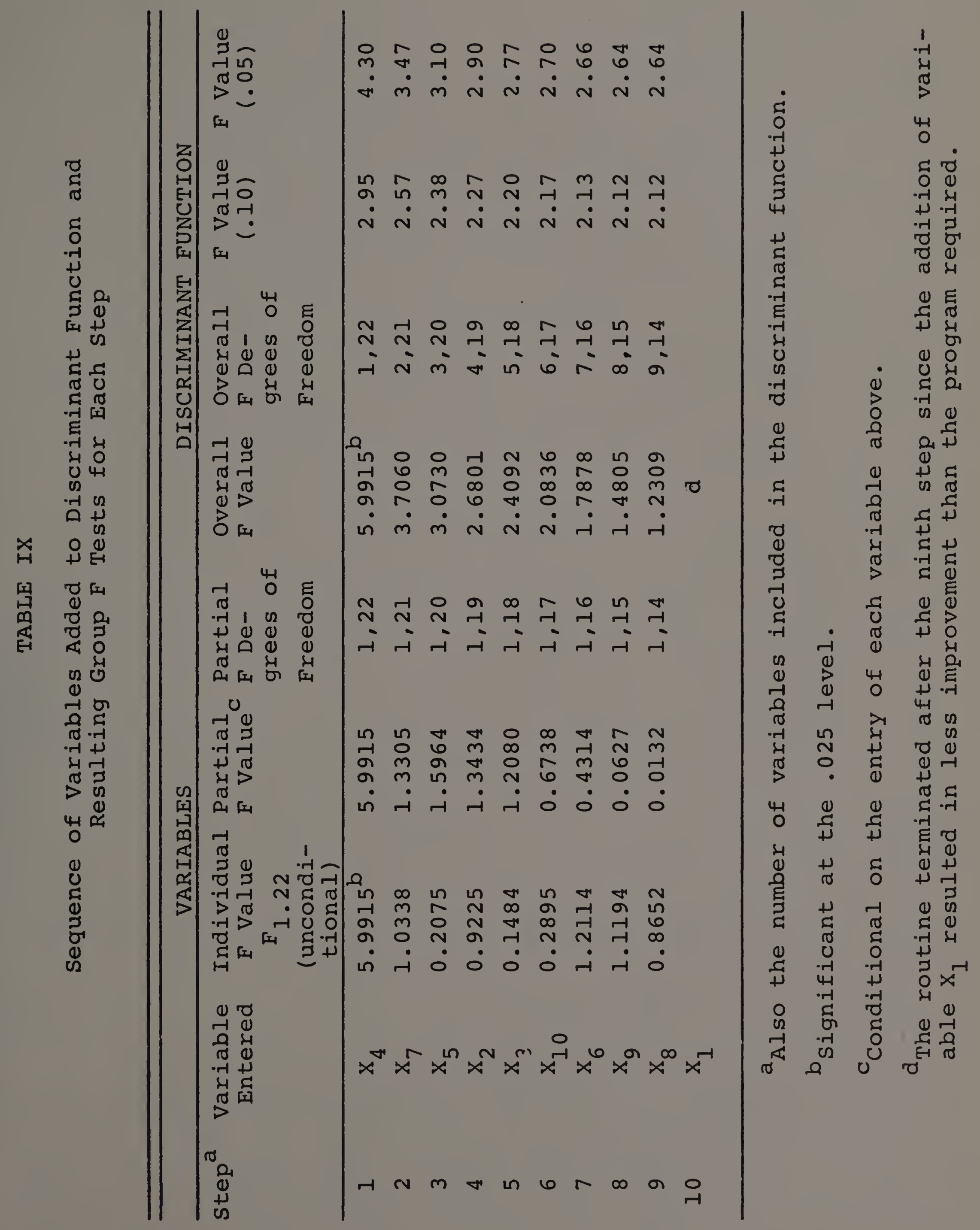




$$
F \text { value } x_{4}=F \text { value } x_{i}
$$

The significance of the $F$ ratio of the individual variables will be one statistical test of the null hypothesis. The F values of the individual variables are shown in Table VIII. The only variable with a significant $F$ value is variable $x_{4}$. Variable $\mathrm{x}_{4}$ is thus shown to be the only variable (taken singly) that showed significant differences between the means of the two groups as measured on one variable. The significance of the $\mathrm{F}$ ratio of variable $\mathrm{x}_{4}$ is .025 ; none of the other nine variables had an $F$ value that was significant at the 0.10 level when measured against the significance levels given at the bottom of Table XIII. However, this comparison of the individual $F$ ratios does not give a significance level for rejection of the null hypothesis and further tests and observations were made.

Another series of observations were made of the overall F ratios of the discriminant function computed in various stepwise regression programs. As shown in Table IX, when the discriminant function consisted of variable $x_{4}$ alone in step one, its $F$ ratio was significant at the .025 level showing the difference between the means of the two groups as measured $h_{y}$ the function was significant at the .025 level. . The addition of the balance of the variables to the function (steps 2-10) did not increase the discriminatory ability of the function (as measured by the overall F value) to levels 
greatet than an a lerel of .05. The variable $\mathrm{x}_{4}$ is thus found to be the raxiable that entered the stepwise regression first the progra- selects the variable with the highest individual ( value first) and the edditional variables did not increase the crerall F value of the ciscriminant Eunction.

I second stegwise regression analysis was run using the same grograt (a!mo7!) but chitting the variable $\mathrm{x}_{4}$ from the analysis. The values and significance of the cverall E value of the discriminant function at each step can then be conpared with the overall F value at each step with variable $x_{4}$ included. 10 Exhibit $\mathbb{R}$ sumarizes and compares the results of the two runs of the stepwise discriminant analysis program. BY eliminating variable $\mathrm{X}_{4}$ from the discriminant function, the significance of the overall F values at each step is lowerec; none of the overail F values of the discriminant function without the inclusion of variable $x_{4}$ is significant at the .10 Ievel.

Both of the above tests show that variable $x_{4}$ is an important discriminating variable in the discriminant function, but neither statistically proves that variable $x_{4}$ is a significantly greater discriminator than the other variables. A further test is needed. In Chapter IV, the residual errors

$\overline{10}$ This method was suggested in Frank Andrews, James Morgan, and John Somquist, Multiple Classification fnalysis, (Fnn Arbor, Michigan: Institute for Social Pesearch, The University of Michigan, 1969), p. 99. 


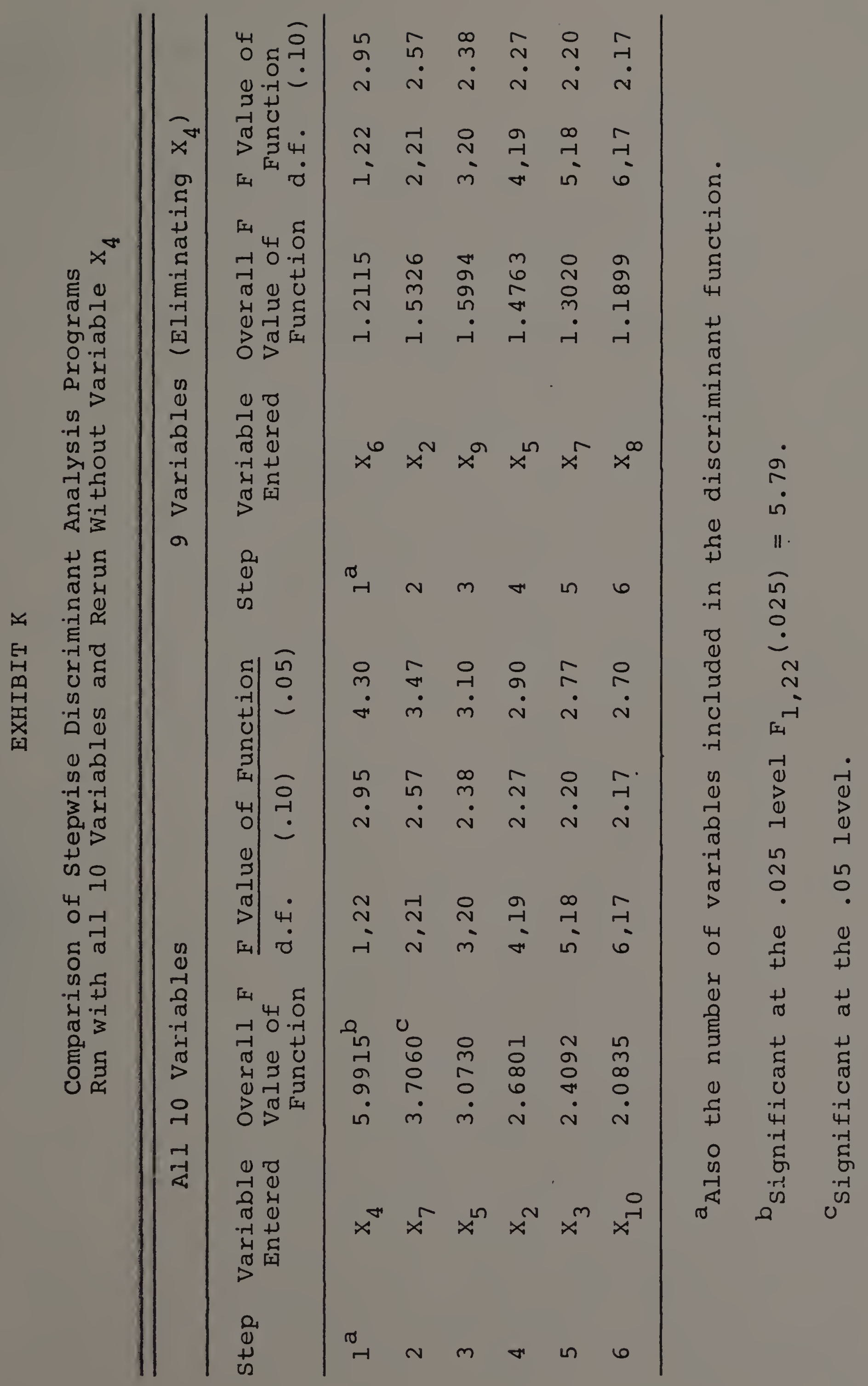


were shown to appear approximately normally distributed; F tests and analysis of variance on these residuals can, therefore, be performed. Hypothesis Two stated that the acquisition criteria with the most discriminatory power will be variable $x_{4}$. One way to test this hypothesis would be to test if the portion of the explained variation in the dependent variable explained by variable $\mathrm{x}_{4}$ was significantly greater than the portion of the variation in the dependent variable explained by the other variables. In the analysis of variance procedure, however, the explained errors (with 2 groups) have only 1 degree of freedom and, therefore, are not subject to powerful $F$ tests. The unexplained errors for each variable, however, have 22 degrees of freedom (24 responses - 2 groups) and are subject to more powerful $F$ tests and they were selected for examination.

An analysis of variance of variable $x_{4}$ and $x_{7}$ (the variable with the next highest partial $F$ value) was computed at the step where variable $x_{7}$ entered the discriminant function already containing variable $x_{4}$. The hypothesis to be tested was that the portion of the error unexplained by variable $x_{7}$ would be greater than the portion of the error unexplained by variable $\mathrm{x}_{4}$ - the more powerful discriminator. The null hypothesis corresponding to this is:

$$
\operatorname{Ss}_{\mathrm{w}} \mathrm{X}_{4} / 22=\mathrm{SS}_{\mathrm{w}} \mathrm{X}_{7} / 22
$$

The sum of squared deviations within the group (unexplained variations) are equal for variables $x_{4}$ and $x_{7}$. A level of 
$\alpha=.10$ was set for rejection of the null hypothesis.

The results of the analysis of variance for both variables are summarized in Exhibit L.

\section{EXHIBIT L}

Analysis of Variance Table Variables $\mathrm{x}_{4}$ and $\mathrm{x}_{7}$

\begin{tabular}{|c|c|c|c|c|}
\hline $\begin{array}{l}\text { Source of } \\
\text { Variation }\end{array}$ & $\begin{array}{l}\text { Sum of } \\
\text { Squares }\end{array}$ & $\begin{array}{l}\text { Degrees } \\
\text { of } \\
\text { Freedom } \\
\end{array}$ & $\begin{array}{l}\text { Mean } \\
\text { Square }\end{array}$ & $\begin{array}{c}\text { Unexplaineo } \\
\text { Mean } \\
\text { Square } \\
\end{array}$ \\
\hline Variable $x_{4}$ & & & & $\mathrm{x}_{4}$ \\
\hline Between (Explained) & $10.67-\mathrm{SS}_{\mathrm{b}}$ & 1 & 10.67 & \\
\hline $\begin{array}{l}\text { Within (Unex- } \\
\text { plained }\end{array}$ & $39.17-\mathrm{SS}_{\mathrm{W}}$ & 22 & 1.78 & 1.78 \\
\hline Total & 49.83 & 23 & 2.167 & \\
\hline Variable $x_{7}$ & & & & $x_{7}$ \\
\hline $\begin{array}{l}\text { Between (Explained) } \\
\text { Within (Unex- }\end{array}$ & $4.16-\mathrm{SS}_{\mathrm{b}}$ & 1 & 4.16 & \\
\hline plained) & $88.66-S_{\mathrm{W}}$ & 22 & 4.03 & 4.03 \\
\hline Total & 92.83 & 23 & 4.02 & \\
\hline
\end{tabular}

The ratio of the two unexplained mean square quantities (which are independent $\chi^{2}$ distributions divided by their respective degrees of freedom) is called the variance ratio and the distribution of this ratio is called the $F$ distribution and can be measured by the F test. ${ }^{11}$

The variance ratio $\mathrm{F}$ is

$$
F_{0}=\frac{S S_{w} x_{7} / 22}{S S_{w} X_{4} / 22}
$$

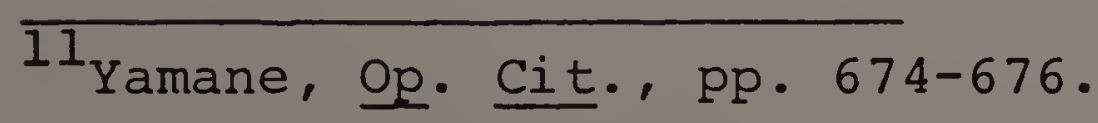




$$
\begin{aligned}
& F_{0}=\frac{4.03}{1.78} \\
& F_{0}=2.27
\end{aligned}
$$

This F distribution has 22 and 22 degrees of freedom, for $\alpha=.10$ (the determined level of rejection),

$$
F_{22,22}(.10)=1.75 ; \quad F_{22,22}(.05)=2.05 ; \quad F_{22,22}(.01)=2.79
$$

Since $F_{0}=2.27>2.05$ the null hypothesis that the unexplained variations would be equal is rejected at the .05 level of significance, and the original hypothesis (that the error unexplained by variable $x_{7}$ would be greater than the error unexplained by variable $x_{4}$ ) is supported at the .05 level of significance. Since variable $x_{7}$ had the greatest partial $F$ test of all the variables except $x_{4}$ and its portion of the unexplained variation was significantly greater than variable $\mathrm{x}_{4}$ 's portion of the unexplained variation, variable $\mathrm{x}_{4}$ is shown to be the most powerful explaining variable (or discriminator) in the discriminant function.

Care should be taken when drawing statistical inferences from data derived from various stepwise regression programs when all the variables have been left in the program as was done in this research. Since interaction and correlations between variables can be present when weaker discriminators are not eliminated, ${ }^{12}$ overall $F$ values can be incon$\overline{12}$ Andrews et al., op. i.t. pp. 24-25. 
sistent. For this reason, several tests were performed on Hypothesis Two and variable $x_{4}$ is examined further in the next section (see tables XVI and XVII).

The Variables

The ten variables originally selected were chosen on the basis of their frequency of occurrence on nineteen corporate criteria lists collected by the author. The ten variables were then placed on the questionnaire in order of this frequency of occurrence. As stated previously in the study, the nineteen corporations were of both the conglomerate and nonconglomerate types as defined by the study. In order to check that no other important criteria had been left out of the questionnaire, question three was added which asked the respondents to write in any other important criterion they felt should be included in the survey (see Appendix B). The answers to question three are summarized below. Of the 120 responses used in the study, only thirty-five answered question three; the results of these answers to question three are summarized in Table $\mathrm{x}$.

An examination of Table $x$ shows that no single additional criterion should have been included in the original list of ten criteria. The two most important criteria listed by the combined respondents had a frequency of only five total occurrences each while the least frequently checked criterion on the original list $\left(\mathrm{x}_{3}\right)$ was checked thirty-one times by the respondents (eleven conglomerate replies and twenty non-con- 
TABLE X

Additional Criteria Listed by Respondents

\begin{tabular}{|c|c|c|}
\hline Conglomerate & (Total $N=53$ ) & Non-Conglomerate (Total $\mathrm{N}=67$ ) \\
\hline Criteria & Occurrence & $\overline{\text { Occurrence }}$ \\
\hline
\end{tabular}

Future product sales

Cash flow

Future capital requirements

Future earnings growth 1

Method of acquisition 1

Quality of new personnel

Market share

Capital intensity of new company

Mineral reserves

Geographic area

High technology of new company

State of company growth cycle

1
$3 \quad$ Future market penetration

2 Cash flow 3

$2 \quad$ Financial synergy 2

Future earnings growth 3

1 Method of acquisition 2

Quality of new personnel 2

$1 \quad$ Market share $\quad 2$

Capital intensity of 1 new company 2

$1 \quad$ Patent rights $\quad 2$

$1 \quad$ Industry concentration 2

High technology of new company 1

Tax shelters 2
Total responding: Conglomerates 13 of 53

Total new criteria: Conglomerates
Non-conglomerates 22 of 67

\section{2}

glomerate replies). While this seems to be conclusive evidence of the unbiased nature of the ten criteria selected, most respondents probably tried to include their choices in- 
to the ten given criteria if at all possible and it has been found that "Very few persons write in responses under the 'Other' category even though the responses are apparently important."13 However, no analysis of the "write-in" variables seems necessary to the study, and none will be attempted. An analysis of the ten selected criteria follows; the criteria will be tabulated in order of their relative total rankings on the questionnaire - Table XI - and in order of the total number of times each criteria was selected by the respondents - Table XII. Table XIII tabulates the criteria in order of the average point total, and also gives the average point total for both the conglomerate and non-conglomerate groups for each variable.

TABLE XI

The Relative Importance of Variables as Ranked by Respondents

Points (5 point Scale)

\begin{tabular}{|c|c|c|c|c|}
\hline Rank & Criteria & Total & Non-Conglomerate & Conglomerate \\
\hline 1 & $x_{2}$ & 400.5 & 213 & 187.5 \\
\hline 2 & $x_{1}$ & 342.5 & 198.5 & 144 \\
\hline 3 & $x_{7}$ & 218.5 & 148.5 & 70 \\
\hline 4 & $x_{5}$ & 206.5 & 118.5 & 88 \\
\hline 5 & $x_{9}$ & 163 & 80.5 & 82.5 \\
\hline 6 & $x_{4}$ & 146.5 & 51.5 & 95 \\
\hline 7 & $x_{3}$ & 85.5 & 62.5 & 23 \\
\hline 8 & $x_{8}$ & 83.5 & 50.5 & 33 \\
\hline 9 & $x_{6}$ & 78 & 44 & 34 \\
\hline 10 & $x_{10}$ & 75.5 & 37.5 & 38 \\
\hline Tota & $\begin{array}{l}\text { pts. } \\
(120 \times 15) \\
\end{array}$ & 1800 & 1005 & 795 \\
\hline
\end{tabular}

${ }^{13}$ Lindzey and Guest, op. Cit., p. 358. 
There are differences between the rankings of criteria by importance and by frequency and the discriminant coefficient rankings. For this reason, even those criteria whose discriminant coefficients were relatively low were retained in the study. The variables will next be studied individually. An examination of each variable's ranking in Tables XI, XII, and XIII and their corresponding discriminant coefficient will be the basis of the analysis of the individual acquisition criteria.

\section{TABLE XII}

The Relative Frequency of Variables Indicated by Respondents

Rank Criteria $\frac{\text { Number of Respondents Checking Variable }}{\text { Total Non-Conglomerate Conglomerate }}$

\begin{tabular}{rrrrr}
\hline 1 & $\mathrm{x}_{2}$ & 104 & 55 & 49 \\
2 & $\mathrm{x}_{1}$ & 99 & 57 & 42 \\
3 & $\mathrm{x}_{5}$ & 70 & 38 & 32 \\
4 & $\mathrm{x}_{7}$ & 69 & 44 & 25 \\
5 & $\mathrm{x}_{4}$ & 62 & 30 & 32 \\
6 & $\mathrm{x}_{9}$ & 59 & 31 & 28 \\
7 & $\mathrm{x}_{6}$ & 39 & 24 & 15 \\
8 & $\mathrm{x}_{8}$ & 37 & 20 & 17 \\
9 & $\mathrm{x}_{10}$ & 35 & 18 & 17 \\
10 & $\mathrm{x}_{3}$ & 31 & 23 & 8 \\
Total & & & 340 & 265 \\
Occurrences & 605 & & \\
\hline
\end{tabular}


For ease of organization and clarity, the individual corporate acquisition criteria will be examined in the order that they appear on the questionnai.e and in the multiple discriminant equation. That is the order of the subscripts of the independent variable notation: $x_{1}, x_{2}, \ldots, x_{10}$.

TABLE XIII

Average Point Score for Each Variable

$(5$ Point Scale)

\begin{tabular}{ccccc} 
Rank & Criteria & $\begin{array}{r}\text { Total Group } \\
\text { ave. } N=120\end{array}$ & $\begin{array}{r}\text { Non-Conglomerate } \\
\text { ave. } N=67\end{array}$ & $\begin{array}{r}\text { Conglomerate } \\
\text { ave. } N=53\end{array}$ \\
\hline 1 & $\mathrm{x}_{2}$ & 3.33 & 3.18 & 3.54 \\
2 & $\mathrm{x}_{1}$ & 2.87 & 2.97 & 2.72 \\
3 & $\mathrm{x}_{7}$ & 1.82 & 2.22 & 1.32 \\
4 & $\mathrm{x}_{5}$ & 1.72 & 1.77 & 1.67 \\
5 & $\mathrm{x}_{9}$ & 1.36 & 1.20 & 1.55 \\
6 & $\mathrm{x}_{4}$ & 1.22 & 0.77 & 1.79 \\
7 & $\mathrm{x}_{3}$ & 0.72 & 0.93 & 0.43 \\
8 & $\mathrm{x}_{8}$ & 0.70 & 0.75 & 0.62 \\
9 & $\mathrm{x}_{6}$ & 0.65 & 0.66 & 0.65 \\
10 & $\mathrm{x}_{10}$ & 0.63 & 0.56 & 0.72 \\
\hline
\end{tabular}

$\underline{\text { Variable } \mathrm{x}_{1} \text { - Rate of Growth of Earnings }}$

Variable $x_{1}$ which is the rate of growth of earnings of the acquisition candidate was plactd first because it had the highest frequency of occurrence in the presurvey of nineteen companies conducted by the author. The results of the present questionnaire study confirm this early finding as variable 
$\mathrm{x}_{1}$ was ranked first among the non-conglomerate returns in frequency and second among the conglomerate frequency rankings (see Table XII). In Table XI this variable was ranked second in relative importance as measured by the total point scores of both conglomerate and non-conglomerate respondents. Thus, the results of the survey seem to uniformly point to the importance of "rate of growth of earnings" to prospective acquirers of both groups. The multiple discriminant equation coefficient for this variable was -0.01367 . The individual $F$ ratio associated with this coefficient was 0.0162 which was the smallest $F$ value of all ten criteria in the questionnaire (see Table VIII). This small F value shows that this variable adds little to the discriminatory power of the discriminant model. Since both groups rated growth of earnings almost equally high, its value as an acquisition criteria is shown to be high but its sorting ability is low. A summary of the findings on variable $x_{1}$ is shown in Table XIV.

This criterion and criterion $x_{2}$ that follows were the most frequently chosen and highest ranked of the ten variables. 
TABLE XIV

Rate of Growth of Earnings - Variable $\mathrm{x}_{1}$

\begin{tabular}{|c|c|c|c|c|c|c|}
\hline \multirow{2}{*}{ Measure } & \multicolumn{2}{|l|}{ Total } & \multicolumn{2}{|c|}{ Non-Conglomerate } & \multicolumn{2}{|c|}{ Conglomerate } \\
\hline & Measure & Rank & Measure & Rank & Measure & $\operatorname{Rank}$ \\
\hline $\mathrm{x}_{1} \begin{array}{l}\text { Total } \\
\text { Ranking }\end{array}$ & & & & & & \\
\hline Points & 342.5 pts. & 2 & 198.5 pts. & 2 & 144 pts. & 2 \\
\hline $\begin{array}{l}\mathrm{x}_{1} \begin{array}{l}\text { Frequency } \\
\text { of Re- }\end{array}\end{array}$ & & & & & & \\
\hline sponse & 99 cks. & 2 & $57 \mathrm{cks}$. & 1 & $42 \mathrm{cks}$ & 2 \\
\hline $\mathrm{x}_{1} \begin{array}{l}\text { Percentage } \\
\text { of }\end{array}$ & & & & & & \\
\hline Responses & $83.5 \%$ & 2 & 858 & 1 & 798 & 2 \\
\hline 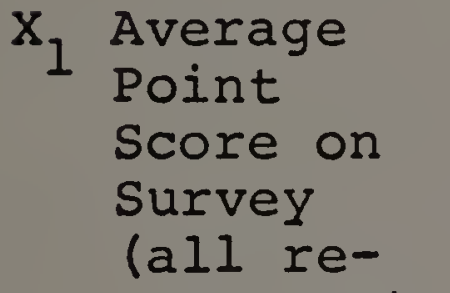 & & & & & & \\
\hline sponses) & 2.87 pts. & 2 & 2.97 pts. & 2 & 2.72 pts. & 2 \\
\hline
\end{tabular}

$\underline{\text { Variable } \mathrm{x}_{2}-\text { Return on Investment }}$

This merger criterion ranked first in total points as ranked and in total number of returns checked. The results of the survey show this acquisition criterion to be the one most frequently chosen and to have the highest total of ranking points. Its average point total was 3.89 among the 104 respondents who checked it as one of their five most important criteria and its average point total was 3.37 among the total 120 respondents (as measured on the five-point scale). The survey shows that criterion $\mathrm{x}_{2}$ is the most important of the ten variables considered by all the prospec- 
tive acquirers responding. Table XV summarizes these findings.

TABLE XV

Return on Investment - Variable $\mathrm{x}_{2}$

\begin{tabular}{|c|c|c|c|c|c|c|c|}
\hline \multirow{2}{*}{\multicolumn{2}{|c|}{ Measure }} & \multicolumn{2}{|c|}{ Total } & \multicolumn{2}{|c|}{ Non-Conglomerate } & \multicolumn{2}{|c|}{ Conglomerate } \\
\hline & & Measure & Rank & Measure & Rank & Measure & $\operatorname{Rank}$ \\
\hline \multirow[t]{2}{*}{$\mathrm{x}_{2}$} & Total & & & & & & \\
\hline & Points & 400.5 pts. & 1 & 213 pts. & 1 & 187.5 pts. & 1 \\
\hline \multirow[t]{2}{*}{$x_{2}$} & $\begin{array}{l}\text { Frequency } \\
\text { of }\end{array}$ & & & & & & \\
\hline & Response & $104 \mathrm{cks}$. & 1 & $55 \mathrm{cks}$. & 2 & $49 \mathrm{cks}$. & 1 \\
\hline \multirow[t]{2}{*}{$x_{2}$} & $\begin{array}{l}\text { Percentage } \\
\text { of }\end{array}$ & & & & & & \\
\hline & Response & $87 \%$ & 1 & 82.28 & 2 & $92.5 \frac{8}{8}$ & 1 \\
\hline \multirow[t]{2}{*}{$\mathrm{x}_{2}$} & $\begin{array}{l}\text { Average } \\
\text { Point } \\
\text { Score on } \\
\text { Survey } \\
\text { (all }\end{array}$ & & & & & & \\
\hline & responses) & 33.3 pts. & 1 & $3.18 \mathrm{pt}$ & s. 1 & 3.54 pts & - 1 \\
\hline
\end{tabular}

It is interesting to note that $92.5 \%$ of the conglomerate responses checked "Return on investment" for the highest response total in the survey.

With both conglomerate and non-conglomerate respondents ranking "Return on investment" uniformity high, its discriminatory power is predictably low. Its discriminant coefficient was +0.02734 which in discriminatory power of the coefficients as measured by its individual $F$ ratio was insignificant at the .10 level. Like variable $x_{1}$ its discriminatory 
power is low. Again, it was demonstrated that the coefficients are measures of discrimination between groups and not necessarily within the groups.

The findings on $x_{2}$ - "Return on investment" and on $x_{1}$ "Rate of growth of earnings" show that these two variables are the dominant acquisition criteria both in frequency of returns and in importance of ranking. An examination of Tables XI and XII gives an indication of the clear dominance of these two criteria. In Table XI there is a difference of 124 total points in the rankings between $x_{1}$ and the next highest ranking $x_{7}$. With the table constructed on $120 \mathrm{re-}$ sponses, this represents an average difference of one point or one whole ranking per response between $x_{1}$ and $x_{7}$ (the next highest ranking). This represents by far the greatest differential in the Table. Similarly, in Table XII the number of responses arops from 99 to 70 from $x_{1}$ to $x_{5}$ for the largest difference as measured by frequency of response. The importance of variables $x_{1}$ and $x_{2}$ is clearly indicated by an examination of the survey results. Any discussion of either conglomerate or non-conglomerate acquisitions should give particular emphasis to these two criteria.

$\underline{\text { Variable } \mathrm{x}_{3} \text { - Rate of Growth of Sales }}$

This variable was found to be not too important as measured by the survey. It ranked last in total frequency of returns and seventh in total ranking points. The last four 
rankings on both Table XI and Table XII were closely grouped and uniformly unimportant when compared to the top six rankings on each chart. The comparative unimportance of this variable is also shown in Table VIII by the low discriminatory power of its discriminant coefficient (ninth ranked) and the low average point score on the questionnaire as shown in Table \%III. There is one interesting fact concerning this criterion that is shown by the survey results; that is, on Table KII there is a large percentage difference between the Erequency of responses checked for this variable as checked by conglomerate (eight responses) and non-conglomerate (23 responses). This large difference in response rates would seen to indicate a larger individual $E$ value as there seens to be a measurable difference between the response rate of the two groupe on this criterion. However, since only 31 respondents cheched this variable, there were 89 tied responsea (zero rankings) which obviously lessened the diecriminatory power of the variable.

$\%_{4}$ - Present lianagernent willing to Continue

Variable $\%_{4}$, the management continuation variable, is the moat important criterion of the multiple discriminant model. It diecriminant model coefficient is the highest of the ten variables; the difference between it and the average adjusted coefficient is +0.06387 which represents the largest absolute difference of either the highest or lowest 
coefficients in the discriminant equation as shown in Table IVI. This table ranks the discriminat coefficients by relative size and shows the difference between coefficients. Ii is this iargest absolute difference between $x_{4}$ and the average adjusted coefficient that shows that this variable has the greatest importance in the discriminant function relative to the other variables. In the discriminant model equation, high positive values are associated with high $\mathrm{z}$ scores and, therefore, are associated with conglomerate responses. Thus, criterion $x_{4}$ is the cominant selecting factor of the model for conglomerate responses as shown in Table XVI.

Variable $\mathrm{x}_{4}$ is also the only variable with an $\mathrm{F}$ ratio that is statistically significant at the .025 level as presented in Table VIII. Thus this acquisition criterion is found to be the most powerful discriminator as well as the dominant discriminant function coefficient.

"Present management willing to continue" was chosen by 62 respondents (an average number of responses) for a total ranking point total of 146.5 (close to the mode in this scale). The discriminatory power of this variable seems to come from the difference in average scores given by the respondents to this criteria. The non-conglomerate average score on 30 responses was 0.77 while the conglomerate score measured on 32 responses was 1.79 . The finding that this criterion was the prime discriminator of the conglomerate group was used earlier in the chapter to test the a priori 
Hypothesis Two that the conglomerate executives would attach more importance to continuity of present management than to the other criteria listed. The finciings on variable $\mathrm{x}_{4}$ are summarized in Table XVII.

TABLE XVI

Size Differential of Discriminant Coefficients

\begin{tabular}{ccccc}
\hline \multicolumn{6}{c}{} & \multicolumn{4}{c}{ Coefficients } & \multicolumn{2}{c}{$\begin{array}{c}\text { Deviation from } \\
\text { Rverage Coef. }\end{array}$} \\
\hline 1 & $x_{4}$ & +0.06934 & 0.11620 & +0.06387 \\
2 & $x_{5}$ & +0.04785 & 0.09471 & +0.04238 \\
3 & $x_{3}$ & +0.03027 & 0.07713 & +0.02480 \\
4 & $x_{2}$ & +0.02734 & 0.07420 & +0.02187 \\
5 & $x_{10}$ & +0.00488 & 0.05174 & -0.00059 \\
6 & $x_{1}$ & -0.01367 & 0.03319 & -0.01914 \\
7 & $x_{9}$ & -0.01367 & 0.03319 & -0.01914 \\
8 & $x_{8}$ & -0.02441 & 0.02245 & -0.02988 \\
9 & $x_{7}$ & -0.02637 & 0.02049 & -0.03184 \\
10 & $x_{6}$ & -0.04686 & 0 & -0.05233 \\
& \multicolumn{5}{c}{ Average Adjusted Coefficient +0.05233} \\
\hline
\end{tabular}


TABLE XVII

Management Willing to Continue--Variable $\mathrm{x}_{4}$

\begin{tabular}{|c|c|c|c|c|c|c|c|}
\hline \multirow{2}{*}{\multicolumn{2}{|c|}{ Measure }} & \multicolumn{2}{|l|}{ Total } & \multicolumn{2}{|c|}{ Non-Conglomerate } & \multicolumn{2}{|c|}{ Conglomerate } \\
\hline & & Measure & Rank & Measure & $\overline{R a n k}$ & Measure & Rank \\
\hline \multirow[t]{2}{*}{$x_{4}$} & Total & & & & & & \\
\hline & Points & 146.5 pts. & 6 & 51.5 pts. & 7 & 95 pts. & 3 \\
\hline \multirow[t]{2}{*}{$\mathrm{x}_{4}$} & Frequency & & & & & & \\
\hline & Response & 62 cks. & 5 & $30 \mathrm{cks}$ & 6 & $32 \mathrm{cks}$ & 3 \\
\hline \multirow[t]{2}{*}{$\mathrm{x}_{4}$} & Percent- & & & & & & \\
\hline & Responses & $=51.7 \%$ & 5 & 49.38 & 6 & 60.48 & 3 \\
\hline \multirow{4}{*}{$x_{4}$} & Average & & & & & & \\
\hline & Point & & & & & & \\
\hline & Survey & & & & & & \\
\hline & sponses) & 1.22 pts. & 6 & 0.77 pts. & 7 & 1.79 pts. & 4 \\
\hline
\end{tabular}

$\underline{\text { Variable } \mathrm{x}_{5} \text { - Complement and Augment Existing Markets }}$

The criterion of complementing and augmenting existing markets was found to be a criterion associated with conglomerate executives. This finding is interesting in that this criterion which emphasizes the marketing area might generally be thought to be characteristic of non-conglomerate group since similarities in marketing activities would seem to preclude the supposed more random acquisition policies of the conglomerate group. 14

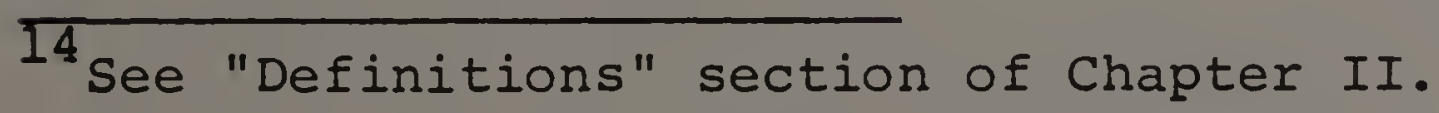


The results of the questionnaire survey show this variable to be the second most important of the conglomerate group of ciscriminant coefficients as measured by its sign and size, however, its individual $F$ ratio as computed and shown in Table VIII was among the lowerst of all the variables. An analysis of Table XVIII given below helps explain the findings on variable $x_{5}$, the market criterion. The number of respondents checking $\mathrm{x}_{5}$ as an important criterion for merger is 38 for the non-conglomerate group and 32 for the conglomerate group and the average point score for each group while close in absolute value does show a higher score for the non-conglomerate group. In total ranking points the non-conglomerate group ranked $x_{5}$ fourth and the conglomerate group ranked $x_{5}$ fifth.

These observations of the data on the market variable would seem to indicate that it is more important to the nonconglomerate respondents which is the expected result for this variable. The low $F$ value shown in Table VIII shows $x_{5}$ to be a weak discriminator. While the size and sign of the discriminant coefficient of this variable would seem to classify it as a conglomerate-oriented variable, a closer look at the data shows that care should be taken in using the discriminant coefficient alone as the sole indicator of a variable's strength and direction. It was for this reason that the variables were studied individually even after the discriminant function had been constructed and tested. 
TABLE XVIII

Complement and Augment Markets--Variable $\mathrm{x}_{5}$

Measure $\frac{\text { Total }}{\text { Measure Rank }} \frac{\text { Non-Conglomerate }}{\text { Measure Rank } \frac{\text { Conglomerate }}{\text { Measure Rank }}}$

$x_{5}$ Total

Ranking

Points

206.5 pts. $4 \quad 118.5$ pts. $4 \quad 88$ pts.

$\mathrm{x}_{5}$ Frequency

Response $\quad 70 \mathrm{cks} . \quad 3 \quad 38 \mathrm{cks} . \quad 4 \quad 32 \mathrm{cks} . \quad 3$

$\mathrm{X}_{5}$ Percentage

of

Response

58.3

$3 \quad 56.9 \%$

$4 \quad 60.4 \%$

3

$\mathrm{X}_{5}$ Average

Point

Score on

Survey

(aII re-

sponses)

1.72 pts. 4

1.77 pts. $4 \quad 1.67$ pts.

4

Variable $\mathrm{x}_{5}$ is seen to be a variable that is important to both groups of acquirers. It's discriminant coefficient is associated with the conglomerate group in size and sign but ranks higher with the non-conglomerate group in total ranking points, total number of responses, and average ranking points. These conflicting findings and variable $x_{5}$ 's low rank as a discriminator indicate that care should be taken on any conclusions drawn about this variable.

Variable $x_{6}$ - Reputation of the Acquired Firm

The criterion number six, "Reputation of the Acquired 
Firm" was a variable associated with non-conglomerate firms. In Table XVI, its discriminant coefficient was -0.04686 which deviated frum the adjusted mean by .0 .05233 the most powerfil coefficient with the sign of the non-conglomerate group although its $F$ value was low. It was ranked seventh in Table XII frequency of response with 24 non-conglomerate responses and only 15 conglomerate responses. In Table XI it ranked ninth showing that the respondents that did rank variable $\mathrm{x}_{6}$ among their first five choices did rank it rather low on their preference scale. It is interesting to note that this criteria had the second lowest average point score of all ten variables as shown in Table XIII. This shows that while "reputation" can discriminate in the model between the two groups, its overall importance as a criterion is not great and should not be considered critical by firms interested either in acquiring or in being acquired. The term "reputation" was not well defined in the survey and thus any conclusions concerning this criterion should be made with care.

It is interesting to speculate at this point in the consideration of the "reputation" criterion $\mathrm{x}_{6}$, what would have been the result if more respondents from each group had expressed a ranking on this variable rather than leaving it blank? If the questionnaire had been constructed in such a way that both conglomerate and non-conglomerate respondents were specifically asked to show a preference or ranking on this criterion, perhaps rather than merely showing a low 
preference by both groups, a discriminatory power might have been discerned.

Variable $x_{7}$ - Complement and Fit with Existing Products

This variable is clearly a non-conglomerate type variable by definition. If an acquisition is selected for "fit" and complementing with existing products, it is clearly not chosen for diversity (one of the original criteria of a conglomerate) but for a horizontal, vertical, or concentric merger as defined in Chapter II of this study. It is not surprising, therefore, that this variable should have the second largest negative discriminant model coefficient and thus be one of the most influential of all the coefficients associated with the non-conglomerate group of respondents. This can be seen by the position of $x_{7}$ in Table VIII and by the size of its negative deviation from the discriminant average adjusted coefficient in Table XVI. The individual F ratio associated with this coefficient is 1.0338 which is not statistically significant at the .10 level.

The fact that this clearly non-conglomerate criterion was ranked by the discriminant model as an important nonconglomerate discriminator was a check on the validity of the questionnaire. Also, the high response rate of non-conglomerate executives ( 44 of 67 for $65.5 \%$ ) and the lower response rate of the conglomerate executives $(25$ of 53 for 47.28 ) was a check on the reliability of the questionnaire. 
The activity of this product-oriented criterion is summarized in Table XIX. Variable $x_{7}$ ranked fourth in frequency of response and third in point-total of rankings; it is therefore a most important criterion to be considered in any predictions of future non-conglomerate acquisitions.

TABLE XIX

Complement and Fit with Existing Products--Variable $\mathrm{x}_{7}$

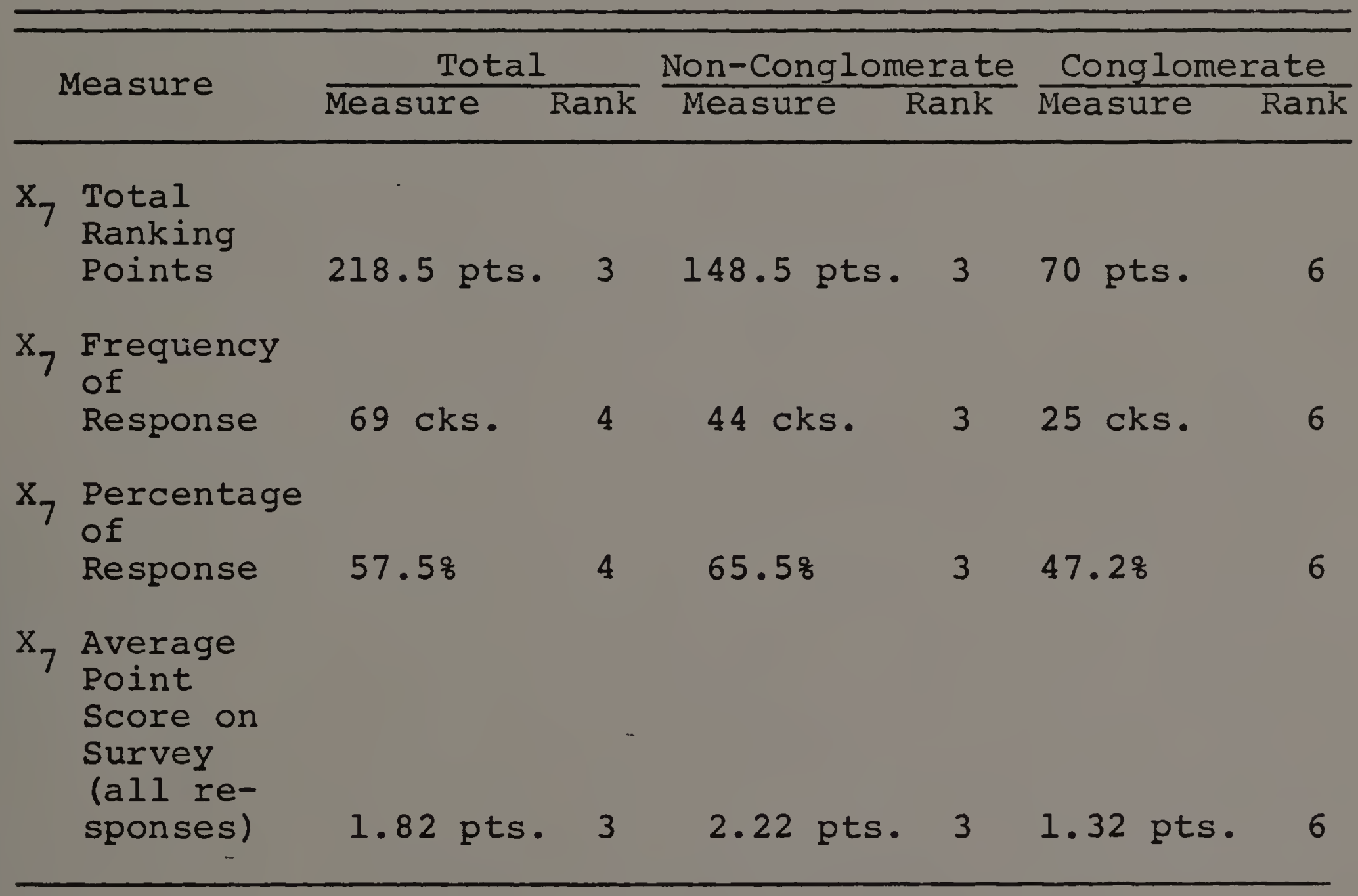

Note the difference between the conglomerate and nonconglomerate rankings of responses on all three measures in Table XIX. This confirms the high negative value coefficient of this variable in the non-conglomerate direction. 
$\underline{\text { Variables } \mathrm{x}_{8}, \mathrm{x}_{9} \text { and } \mathrm{x}_{10}}$

These three variables will be considered together since their contribution to the model and to the study are similar. The discriminant coefficients of criterion $x_{8}-$ size of Company Acquired, $x_{9}$ - Price/Earnings Multiple, and $x_{10}$ - Compatibility of Management objectives were -0.02441, -0.01367 , and +0.00488 respectively. All three coefficients showed discriminatory power in the non-conglomerate direction as measured in Column five of Table XVII which shows deviations from the average adjusted coefficient. of the three variables, Table VIII shows that none has any particularly strong conglomerate discriminatory power as measured by their F ratios; this would seem to indicate that none of the three alone is an important non-conglomerate criterion.

All of these variables are low on the activity tables as well; only variable $x_{9}$ - Price/Earnings Multiple ranks even near the median of Tables XI and XII. A summary of variables $\mathrm{x}_{8}, \mathrm{x}_{9}$ and $\mathrm{x}_{10}$ is presented in Table $\mathrm{xx}$.

The three criteria can be seen to be relatively unimportant both in response totals and in discriminant power although taken as a group, they do exert some influence on the model as non-conglomerate selectors (see Table XVI). 
TABLE XX

$$
\begin{aligned}
& \text { Size of Company to be Acquired }-\mathrm{x}_{8} \\
& \text { Price/Earnings Multiple of Candidate }-\mathrm{x}_{9} \\
& \text { Compatibility of Management Objectives - } x_{10}
\end{aligned}
$$

Measure

$\frac{\text { Total }}{\text { Measure Rank }} \frac{\text { Non-Conglomerate }}{\text { Measure Rank }} \frac{\text { Conglomerate }}{\text { Measure Rank }}$

$x_{8}$ Total

Points

83.5 pts. $8 \quad 50.5$ pts. $8 \quad 33$ pts. 9

$x_{9}$

163 pts. $\quad 5 \quad 80.5$ pts. $5 \quad 82.5$ pts. 5

$x_{10}$

75.5 pts. $10 \quad 37.5$ pts. $10 \quad 38$ pts.

$\mathrm{x}_{8}$ Frequency

Response

$x_{9}$

$37 \mathrm{cks} . \quad 8 \quad 20 \mathrm{cks}$.

$9 \quad 17 \mathrm{cks}$.

59 cks.

$5 \quad 31 \mathrm{cks}$.

$5 \quad 28 \mathrm{cks}$.

$\mathrm{x}_{10}$

$35 \mathrm{cks}$.

$9 \quad 18 \mathrm{cks}$.

$10 \quad 17 \mathrm{cks}$.

At this point in the discussion of survey results, an exhibit has been included to show the relative rankings of each variable as measured by both their individual $F$ values and their average point score on the questionnaire. The individual $\mathrm{F}$ value rankings show the relative discriminatory power of each variable measured alone and the average point score rankings show the relative importance of each variable as an acquisition criteria. These results are summarized in Table XXI.

An examination of Table XXI shows that no single criteria dominates both categories and that the individual ex- 
TABLE XXI

Comparison of Questionnaire Results on Average Point Score and on Discriminatory Power for Each Criteria Surveyed

\begin{tabular}{|c|c|c|c|c|}
\hline $\begin{array}{l}\text { Criteria } \\
\text { variable }\end{array}$ & $\begin{array}{l}\text { Discrimina } \\
\text { Incivicuai } \\
\text { E Value }\end{array}$ & $\begin{array}{l}\text { tory Power } \\
\text { Rank of } \\
\text { Incivicual } \\
\text { F Values }\end{array}$ & $\begin{array}{l}\text { Criteria } \\
\text { Rank by } \\
\text { Ave. point } \\
\text { Score }\end{array}$ & $\begin{array}{c}\text { Importance } \\
\text { Point } \\
\text { Average } \\
\text { Score }\end{array}$ \\
\hline$x_{4}$ & 5.9915 & 1 & 6 & 1.22 \\
\hline$x_{6}$ & 1.2115 & 2 & 9 & .66 \\
\hline$x_{9}$ & 1.1194 & 3 & 5 & 1.36 \\
\hline$x_{7}$ & 1.0338 & 4 & 3 & 1.82 \\
\hline$x_{2}$ & 0.9225 & 5 & 1 & 3.33 \\
\hline$x_{8}$ & 0.8652 & 6 & 8 & 0.70 \\
\hline$x_{10}$ & 0.2895 & 7 & 10 & 0.63 \\
\hline$x_{5}$ & 0.2075 & 8 & 4 & 1.72 \\
\hline$x_{3}$ & 0.1484 & 9 & 7 & 0.72 \\
\hline$x_{1}$ & 0.0162 & 10 & 2 & 2.87 \\
\hline
\end{tabular}

aminations done on each criteria in this chapter were needed for proper evaluation of the whole discriminant model.

Computations of Panking Correlations

At this point in the analysis of the criteria variables, an examination of the correlations between variables within each group of responses was planned. The preceding chapter on methodology describes the coefficients of correlation to be used in this study. When ranked, ordinal data is to be examined for correlations, either the Kendall or Spearman Rank - Correlation Coefficiente can be computed to measure

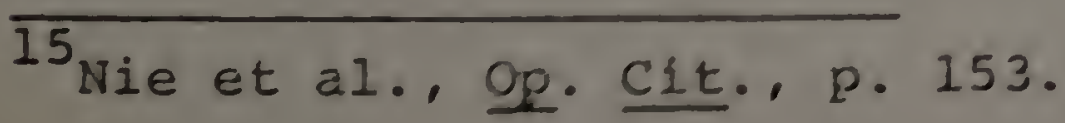


the covariance relationships.

Four computer runs using the SPSS package sub-program NONPAR CORR were made. ${ }^{15}$ The Kendali Rank Coefficient was computed for both the conglomerate and non-conglomerate groups between the ten variables. The same was done for both groups computing the Spearman Rank Coefficient. The results of these four computer runs are shown in the output tables in Appendix C. For each variable pair within both the conglomerate and non-conglomerate groups, the tables give the selected correlation coefficient, the number of cases used in the calculation, and the significance level of the coefficient computed. Unfortunately, the results of these procedures were not useful to the study. An examination of the results showed that only a few of the coefficients that were computed resulted in meaningful levels of significance and of these, none resulted in really high measures of correlation. The total results of the four computer runs showed no consistent patterns or relationships that were germane to this study and no conclusions could be drawn from this data. The correlation output data has been included in Appendix $C$ for reference purposes for future research on individual variables and their correlations.

The results of the computations of both rank-order coefficients were examined and considered inconsequential to the study and will not be analyzed further. One reason for the poor results may have been the small number of cases 
( $N=50$ conglomerate group and $N=67$ non-conglomerate group). For this reason, a proposed computation of the coefficients for subset; of each group (as determined by answers to question one) was not attempted. Future surveys with a larger number of respondents might find this a rewarding area for further research.

Responses on Criteria Lists and Manuals - Question One

Question number one of the questionnaire was concerned with whether or not the respondents' companies had written lists of acquisition criteria or had acquisition manuals to guide their merger activity. The percentage of useable returns from this question was much higher than from the rest of the survey; because of the simplicity of the question, no responses were discarded for unuseable answers. Only two respondents did not answer the question at all - one did not answer the entire questionnaire for reasons of company policy and the other evidently overlooked the question as he completed the rest of the paper. There were 131 responses to Question one out of the 133 returns; fifty-one were conglomerate returns and seventy-two were non-conglomerate. Question one as presented in the questionnaire was:

1. Does your company have a written list of acquisition criteria or a manual for mergers and acquisitions?

\section{Yes}

No

Table XXII shows the percentages of firms responding to question one and their various groupings. 
TFBLE XKII

Inalysis of Responses to Question one of questionnaire

\begin{tabular}{|c|c|c|c|c|c|c|c|}
\hline \multirow{2}{*}{ Responcient Group } & \multicolumn{2}{|c|}{ Yes } & \multicolumn{2}{|r|}{170} & \multicolumn{2}{|c|}{ Ho Answer } & \multirow{2}{*}{$\frac{\text { Total }}{\text { No. }}$} \\
\hline & ino. & $\frac{8}{5}$ & iNo. & $\bar{z}$ & ino. & 3 & \\
\hline Conglomerate & 27 & $27.9 z$ & 42 & 68.98 & 2 & $3.2 z$ & 61 \\
\hline lion-Conglomerate & 19 & $26.4 \frac{7}{5}$ & $\underline{53}$ & $73.6 \%$ & $\underline{0}$ & - & $\underline{72}$ \\
\hline Total Pesponses & 36 & $27.1 z$ & 95 & $71.4 z$ & 2 & $1.5 \frac{2}{2}$ & 133 \\
\hline
\end{tabular}

F.n Examination of Table KXII shows almost the same percentage of both conglomerate and non-conglomerate respondents with written lists or manuals for their acquisition criteria. No a priori hypothesis wae made as to whether either group would make greater use of such mitten liats since both groups were active accuirere. Z question for future study raight be whether well-Eorralated criteria lists are used more Erequently by active acquirers than by firme lese active in the merger fiela, or whether the use of formal criteria stanciarce result in more successful acquisitions. The percentage of firme responding who had written criteria liste wae only 27.1\%. The only comparable study found that 428 of the accuirer's responding to a 1970 study had formal "stuterents of objectines", and 14\% had "a formal annual budget assigned to...eearch and evaluation of acquizition alternativez." 16 The number of companies responding I6 u. Anzoff et al., Op. Cit., pp. 111 and 120. 
to the 1970 survey was $93 ; 133$ responses were used to compute the result of this question in this survey. "Statements of objectives" are really not comparable to "written lists of criteria" as surveyed in this study.

The $27.1 \%$ of the respondents reporting written criteria lists or manuals is consistent for both conglomerate (27.9\%) and non-conglomerate $(26.4 \%)$ respondents. This finding that only $27.1 \%$ of the total group of active acquirers has a formal standard to apply to acquisitions gives insight into a possible reason for the many findings in the literature that acquisitions historically have not shown consistent profitability results. This result will be examined further in the next chapter.

\section{Summary}

The statistical analysis of the questionnaire results were used to construct a discriminant function that was, in turn, used for analysis of executive attitudes concerning acquisition criteria. Also, the results of the survey were tabulated for each question and each variable. Tests were performed on the results and the original hypotheses were tested. In general, the original hypotheses of the study were confirmed by the results of the study. Chapter VI will summarize these results and draw conclusions and implications from them. 


\section{H A P T E R VI}

\section{SUMMARY AND CONCLUSIONS}

The purpose of this study was to examine the acquisition criteria used by active conglomerate and non-conglomerate acquirers. Since the many profitability studies examined in Chapter II showed no consistent pattern of differences between conglomerate merger results and results of mergers in general, perhaps profitability is not an area of difference between these two groups of acquirers. This study attempted to examine the differences between conglomerate and non-conglomerate acquirers by studying the merger criteria favored by the two groups prior to acquisitions. By using this fresh approach of examining corporate attitudes prior to merger rather than examining the results of mergers, a different perspective is possible in the study of mergers and acquisitions.

The question was posed as to whether or not there were significant differences between the two groups and whether any such differences had implications for financial theory. A questionnaire was mailed to 193 financial officers of activeIy acquiring corporations requesting their opinions of ten preselectcd acquisition criteria. The responses to this questionnaire from two groups of executives (conglomerate and nonconglomerate) were used as the input to a discriminant model that was the main instrument of the study. The discriminant 
model that was constructed was used to study the differences in evaluations of criteria by the two groups of executives and to examine the relationships between the criteria preferences within and between the groups. Because the study dealt with subjective evaluations of criteria by different executives working for corporations with varying objectives and in varying stages of their growth, it was not possible to isolate a definitive set of either conglomerate or non-conglomerate accuisition criteria. Also there were no similar studies in the literature to provide comparable data and information for reference and comparison of results. However, certain findings were found to be significant and these are summarized belon.

The discriminant model constructed by the study was composed of ten criteria as variables--each with a coefficient which determined the contribution of each variable to the total discriminant function. Higher positive values of the coefficients were marginally associated with firms of the conglomerate group. Examination of the coefficients and of their associated F ratios gave the relative importance of each variable as a selector and its power as a discriminator between the conglomerate anci non-congiomerate groups. A further tabulation was made of the frequency and average response values of each variable for both groups responding. These tabluations gave information as to the relative importance of each variable within each group. 
of the ten criteria examined, variable $x_{4}$ "the management continuation variable" was found to be the most important. The aiscriminant function coefficient for $\mathrm{x}_{4}$ had the greatest variation from the mean of all the coefficients and had the highest positive value of the ten coefficients which showed it to be the most important conglomerate selector. The individual $F$ ratio associated with this criterion was the only $F$ value that was statistically significant of all the variables tested individually which shows it to be the most powerful discriminator taken single of the entire discriminant model. The major finding of this study was the importance of this criterion as the major discriminator between the conglomerate and non-conglomerate groups.

Variables $\mathrm{x}_{1}$ and $\mathrm{x}_{2}$, "Rate of Growth of Earnings" and "Return on Investment" were the two profit oriented variables in the study. Both of these variables were ranked highest by each group of respondents on frequency of response and on average point score recorded. Both had coefficients that were not strong indicators of either the conglomerate or nonconglomerate groups. Neither the $x_{1}$ nor the $x_{2}$ coefficients had statistically significant individual $\mathrm{F}$ ratios and, thus, were shown to be weak discriminators between the groups. This resulted because both groups had almost equally strong preferences for these two variables. This finding may give some insight into the reasons for the inconclusive results of the profitability studies of the two groups as discussed 
in Chapter II. However, both the profitability variables were ranked highest on the survey responses and they must be considered the most important criteria for both groups of acquirers.

The results of the survey show variable $\mathrm{x}_{5}$ " the "market" criterion to be among the conglomerate group of discriminant coefficients as measured by its sign and size. This finding was interesting since this criterion emphasizes the marketing area and might generally be expected to be a non-conglomerate coefficient. However, since its discriminatory power was among the lowest as measured by its individual $F$ ratio and its frequency of response and average response rates were high for both groups, the "market" variable should be considered an important variable to both groups of acquirers. Since its power as a discriminator was low and other findings on this variable were conflicting (see Table XVIII) care should be taken on any conclusions drawn about variable $x_{5}$.

Variable $x_{7}$, the "product" criteria was the most influential of the non-conglomerate discriminant coefficients. This result was expected since, by definition, acquisitions chosen for product fit would not be chosen for civersity (a conglomerate definition). The $F$ ratio associated with this criterion was low, but the activity measures were high for non-conglomerate respondents. This product--oriented criterion is, therefore, a most important criterion to be con- 
sidered in any study of non-conglomerate acquisitions.

The remaining variables have been examined individualIy in Chapter $\mathrm{V}$ and can be summarizeci as a group here.

These criteria have made smaller individual contributions to the discriminatory power of the model and were the least active in frequency of response and rankings. Since their response rates were low, any conclusions concerning these criteria individually should be made with care since the number responding for each group was small. Their total contributions to the discriminant model were valuable, however. The discriminant model was then used to test the hypotheses of the study.

In order to identify and examine the difference between the two groups, the author formulated two hypotheses. The first hypothesis tested against the data collected concerns the question of differences between the conglomerate and nonconglomerate acquirers. If it is possible to construct a discriminant model of executive evaluations of acquisition criteria that will correctly classify such evaluations as either conglomerate or non-conglomerate, then it can be shown that significant differences exist between the two groups. The discriminant model developed in this study correctly distinguished a control sample group of conglomerate responses from a control sample of non-conglomerate responses with a $67 \%$ level of prediction at a 18 level of significance (Chapter IV). Hypothesis one that there is a significant differ- 
ence in emphasis between the evaluations of the two groups was tested and verified.

Once the model could be shown to discriminate between the groups correctly, a further examination of the results was needed to isolate the more important discriminators within the model. The second hypothesis of the study was suggested by the results of a presurvey and concerned one criterion the presurvey results had shown to be the prime conglomerate criterion. Hypothesis Two postulated that continuity of management was the most important discriminator between the groups. Hypothesis Two was tested by measuring the discriminatory power of each criterion by computing an individual $F$ ratio for each variable. The only $F$ value that was significant was the $\mathrm{F}$ ratio computed for the $\mathrm{x}_{4}$ variable. $\mathrm{x}_{4}$, the management continuation variable, had an individual F ratio significant at the .025 level of significance. A stepwise discriminant analysis program (which ran a regression with a 0,1 dependent variable) was performed for the 24 experimental group responses. The $\mathrm{x}_{4}$ variable alone had an $F$ value of 5.9915 (significant at the .025 level); with the addition of the other variables, the overall $F$ value of the function did not increase. Other stepwise discriminant analyses were run comparing the overall function with and without variable $x_{4}$ included. As a further test of the importance of $\mathrm{x}_{4}$ - the management continuation variable - an analysis of variance of the unexplained portion of total 
variation of the variable was also done. These tests were used to verify Hypothesis Two and further emphasized the importance of variable $\mathrm{x}_{4}$ as the prime discriminator of the discriminant model.

The results of the hypotheses tests considered with the results of the individual examinations of each variable confirm the earlier finding that the importance of variable $x_{4}$ (the management continuation criterion) was the principal finding of the study.

\section{Implications}

The results of the study can be seen to have a number of important implications. The major findings of the study were that there is a measurable difference between conglomerate and non-conglomerate executive attitudes toward acquisitions and that the prime discriminator of this difference is their differing evaluations of variable $x_{4}$--the management continuation criterion. This finding has certain practical implications; any firm desiring to be acquired by another corporation should first evaluate its own position on management continuation after the merger. The decision whether management continues or not affects the type of acquirer who could be interested in the acquisition and should, therefore, direct and limit the search for possible acquirers. More important is placing the results of the study in the current theory of mergers and acquisitions. The arguments 
on profitability have been noted in chapter II. The findings of this study suggest an explanation why these previous studies found is consistant differences jetween conglomerate and non-conglomerate post-merger profitability. Since both groups of acquirers rank return on investment $\left(\mathrm{x}_{2}\right)$ and rate of growth of earnings $\left(\mathrm{x}_{1}\right)$ highest among their acquisition criteria, both would seem to be looking for similar profitable acquisitions.

The study found that in many cases, conglomerate acquirers want existing management to continue. These conglomerate acquirers seem to anticipate no major (short-run) managerial changes in the acquisition and the acquired firm will continue to operate under the existing management. No immediate operational changes can be expected and no major improvement in managerial or economic efficiency will occur. In most cases, the conglomerate acquirers would seem to be investing for financial reasons such as diversity, reduction of earnings risk, and the "chain letter" type of growth discussed in Chapter II. Conglomerates, as seen by the results of the survey, do not seem to be motivated to takeover the management of the acquired firm. The conglomerates, then, will be investing in the acquisition much as a mutual fund or a private investor might.

These findings have further implications relative to the recent merger literature. In the introduction to this project, it was stated that this study would take a different 
approach to the merger process by examining attitudes prior to merger rather than concentrating solely on post-merger results. The atudy of merger criteria gave insights into the motives of conglomerate and non-conglomerate acquirers for entering into mergers. An understanding of the motives of acquirers gives a better understanding of the conflicting results of prior merger studies. For example, the current disagreement between Weston and Mansinghka and S.R. Reid as reported in the Journal of Finance ${ }^{l}$ can be better understood if the conglomerate motivations are examined. Weston and Mansinghka found that conglomerate acquirers were able to improve their profitability performance on various measures from a significantly lower level up to the general level of other groups of firms (see Table V). They concluded that this improvement in profitability performance is an economic function of the conglomerate and demonstrates their "economic efficiency." ${ }^{2}$ Reid found that the profitability of firms following an "internal growth" strategy was greater than the profitability of conglomerate firms (see Table IV). Reid suggests that since conglomerate managers were not profit max-

IJ.F. Weston and S.K. Mansinghka, "Tests of the Efficiency Performance of Conglomerate Firms," Journal of Finance, XXYI (September 1971), pp. 919-936 and S.R. Reid, "A Reply to the Weston/Mansinghka Criticisms Dealing With Conglomerate Mergers," Journal of Finance, XXVI (September 1971), pp. 937946 .

2 Weston and Mansinghka, Op. Cit., p. 934 . 
imizers and that synergy and economies of scale were not the results of conglomerate merger, that conglomerates are not economically efficient and "stockhulders whose objectives are more economic and rational" could make better acquisitions than the conglomerates. ${ }^{3}$

An examination of these conflicting results in the light of the motivational findings of the present study is revealing. If, as this study suggests, the conglomerate firms are acquiring for reasons of diversity and "chain letter growth," then studies of conglomerate profitability should show conglomerate results approaching (but not passing) the general profitability of other firms. This agrees with the weston/ Mansinghka results. Reid's results can be explained as well by examining them from this pre-merger motivational approach. Conglomerate firms that acquire for reasons of diversity can not reasonably expect to out perform "internal growth" companies who expand into areas of their own management expertise. In internal growth situations, economic efficiency results when the acquiring firm's managerial competence can carryover to the new growth area. Reid's findings of superior profitability among internal growth firms is found to be consistant with the findings of this study which found conglomerates investing in acquisitions like a mutual fund or any other investment portfolio builder.

$\overline{3}$ S.R. Reid, Op. Cit., p. 945 . 
Portfolio theory can be seen to be an important adiitional tool to be used in the study of conglomerate acguisition behavior as was shown by Smith and schreiner ${ }^{4}$ (see chap. ter II). Certain differences between traditional portfolio theory and portfolio theory as it applies to conglomerate acquisitions should be pointed out. Conglomerate acquirers may have additional objectives in particular mergers such as obtaining tax-loss carryover, unused borrowing power, or excess cash in the acquisition. Conglomerate acquirers may also desire in certain mergers economies of scale and managerial carryover as well as the traditional portfolio objectives. In addition, conglomerate acquirers must invest in the acquisition to a sufficient degree to gain control which is not necessary for individuals and mutual funds under traditional portfolio theory. With this amount of investment, the conglomerate is able to control the acquisition; this study would indicate that this control will be exercised through existing management. Also, just as the conglomerate had to purchase a large amount of the acquisition, so is it limited in divesting itself of small portions of it once it is integrated into the conglomerate corporate structure and the

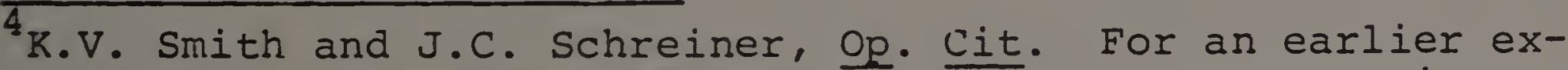
ample see G.A. Christy, "Does Today's Investor Appreciate The Diversified Firm's Significance?" The Commercial and Financial Chronicle, April 7, 1966, pp. $1-20$. 
acquisition's separate stock disappears. For these reasons, traditional portfolio theory should not be applied solely to the study of conglomerate acquisitions, but can be used as an additional evaluation tool by conglomerate executives.

A further implication of portfolio theory as it applies to conglomerate acquisitions should be considered. Since individial investors could easily duplicate the investments of the conglomerates with their own portfolios, and since they need not purchase control, why the great popularity and activity of the conglomerate form during the nineteen sixties? The answer seems to be that the conglomerate form of merger allows the corporation (and thus investors in it) to combine the traditional portfolio theory benefits of risk reduction and maximization of return ${ }^{5}$ with the chain letter effect resulting from high price-earnings multiples on the acquiring conglomerate's stock.

Before these conclusions can be completely accepted, further work is needed to check the post-merger managerial situations of the merged firms to test to what degree conglomerate acquirers actually do retain the acquired managements as implied by the survey. Also, the relationship between conglomerate stock price-earnings ratios and conglomerate acquisition activity was not empirically defined, nor did

5.M. Markowitz, "Portfolio Selection," Journal of Finance, VII, no. 1, (March, 1952), pp. 77-91. 
the author attempt to find any correlation between postmerger profitability and specific acquisition criteria. This study merely suggests a new direction for conglomerate study; more theoretical and empirical work is needed to develop these implications. 
BIBLIOGRAPHY

\section{A. Books}

Alberts, William W. and Joel E. Segall (ed.). The Corporate Merger. Chicago: University of Chicago Press, 1966.

Ansoff, H. Igor. Corporate Strategy. IJew York: McGraw-Hill, 1965 .

Ansoff, H. Igor, R.G. Brandenburg, F.E. Portner, and R. Radosevich. Acquisition Behavior of U.S. Manufacturing Firms, 1946-1965. Nashville, Tennessee: Vanderbilt Universiti Press, 1971.

Archer, Stephen H. and Charles A. D'Ambrosio. The Theory of Business Finance: A Book of Readings. New York: Mackillan Company, 1967 .

Boyd, H.W. and R. Westfall. Marketing Research Text and Cases. Homewood, Illinois: Richard Irwin, Inc., 1972.

Butters, J. Keith, John Lintner, and William Cary. Effects of Taxation on Corporate Mergers. Cambridge, Massachusetts: Riverside Press, 1951.

Dettmer, R.C. "Reasons for Mergers and Acquisitions," Corporate Growth through Herger and Acquisition, LMA, Management Report 10.75 . Wew York: Fmerican lianagement Association, 19 1963.

Dun and Bradstreet. Reference Book of Corporate Managements 1971-72. New York, New York: Dun and Bradstreet, 1971.

Dixon, W.J. (ed.). Biomedical Computer Programs. Berkeley, California: University of California Press, 1968.

Fisher, R.A. Statistical Methods for Research Workers. Edinburgh: Oliver and Eoya, 1946.

Hunt, Pearson, Charles 11. Williams, and Gordon Donalaison. Basic Business Finance, third edition. Homenood Illinois: Richard D. Irwin, Inc., 1966.

Hutchinson, G. Scott (ed.). The Business of E.cguisitions and Mergers. New York: Residents Publishing House, 1968. 
Kelly, Eamon. The Profitability of Growth through Merger. University Park, Pennsylvania: Center for Research of the College of Business Administration, Pennsylvania State University, 1967.

LaPorte, Lowell. Merger Policy in the Small Firms. New York: National Industrial Conference Board, 1969.

Luck, Wales, and Taylor. Marketing Research. Englewood Cliffs, New Jersey: Prentice-Hall, Inc., 1961.

Mergers and Acquisitions, Inc. Roster Cross-Index 1966-1970. Special issue, 1971.

Moody's Handbook of Common Stocks, First Quarter, 1971. New York: Moody's Investor Service, 1971.

Nelson, Ralph L. Merger Movements in American Industry: 1895-1956. Princeton, New Jersey: Princeton University Press, 1959 .

Nie, N., D.H. Bent, and C.H. Hull. Statistical Package for the Social Sciences. New York: McGraw-Hill, 1970.

Nunnally, J.C., Psychometric Theory. New York: McGraw-Hill, 1967.

Parkinson, C. Northcote. In-Laws and Outlaws. Cambridge, Massachusetts: The Riverside Press, 1962.

Penrose, Edith. The Theory of the Growth of the Firm.

Oxford: Basil Balckwell \& Mott, Ltd., 1959.

Perles, B. and Charles Sullivan. Freund and Williams' Modern Business Statistics, Revised. New Jersey: Prentice-Hall, Inc., 1969.

Reid, Samuel R. Mergers, Managers and the Economy. New York: McGraw-Hill, 1968 .

Corporate Mergers and Acquisitions Involving Firms in Missouri 1959-1969: Some Economic Results and Administrative Policies and Procedures. Ann Arbor, Michigan: University Microfilm. 1962 .

St. John's Law Review. Conglomerate Mergers and Acquisitions, XIIV (Spring 1970), Special Issue.

Schultz, Raymond G. (ed.). Readings in Financial Managements, second edition. Scranton, pennsylvania: International Textbook Co., 1970 . 
Selltiz, Jahoda, Deutsch, Cook. Research Methods in Social Sciences. New York: Holt, Rinehart and Winston, 1967.

Siegel, S. Nonparametric Statistics for the Behavioral Sciences. New York: McGraw-Hill, 195t.

Spiegel, Murray. Theory and Problems of Statistics. New York: McGraw-Hill, 1961.

Turabian, Kate L. A Manual for Writers of Term Papers, Theses and Dissertations. Chicago: University of Chicago Press,

Vanhorne, James C. Fundamentals of Financial Management.

Englewoc d Cliffs, New Jersey: Prentice Hall, Inc., 1971.

Weston, J. Fred and Eugene F. Brigham. Managerial Finance. New York: Holt, Rinehart and Winston, 1969.

Wyatt, Arthur R. and Donald E. Kieso. Business Combinations: Planning and Action. Scranton, Pennsylvania: The International Text Book Bompany, 1969.

\section{B. Articles}

Altman, E.I. "Financial Ratios, Discriminant Analysis, and the Prediction of Corporate Bankruptcy," Journal of Finance (September 1968), 589-610.

II70-1i "A Reply," Journal of Finance, XXV (December 1970), $1170-1172$.

$\overline{721 .}$

"Reply," Journal of Finance, XXVII (June 1972), 711-

Ansoff, H. Igor and J. Fred Weston. "Merger objectives and Organization Structure," Quarterly Review of Economics and Business, II (August 1962), 49-58.

Baumol, William J. "On the Theory of Expansion of the Firm," American Economic Review, LII, no. 5 (December 1962), 10851090 .

Block, Staniey B. "The Effect of Mergers and Acquisitions in the Market Value of Common Stocks," Southern Journal of Business, IV (October 1969), 189-195.

Burch, Gilbert. "The Merger Movement Rides High," Fortune (Eebruary 1969), 78-82. 
Carr, B.B. and S.J. Browne. "Method vs. Myth in Measuring Merger Activity," Mergers and Acquisitions, VI, no. 3.

Christy, G.A. "Does Today's Investor Appreciate the Diversified Firm's Significance?" The Coimercial and Financial Chronical, April 7, 1966, 1-20.

Cohen, Jerome B. "The Economic Aspects of Conglomerates," St. John's Law Review, XLIV, special edition (Spring 1970).

Crane, Roger. "The Place of Scientific Techniques in Mergers and Acquisitions," The Controller (July 1961), 326-329, 340-

342 .

Dean, Joel. "Causes and Consequences of Growth by Conglomerate Merger: An Introduction," St. John's Law Review, XIIV, special edition (Spring 1970), $\overline{15-36 .}$

Deban, Gerald and S. John Loscocco. "Pooling vs.. Purchase Perturbations," Mergers and Acquisitions, VI, no. 3 (Fall 1971), 16-23.

Donaldson, Gordon. "Financial Goals: Management vs. Stockholders," Harvard Business Review, XLI, no. 3 (May-June 1963), 118 .

Durand, D.D. "Risk Elements in Consumer Installment Financing," Studies in Consumer Installment Financing. New York: National Bureau of Economic Research (1941), 105-142.

Frank, R.E. "Bias in Multiple Discriminant Analysis," Journal of Marketing Research, II (August 1965), 250-258.

Gullahorn, Jeanne E. and John T. "An Investigation of the Effects of Three Factors on Response to Mail Questionnaires," Public Opinion Quarterly, XXVII (1963).

Hanna, Mark. "Corporate Bankruptcy Potential, Stockholders Returns, and Share Valuation: Comment," Journal of Finance, XXVII (June 1972), 711-717.

Hogarty, Thomas $F$. "The Profitability of Corporate Mergers," Journal of Business, XIIII (July 1970), 317-327.

Hollman, Robert $w$. "Evaluation of the Corporate Complex," Mergers and Acquisitions, III, no. 1 (January-February 1968).

Johnson, Craig G. "Ratio Analysis and the Prediction of Firm Failure," Journal of Finance, KXV (December 1970), 1166-1170.

Kemp, Bernard A. "Understanding Merger Activity - Assessing the structural Effects of Acquisitions," The Bulletin, H.Y.U. Graduate School of Eusiness, Ho. 55-56 (April 1969). 
Kimball, A.E. "Increasing the Rate of Return in Mail Surveys," Journal of Marketing, XXV, no. 6 (October 1961).

Kitching, John. "Why Mergers Miscarry?" Harvard Business Review (Novcmber-December 1967), 84-1C1.

Kuhlman, J.M. and R.M. Duke. "A Concept of the Conglomerate Firm," St. John's Law Review, XLIV (Spring 1970), 61-65.

Lev, B. and G. Mandelker. "Microeconomic Consequences of Corporate Mergers," Journal of Business, XLV, no. I (January 1972).

Lindzey, G.E. and I. Guest. "To Repeat-Check Lists Can Be Dnagerous," Public Opinion Quarterly, XV (1951), 351-358.

Lintner, John. "The Cost of Capital and Optimal Financing of Corporate Growth," Journal of Finance, XVIII, no. 2 (May 19631,292 .

Lorie, James H. and Paul Halpern. "Conglomerates: The Rhetoric and the Evidence," Journal of Law and Economics, XIII (April 1970), 149-166.

Markowitz, H.M. "Portfolio Selection," Journal of Finance, VII, no. 1, (March 1952), 77-91.

May, Marvin M. "The Chain Letter Revisited," Financial Analysts Journal (May-June 1968), 113-117.

Mecimore, Charles. "Financial Ratio Analysis of Prospective Merger Candidates," Mergers and Acquisitions, III, no. 5 (September-October 1968), 12-21.

Miller, Morton H. and Franco Modigliani. "Dividend Policy, Growth and the Valuation of Shares," Journal of Business, XXXIV, no. 5 (October 1961), 411-433.

Myers, H. and E.W. Forgy. "Development of Numerical Credit Evaluation Systems," Journal of the American Statistical Association, L (September 1963), 797-806.

Norgaard, R.L. and D.T. Crary. "Identifying Merger Targets in the Property and Liability Insurance Industry," Financiai. Analysts Journal (January-February 1970).

O'Dell, W.F. "Personal Interviews or Mail Panels?" Journal of Marketing, XXVI, no. 4 (October 1962), 34-39. 
Plog, S.C. "Explanations for a High Return Rate on a Mail Questionnaire," Public Opinion Quarterly, XXVII (Summer 1963), 297-298.

Reed, Stanley Foster. "Corporate Diversification," Mergers and Acquisitions, V, no. 4 (July-August 1970), 4-16.

- "Mergers and the ALCPA," Mergers and Acquisitions, $V$, no. 5 (September-October 1970), 20-23.

Roeher, G. Allan. "Effective Techniques in Increasing Response to Mailed Questionnaires," Public Opinion Quarterly, XXVII (1963), 499-502.

Shick, Richard A. "The Analysis of Mergers and Acquisitions," The Journal of Finance, XXVII, no. 2 (May 1972), 495-501.

Simkowitz, M.J. and R.J. Monroe. "A Discriminant Analysis Function for Conglomerate Targets," Southern Journal of Business $(1971), 1-16$.

Smith, K.V. and J.C. Schreiner. "A Portfolio Analysis of Conglomerate Diversification," Journal of Finance, XXIV (June $1967), 413-428$.

Walter, J.E. "A Discriminant Function for Earnings Price Ratios of Large Industrial Corporations," Review of Economics and Statistics, XII (February 1959), 44-52.

Westerfield, R. "A Note on the Measurement of Conglomerate Diversification," Journal of Finance, XXV, no. 4, (September, 1970), 909-914.

Weston, J.F. "The Nature and Significance of Conglomerate Firms," St. John's Law Review, XLIV (Spring 1970).

Weston, J. Fred and Surenda K. Mansinghka, "Tests of the Efficiency Performance of Conglomerate Firms," Journal of Finance, XXVI (September 1971), 919-936.

\section{Reports}

American Institute of Certified Pub+ic Accountants. Accounting Principles Board Opinion \#16: Business Combinations. New York American Institute of Certified Public Accountants, 1970.

American Institute of Certified Public Accountants. Accounting Principles Board Opinion \#17: Intangible Assets. New York American Institute of Certified Public Accountants, 1970. 
"Disclosure of Supplemental Financial Information by Diversified Companies," The Journal of Accountancy (October 1967), 51.

Smith, K.V. "Classification of Investment Securities Using MDA," Institute paper \#101. Lafaỳette, Indiana: Purdue University, Institute for Research in the Behavioral, Economic, and Management Sciences, 1965.

Office of Statistical Standards, Bureau of the Budget. Standard Industrial Conference Manual, 1967.

D. Dissertations:

Block, S.B. "The Effect of Mergers and Acquisitions on the Market Value of Common Stock," Ph.D. dissertation, Louisiana State University, 1970.

Poindexter, E.O. "The Profitability of Industrial Merger," Ph.D. dissertation, Syracuse University, 1970.

Rankin, D.F. "Security Based Conglomerate Acquisitions: The Effect on Residual Ownership," Ph.D. dissertation, University of Mississippi, 1970. 


\section{APPENDICES}




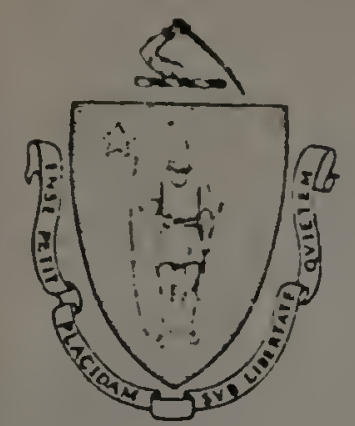

ool of Business Administration

Coportment of Ganapol Businese

and Finone.

APPEIDIX A

\section{Dear}

I am a 45 year old Ph.D. candidate at the University of Massachusetts. After 20 years as a manufacturino executive I returned to school to change careers and enter tine field of college teaching. As a finsncial executive in a large corpora tion, I need your help in the completion of my Ph.D. dissertation.

Will you please conplete the enclosed one-puese anonymous questionnaire concerned ith cxecutive attitudes toward corporate mercer and acquisition criteria. Having been in business, I realize and apprcciate the value oi your time: hoiever, feedback

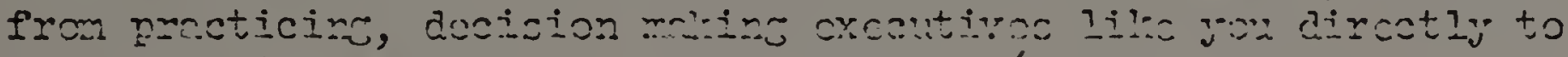
the academic ccimunity is most important (narticularly in these days of stucient misunderstandings of business operations and objectives).

By completing the questionnaire and prompily returning it in the enclosed self-adaressed envelope, you will have helped place one more businessman on a university faculty, where hopcfully, he can work towards training fliture executives and towards better student understanding of management objectives.

A prompt reply would be most helpful. Thank you again for your cooperation and consideration.

Sincerely yours,

A. Hermann

Lecturer in Finance

University of lisssachusetts 


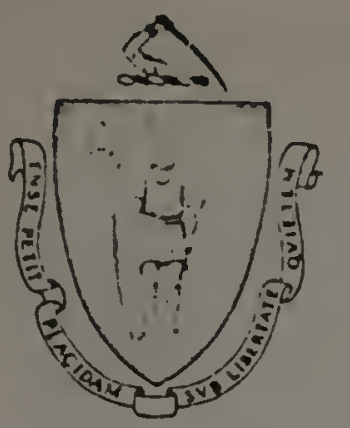

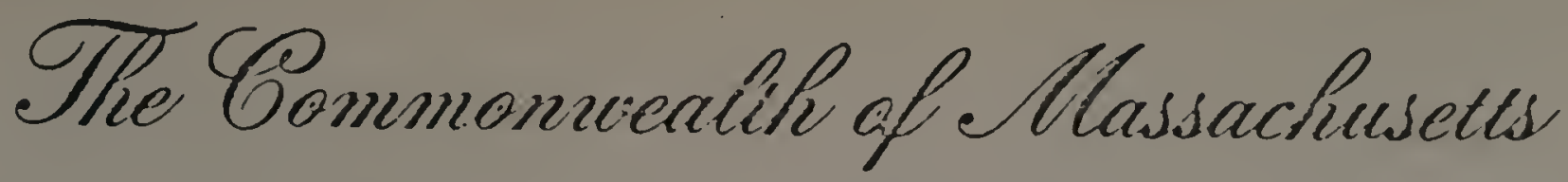

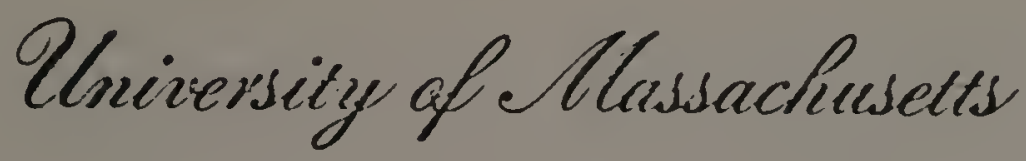

Elmherse 01002

APPEINDIX B

\section{STRICIUY CONEIDENTIAL}

\section{A STUDY OF EXECUTIVE ATTITUDES TOJARDS SELECTED ACQUISITICN CRITERIA}

As a corporate executive knowledgeable about your company's acquisition program, your help in providing the information requested in this questionnaire will be greatly appreciated and will be of much help to a doctoral candidate in the conpletion of a $\mathrm{Ph}$. D. dissertation.

Please remember that your answers are anonymous and you do IrOT sign your name or identify your company UILESS you would like the results of the survey sent to you when $1 t$ is completed. Thank you.

1. Does your company bave a written list of acquisition criteria or a manual for mergers and acquisitions?

$$
\text { Yes. }
$$

No.

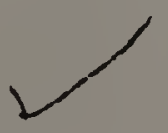

If yes, we would appreciate a copy for inclusion in a Statistical analysis of criteria (individual returns will be kept confidential).

2. Folloring is a list of ten frequently used acquisition criterla. The writer realizes that these are neither mutually exclusive nor independent; however, please rank the five most important in your acquisition prosram, putting a 1 before the critcrion you rank most important of those listed, a 2 before the second most important, etc. Please put NA (for not applicable) after any criteria that your company either does not consider at all or considers to be unimportant.

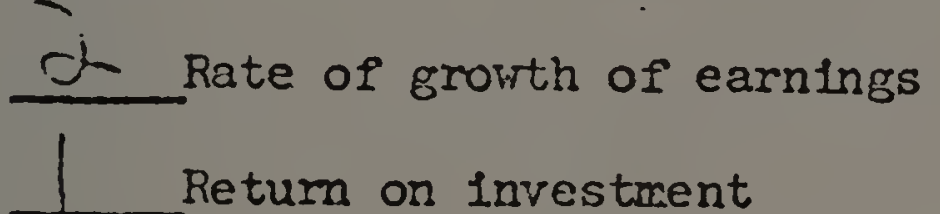

Rate of growth of sales

3 Present management willing to continue

Complement \& augment existing markets

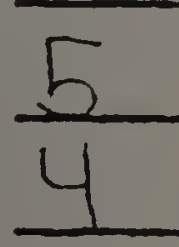

Reputaticn of acquired firm

Coüplement \& fit with exlsting products

Size of company to be acquired (Max. or minfmum limits)

Price/earnings multiple of candidate

Compatibility of management objectives

3. Any other important criterion not listed? (write in below)

Thank you for your cooperation in this doctoral research project. 

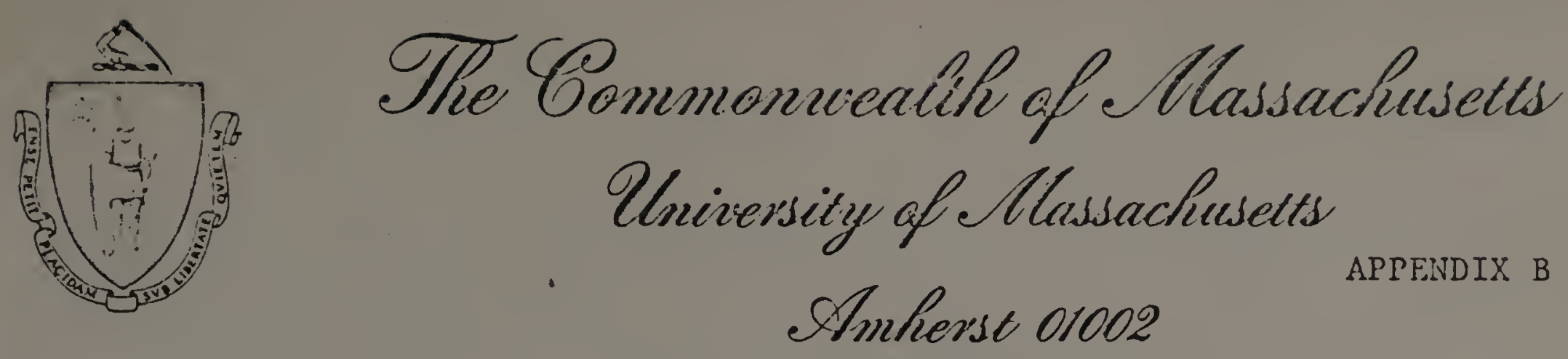

STRICILY CONFIDENTTAL

\section{A STUDY OF EXECUTIVE ATTITUDES TONARDS SELECTED ACQUISITICI CRITERIA}

As a corporate executive knowledgeable about your company's acquisition program, your help in providing the information requested in this questionnaire will be greatly appreciated and will be of much help to a doctoral candidate in the completion of a Ph. D. dissertation.

Please remember that your answers are anonymous and you do loT sign your name or Identify your company UnLESS you would like the results of the survey sent to you when it is completed. Thank you.

1. Does your company bave a written list of acquisition criteria or a manual for mergers and acquisitions?

Yes No

If yes, we would appreclate a copy for inclusion in a Statistical analysis of criteria (individual returns will be kept confidential).

2. Folloring is a list of ten frequently used acquisition criteria. The writer realizes that these are neither mutually exclusive nor independent; however, please rank the five most important in your acquisition program, putting a 1 before the criterion you rank most important of those listed, a 2 before the second most inportant, etc. Please put NA (for not applicable) after any criteria that your company either does not consider at all or considers to be unimportant.

-

of Rate of growth of earnings

$\perp$ Return on Investment

Rate of growth of sales

3 present management willing to continue

Complement \& augment existing markets

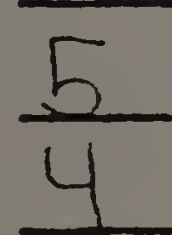

Reputaticn of acquired firm

Couiplement \& fit with existing preducts

Size of company to be acquired (Max. or minimum limits)

Price/earnings multiple of candidate

Compatibility of management objectives

3. Any other important criterion not listed? (write in below)

Thank you for your cooperation in this doctoral research project. 
APPENDIX C

Output Tables Correlation Programs 


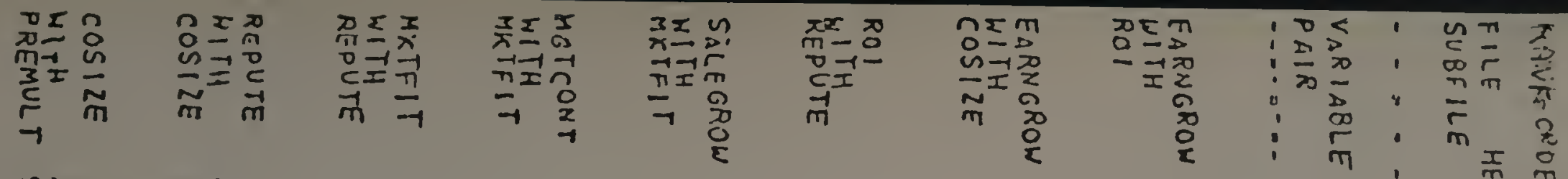

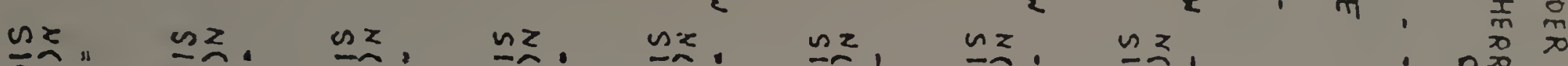
万人:

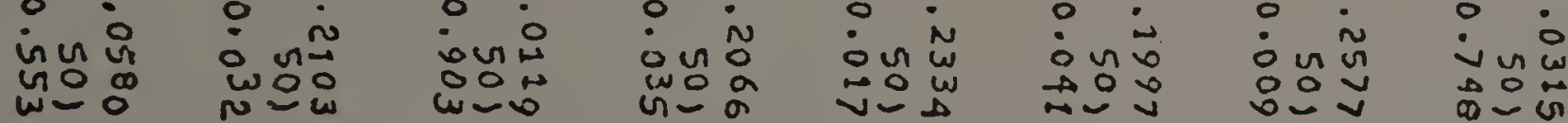

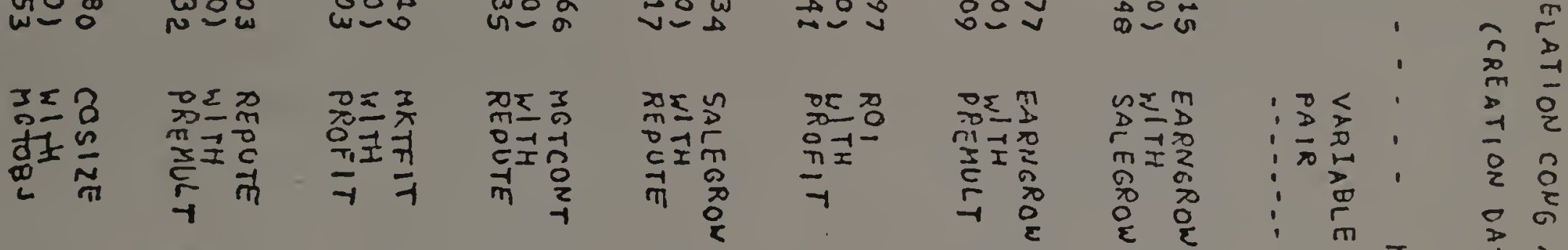

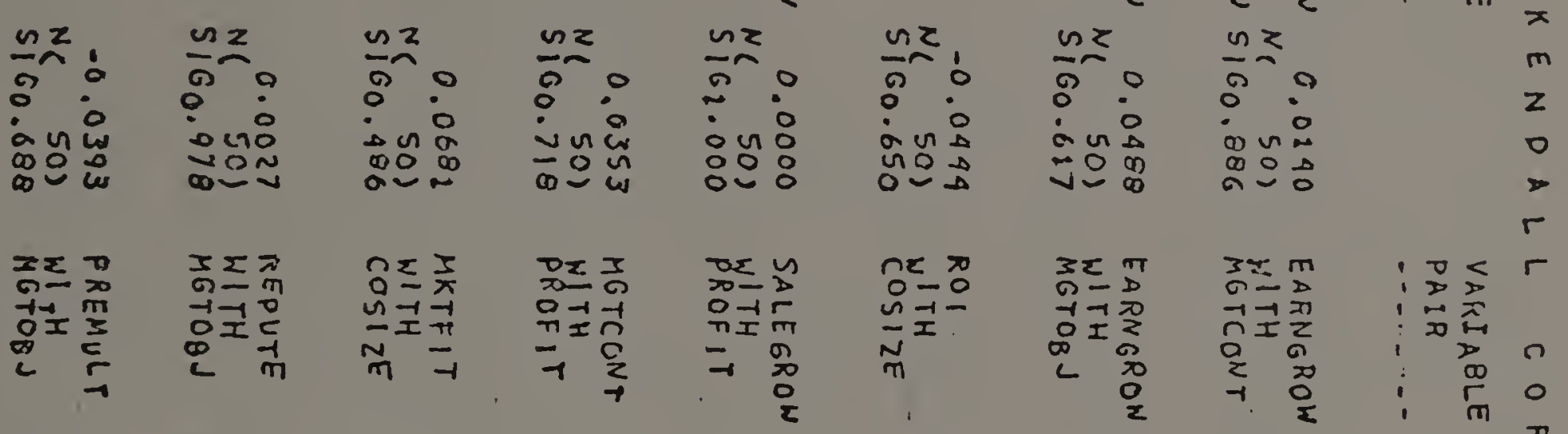

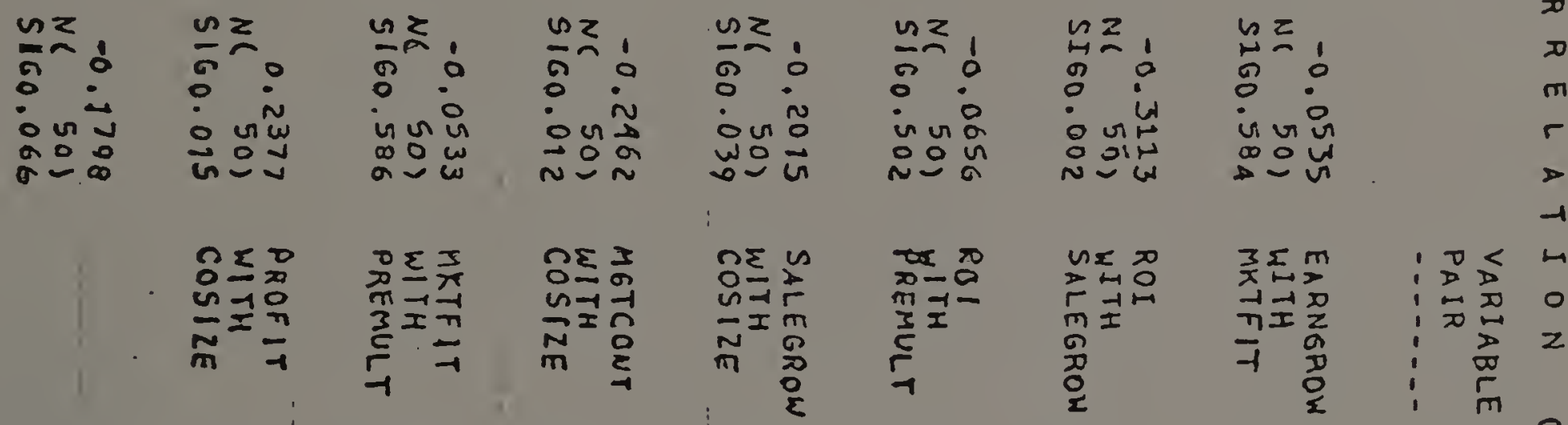

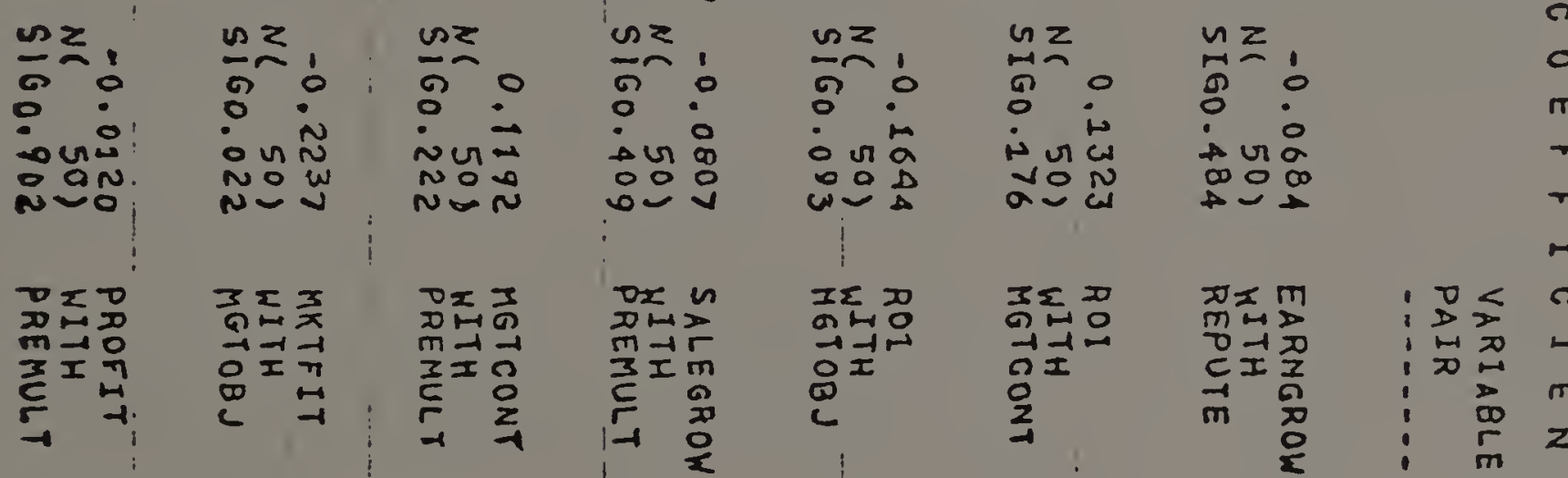
$n z, n z, n z, n z, n z, n z, n z, n$ 岁苔

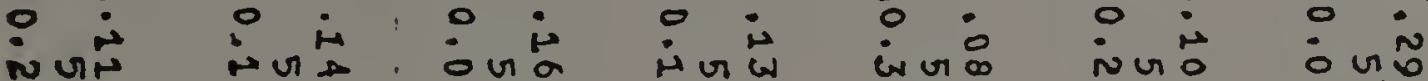

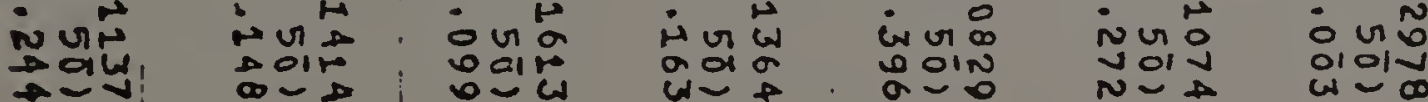

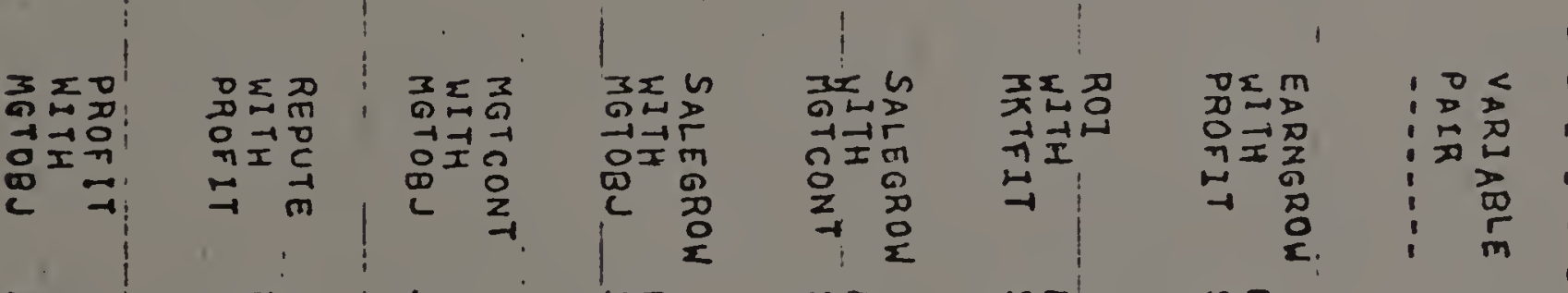

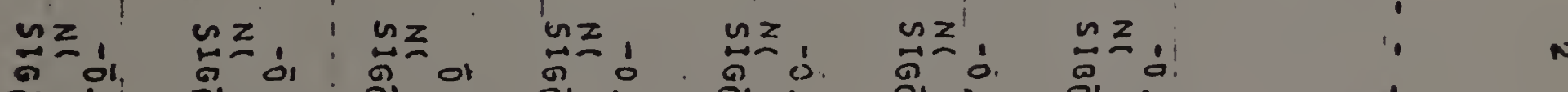

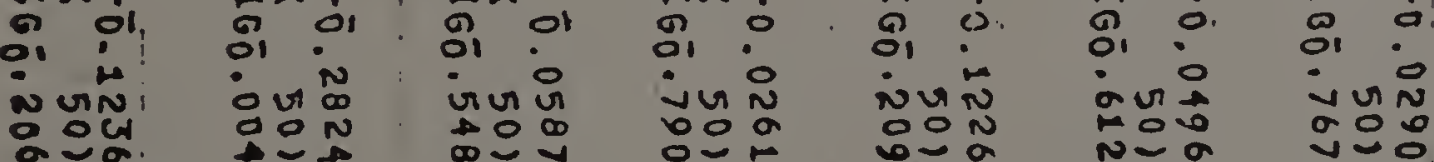




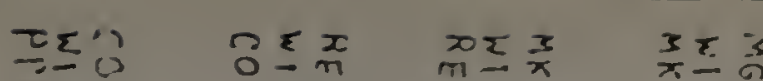

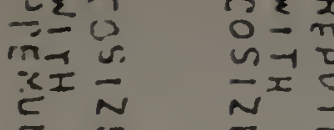

r

$\frac{n \geq}{n}: \quad \frac{0}{0}$

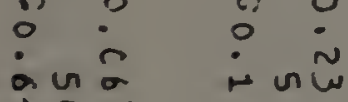

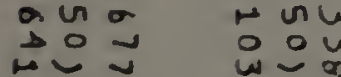

른?

Dू

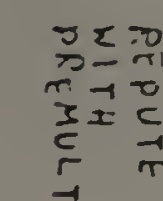

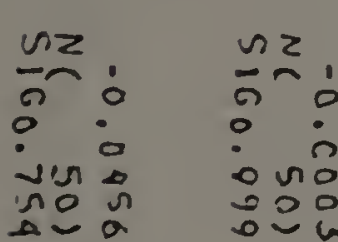

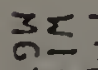

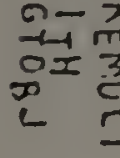

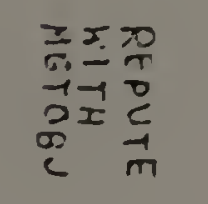

nz, nz कृ

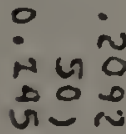

$\pi=1$
$=\pi$

$\vec{\pi} \frac{1}{7}=$

$a-n$

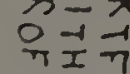

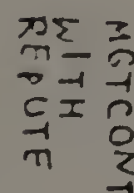

$\neg$

in w :

$\begin{array}{lll}2 & 0 \\ 1 & 0 & 0\end{array}$

$n x \vec{r}$

유픔

$\frac{0}{2} z$

:

:

a u

200 $\overrightarrow{7}=\overrightarrow{2}$

$3 E$ in

$x=2$

금

$\exists=m$ c

$n \leq \pi$

oxm

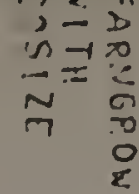
जँำ i 엔

$\frac{n}{2} \pi$

in

$\begin{array}{lll}n & 0 \\ 0 & 0 & 0 \\ 0 & 0\end{array}$

$\pi \sum u$

$\square=$

ज光

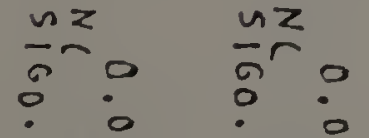

vin

क्ष

$n=$

कृ

iิ

עo 0

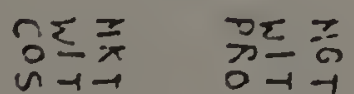

-1?

og u

$0=1$
$0 \pi 5$

nat

7 分

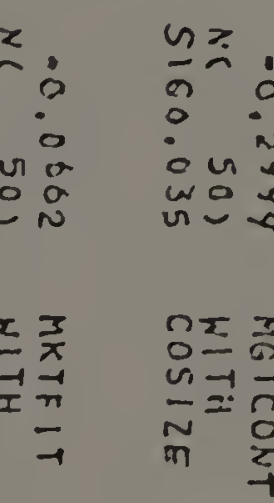

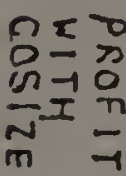

\section{$n x$}

का

is $n N$

$\pi 0 a$

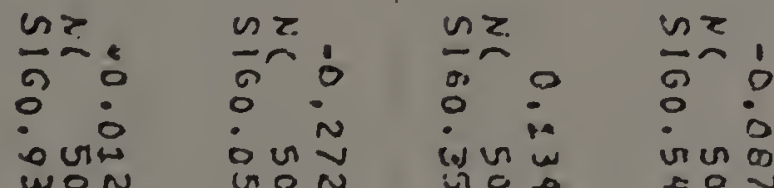

WON

GN

Go

है U

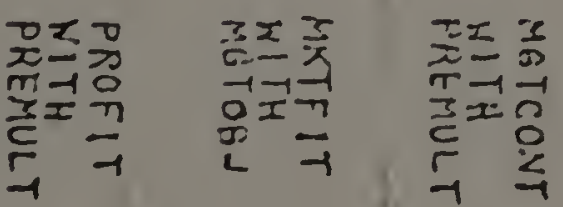

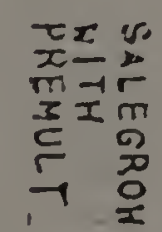

$\frac{n}{2} \geq$

is

wa

nz

$\frac{n \geq}{0} !$

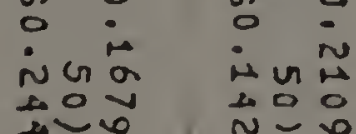

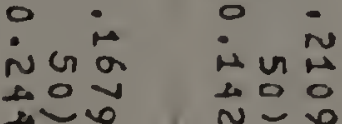

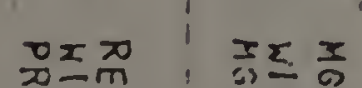

$x \leq x$
$0=1$

$x_{0=\pi}^{0 x}$

品开

들 $\vec{~}$

$\begin{array}{ll}0 & 0 \\ 2 & 0\end{array}$

$n \geq: \quad n \geq$

$\frac{n z}{a} !$

is जua $\therefore$

Nov
onN

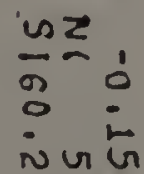

inc

జ은

$x$

$x x$
$0=1$
$0=1$

品正

$\begin{array}{ll}\infty \\ \vdots & 0 \\ \vdots & c \\ 1 & 2\end{array}$

$\frac{n}{n}$

$\because$ :

$\infty \cup N$

$\infty$

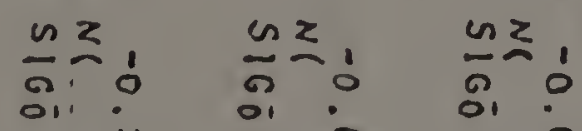

$\frac{n}{0} \geq$

in

.

$0 \sim w$

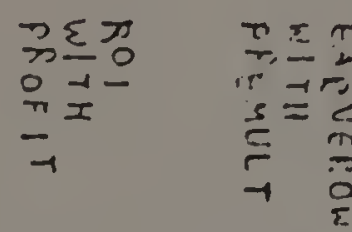

$\frac{n z !}{n}: \frac{n z}{n}: \quad \frac{n}{5} 0$

in i in: ini

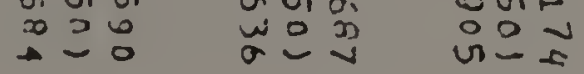

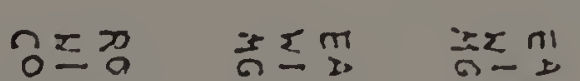

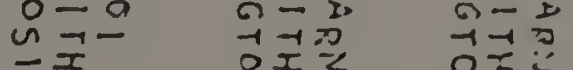

$\bar{n}^{x}$

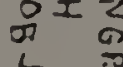

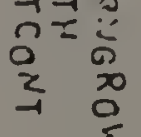

$\frac{n \geq}{n} \dot{0} \quad \frac{n}{n} \dot{0} \quad \frac{a}{0}$

$\because \quad 0 \quad$ in $: 0$

मीก

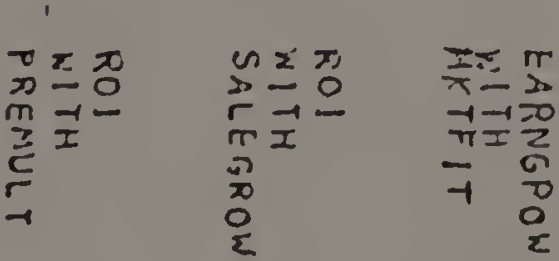

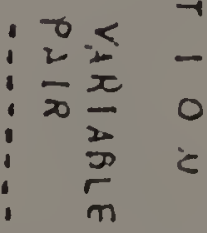

$n z$
$n$
0
$i$
$i$
$i$

$v a$

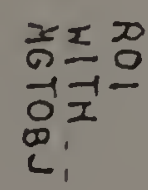

$n \geq$

$\frac{n z}{2}:$

$\therefore$ U

$a 20$

1

$x x$ un $x \leq x$ or

$\frac{n \geq}{n} a \quad \frac{a}{0}:$

ivin iñ

$\infty 00$ जiln

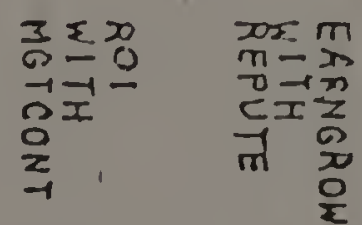

$\frac{n \geq}{2} \dot{0} \quad \frac{n \geq}{2}$

in in

WUA 0 की

$\sum_{\infty}^{\infty}=\sqrt{\infty}= \pm$

$\vdots \bar{\infty} \frac{\infty}{2}$

$\begin{array}{ll}\pi & n \\ \pi & 0\end{array}$

$x$

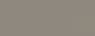

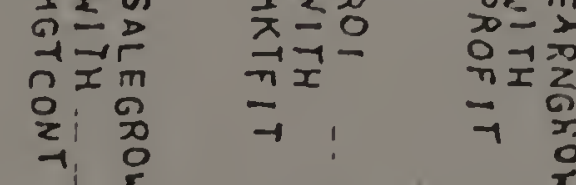

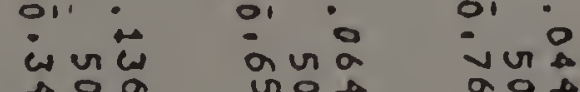

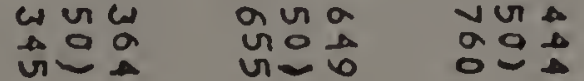

$\sum_{n}^{2}$<smiles>[CH][AlH]</smiles> 


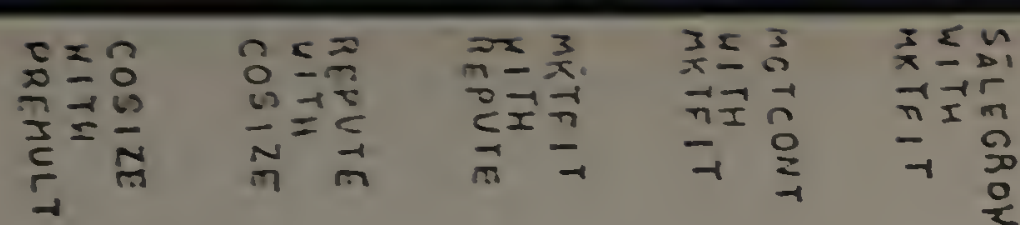

$x=x$

$n \leq n$

xe $m$

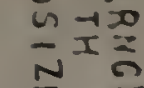

$\underset{n}{c}$

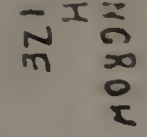

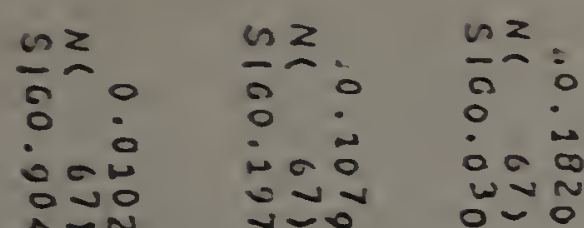

$n \geq$

$n z$

$n=$

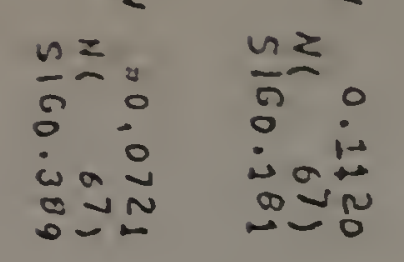

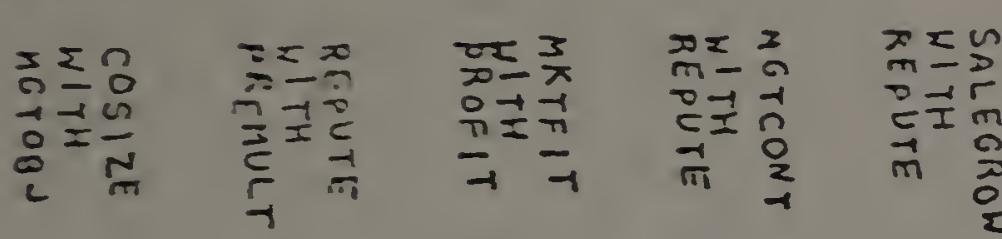

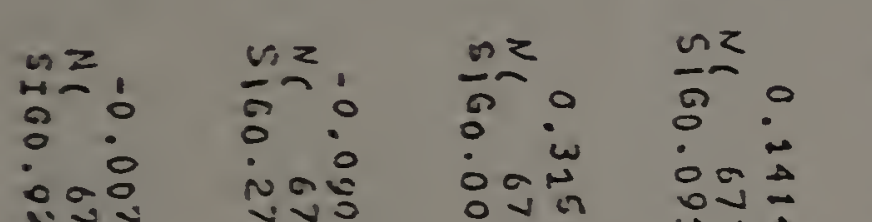

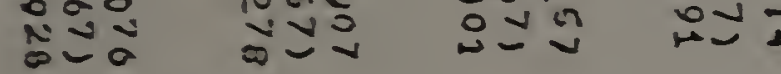

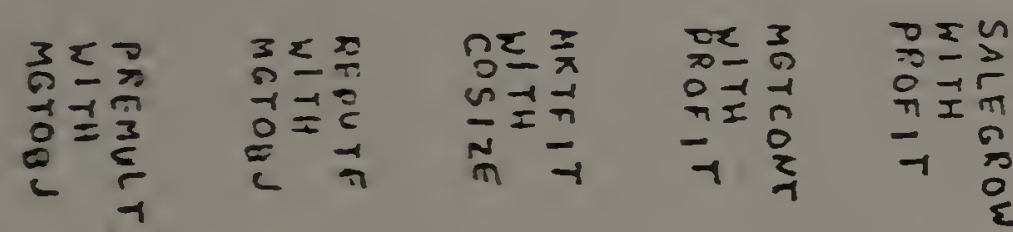

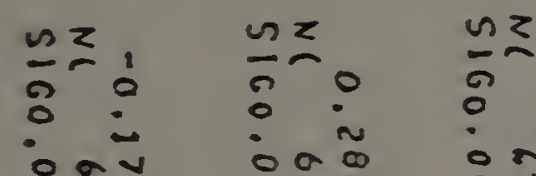

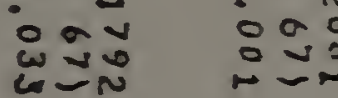

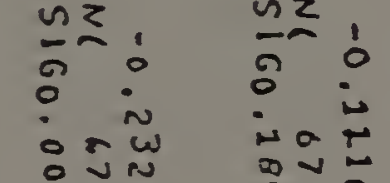

$\frac{\ln }{5} \leq$

$\because 00$

$\frac{1}{2}=$

$\infty=\infty$

$a \simeq i$

$\frac{n z}{0}$

:

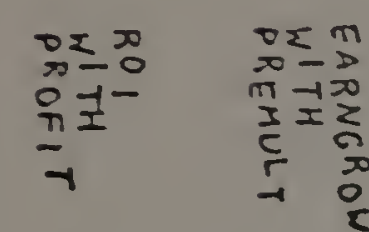

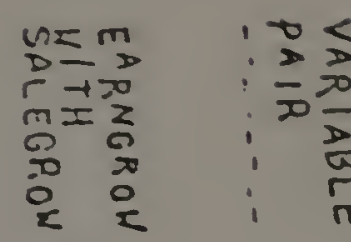

$n \geq, \quad n \geq 1 \quad n \geq$

$\frac{n \gtrless}{\circ}$

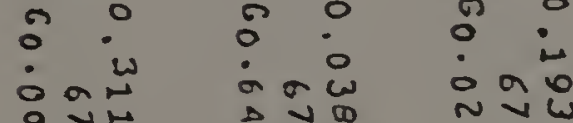

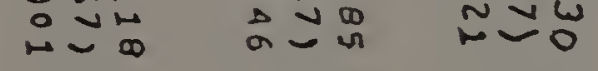

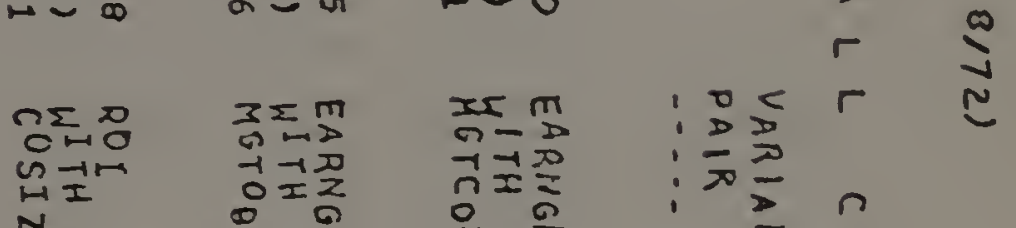

N

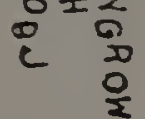

$n z \quad n z \quad n z \quad \infty$

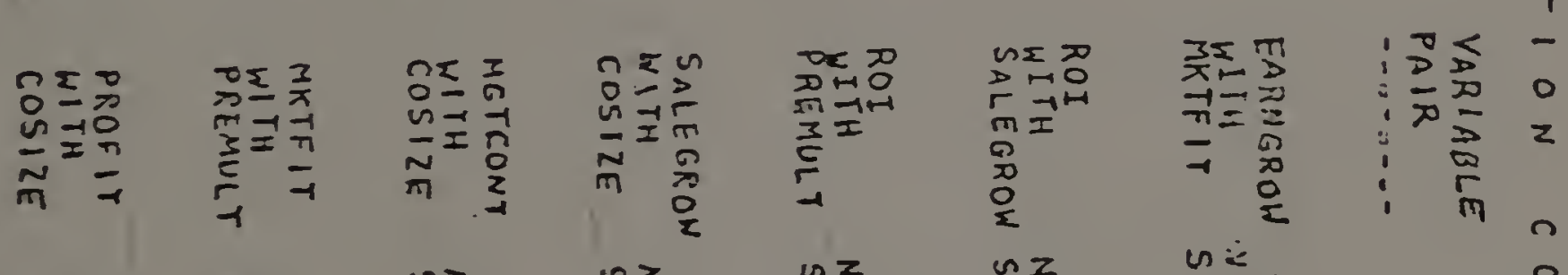

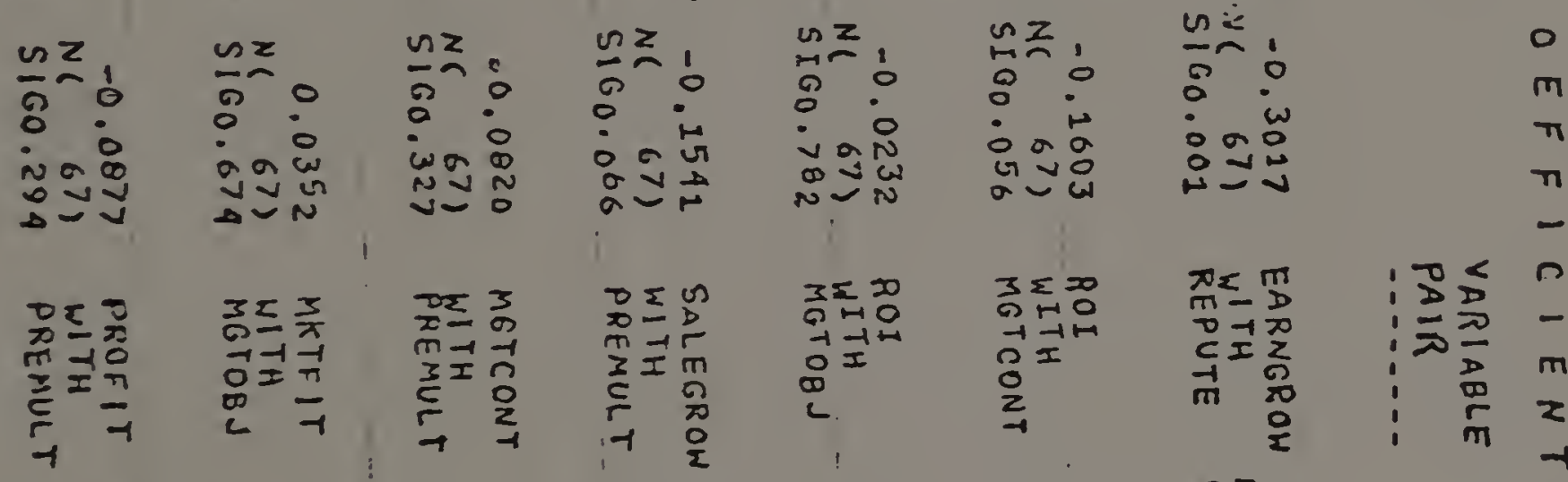

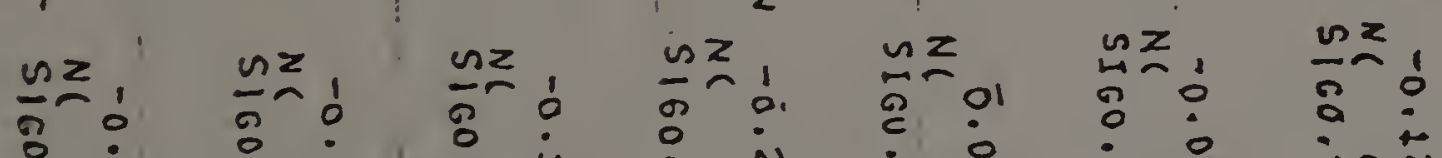

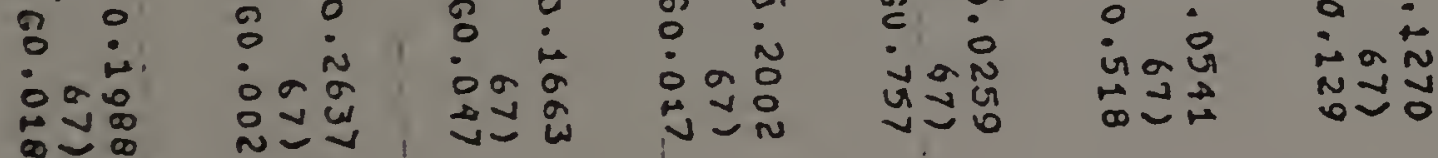

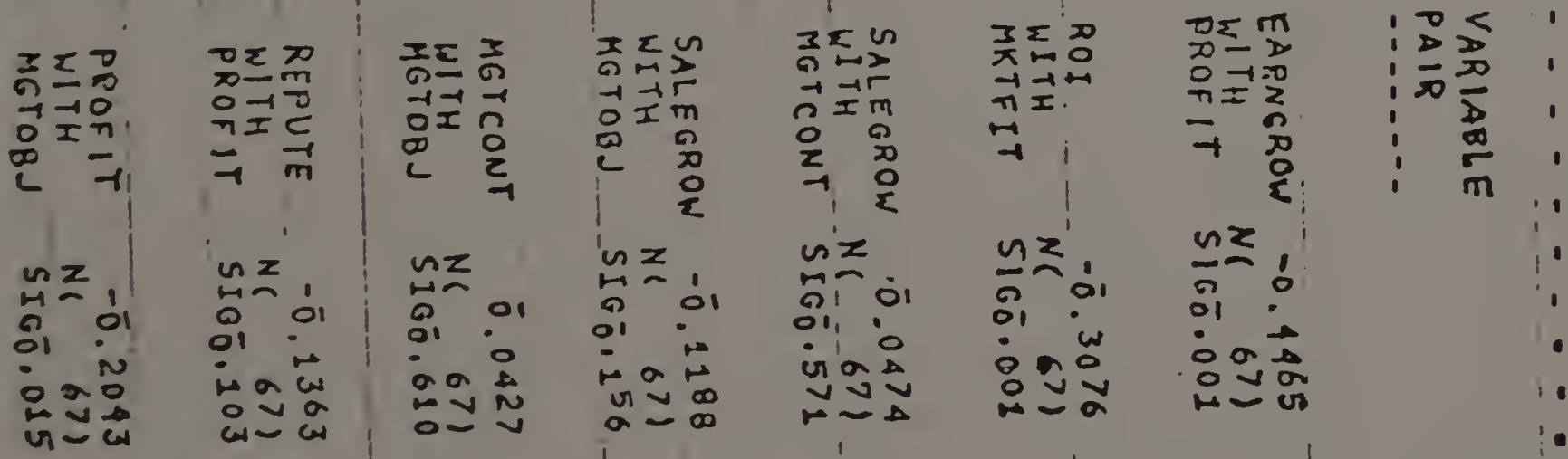




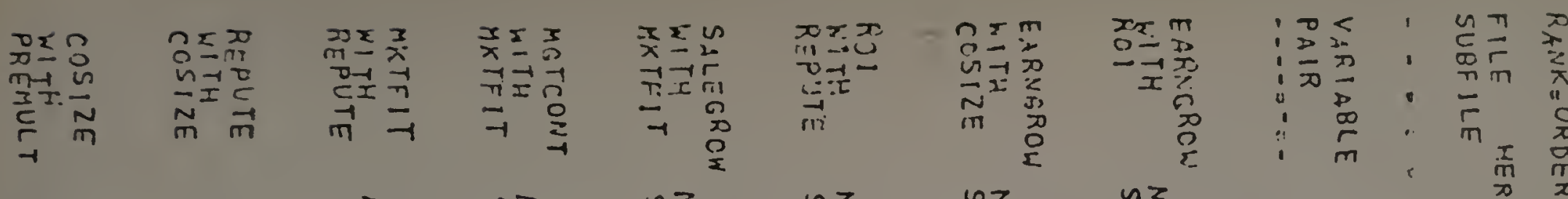

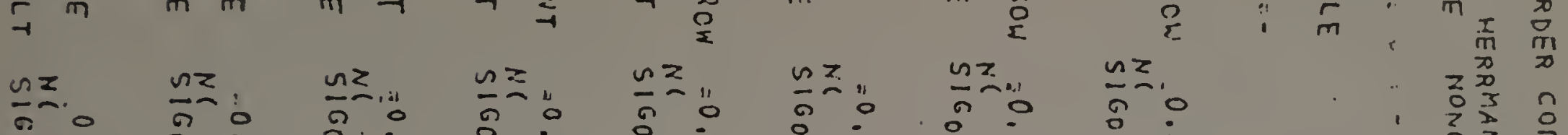

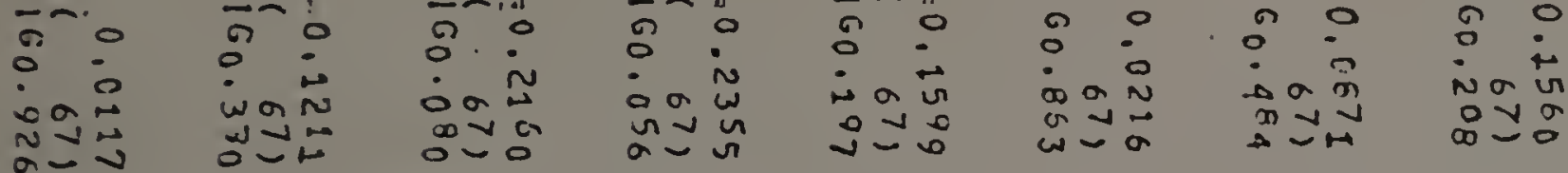

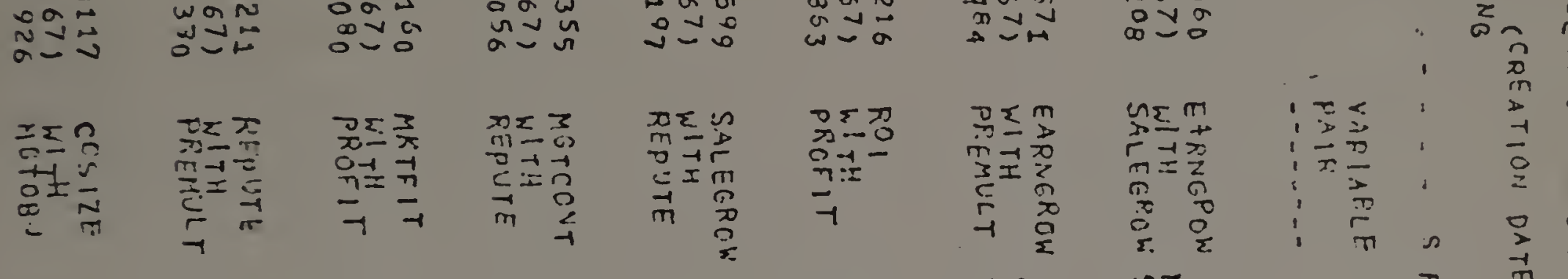

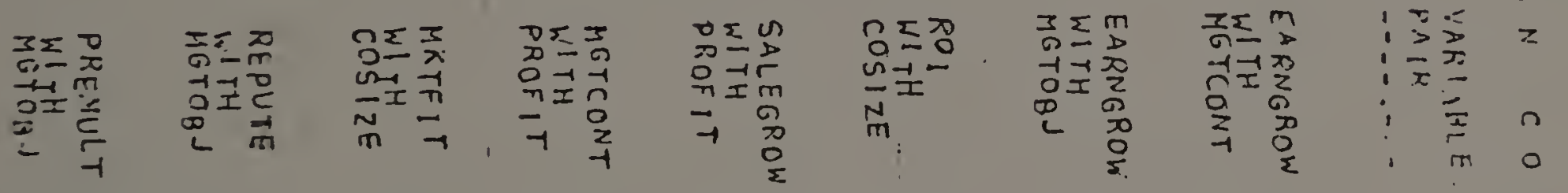

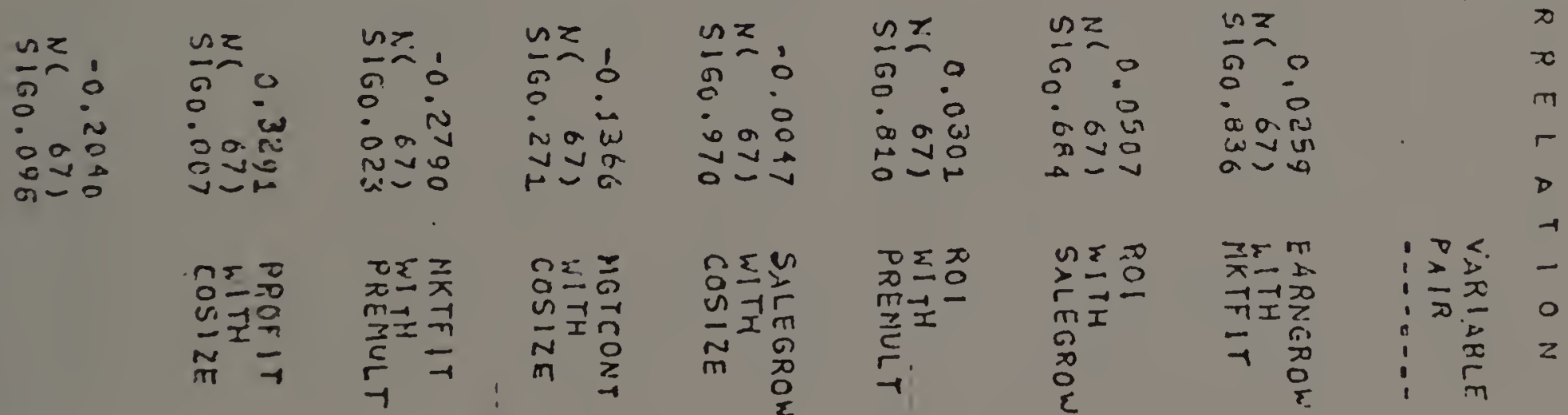

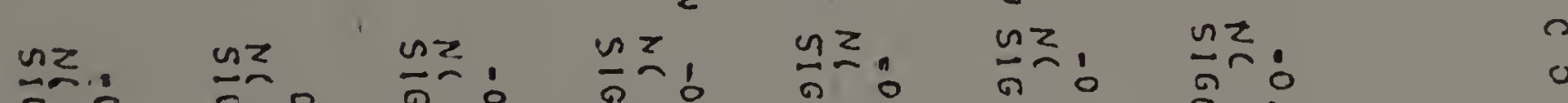

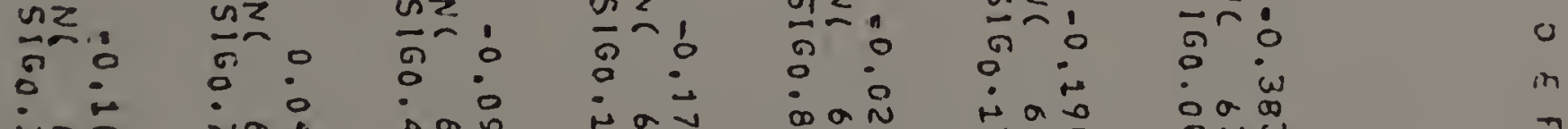

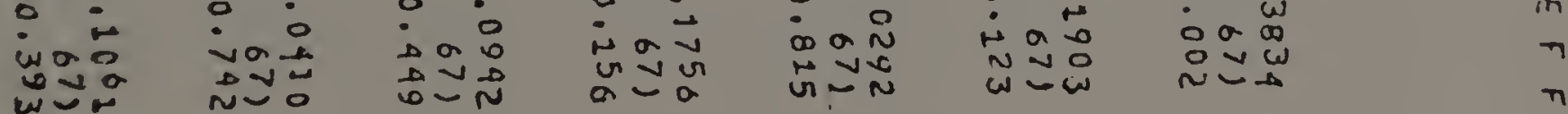

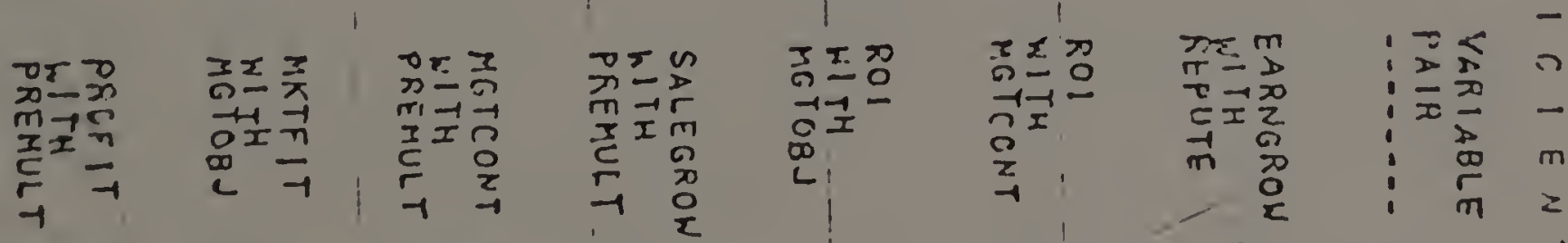

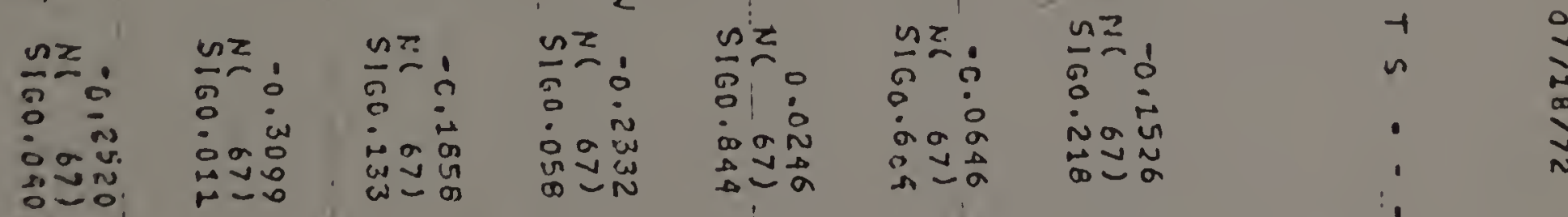

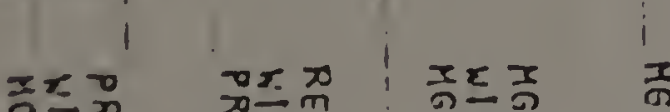

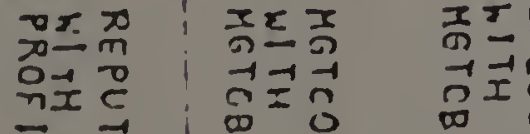

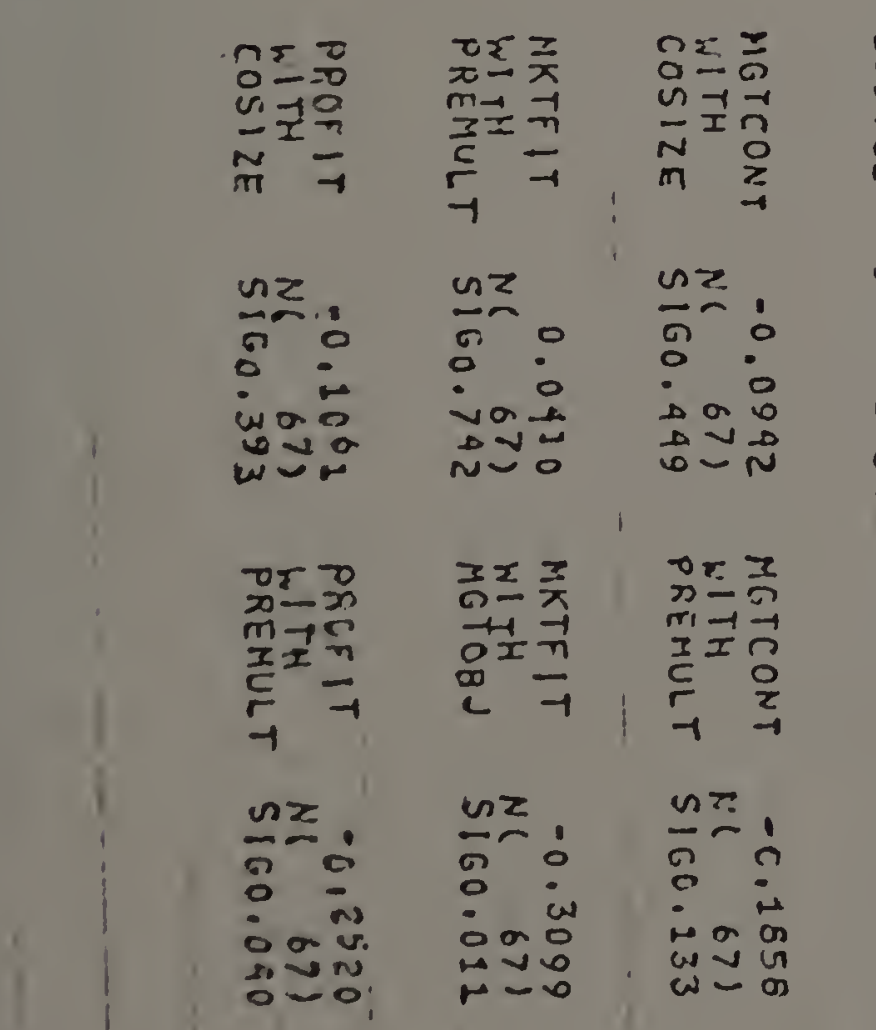

मำ $\vec{n}=\vec{a} \quad \vec{D} \vec{x} \frac{\pi}{0}$ $\begin{array}{llll:l} & -1 & -1 & m & 2 \\ 1 & & 0\end{array}$

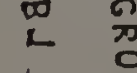

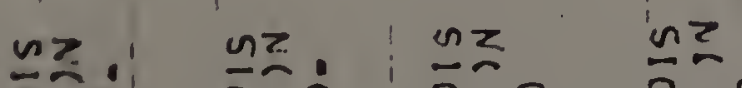

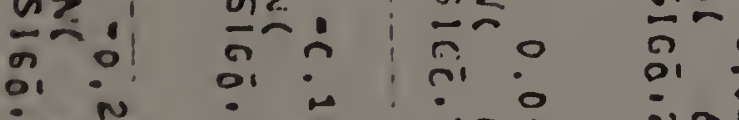

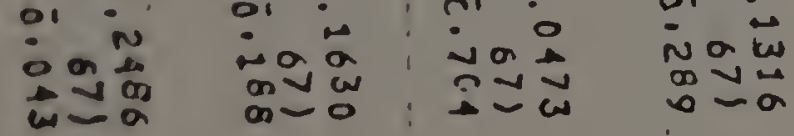
$\rightarrow$

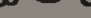

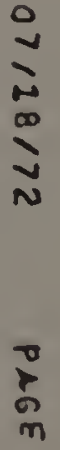

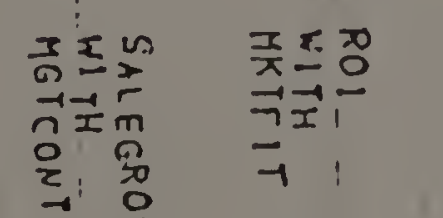

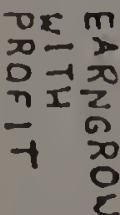

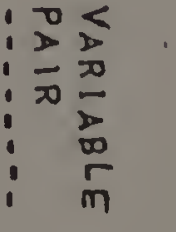

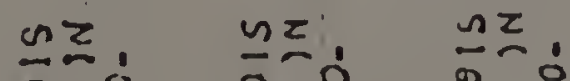
म.

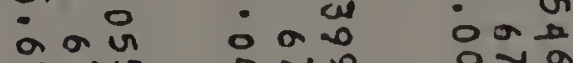

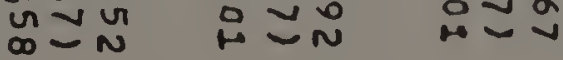



